Universidad de Lima

Escuela de Posgrado

Maestría en Administración y Dirección de Negocios

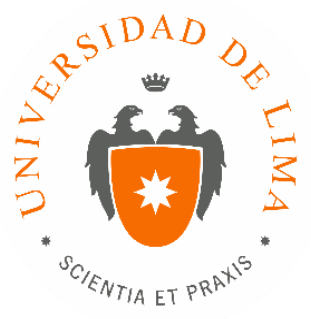

\title{
RESTAURANTE "INDOORS-FARMING" DE COMIDA SALUDABLE
}

Trabajo de Investigación para optar el Grado Académico de Maestro en Administración y Dirección de Negocios

\section{Carmen Luisa Abad Schoster \\ Código 19842891}

Asesor

Edmundo Casavilca Maldonado

Lima - Perú

Enero, 2018 
Dedico este trabajo de investigación a mi Pedrito que siempre me inspiró para amar, pensar y soñar en un Perú mejor: un país de progreso y oportunidades para todos. A la gente de mi país, para que la semilla de este trabajo de investigación contribuya a dar frutos en bien de una población sana, bien nutrida y talentosa; y que su gente, su capital humano, sea la mayor riqueza de nuestro Perú. 


\section{Agradecimiento}

Mi eterno y profundo agradecimiento al amor de mi vida, Pedro Agustín Guevara Ballón, por su apoyo incondicional, por su gran amor a lo largo de toda su vida, por alentarme siempre con esa alegría, actitud y espíritu positivo que lo caracteriza para que logre cada una de las metas que me proponga en la vida y por seguirme en el hermoso camino de compartir una vida y nuestros sueños. Que Dios bendiga nuestro amor siempre.

A mi hijos, Patrick Engelhard Abad y Andrew Engelhard Abad por ser mi motor y mi máxima inspiración para el logro de mis metas.

A mi padre, Belisario Abad Bermúdez hasta el cielo por sentirlo siempre a mi lado.

A mi madre, Elsa Schoster de Abad porque su presencia es el mejor ejemplo de valores, coraje, lucha y amor.

A mis amigos, Augusto Díaz Chávez, Fidel Gallegos Espinoza y Felipe Leno Montero, por haberme apoyado incansablemente en mi arduo camino de crecimiento profesional.

A Dios por ser parte de mi vida, por darme su mano en todo momento y por caminar siempre junto a mí. 


\section{RESTAURANTE "INDOORS-FARMING" DE COMIDA SALUDABLE}




\section{TABLA DE CONTENIDO}

Dedicatoria. .ii

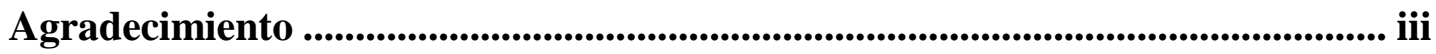

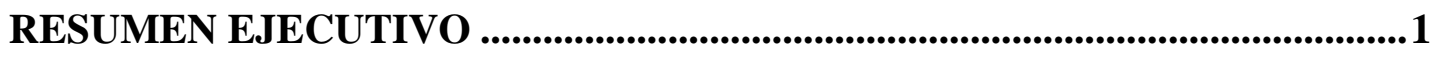

CAPÍTULO I: ASPECTOS GENERALES DEL NEGOCIO ................................4

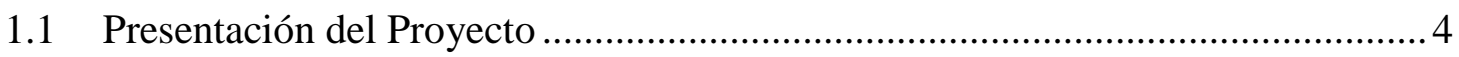

1.2 Marco Teórico y Mercado (benchmark y mejores prácticas empresariales) ........ 4

1.2.1 Agricultura en ambiente controlado ("Indoors farming").................................. 4

1.2.2 Ventajas de la agricultura en ambiente controlado. ......................................... 6

1.2.3 Desventajas de la agricultura en ambiente controlado......................................

1.2.4 La nutrición: el plato para comer saludable de acuerdo con la Escuela de Salud Pública de la Universidad de Harvard.............................................................. 8

1.2.5 Educación nutricional utilizando el marketing experiencial y el "Círculo de Oro"

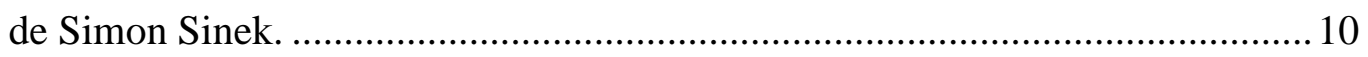

1.2.6 Evaluación y formulación de proyecto de inversión........................................... 13

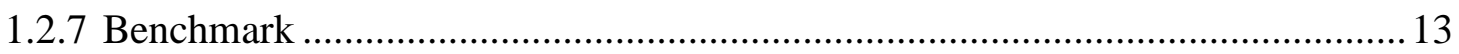

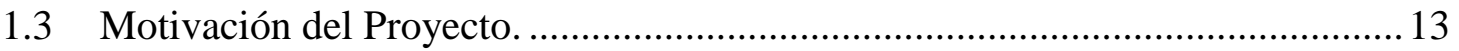

1.4 Percepción de la Necesidad: Análisis-Problema-Solución. ................................ 14

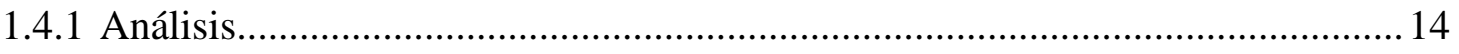

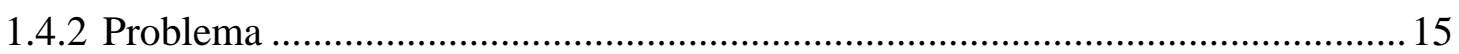

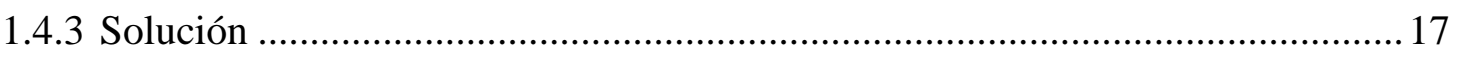

1.5 Descripción de la Idea y la Oportunidad......................................................... 18

1.6 Justificación del Atractivo de la Propuesta ........................................................ 19

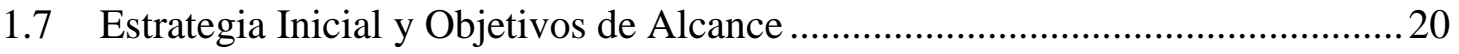

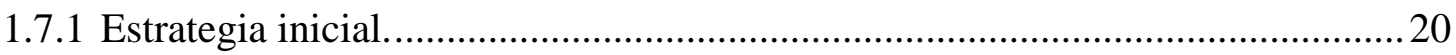

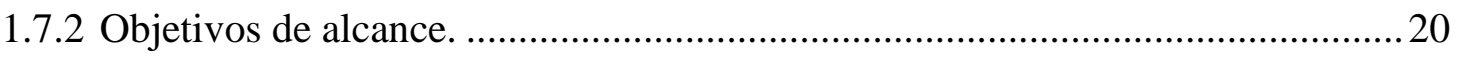

1.8 Impacto Comercial y Responsabilidad Social ................................................ 21

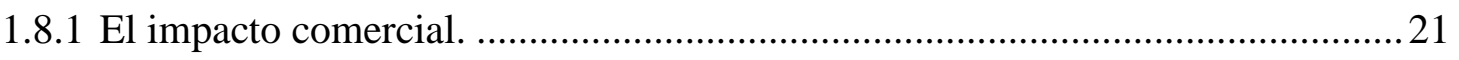

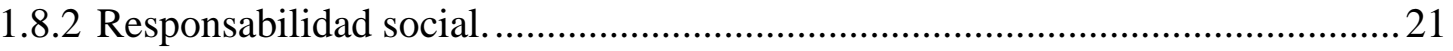




\section{CAPÍTULO II: IDEA, INVESTIGACIÓN Y VALIDACIÓN DE SOLUCIÓN23}

2.1 Diseño y Metodología de la Investigación.......................................................23

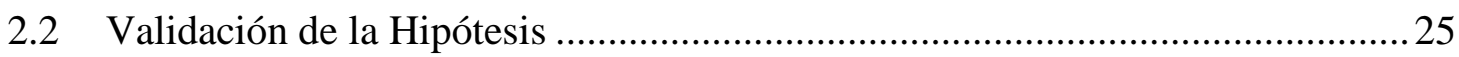

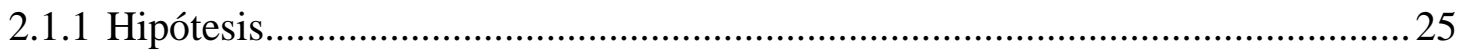

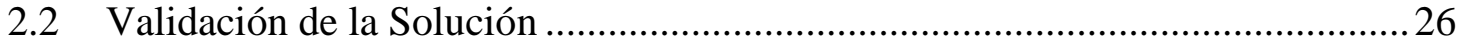

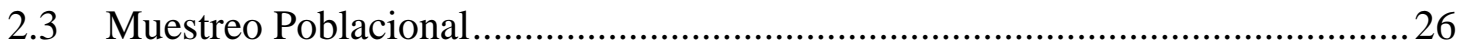

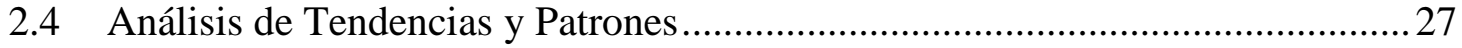

2.5 CANVAS del Modelo de Negocio.......................................................................29

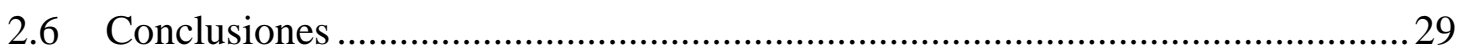

CAPÍTULO III: PLANEAMIENTO ESTRATÉGICO .........................................31

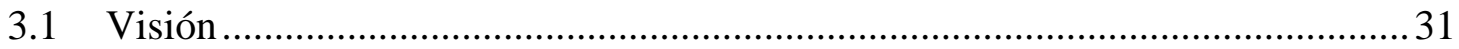

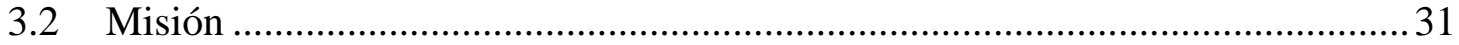

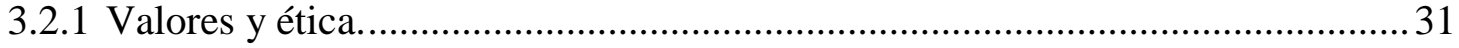

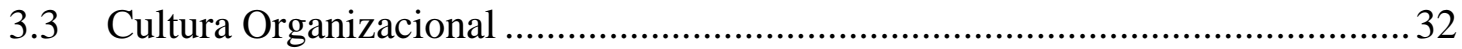

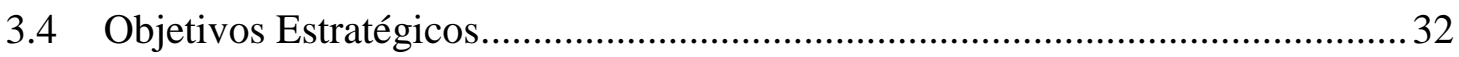

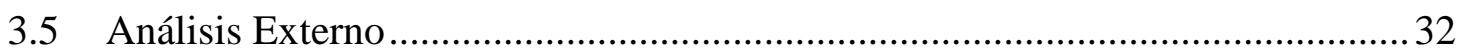

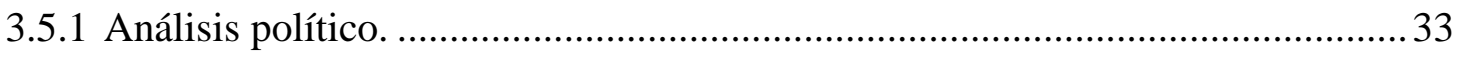

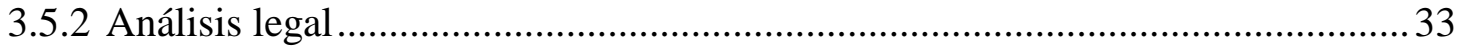

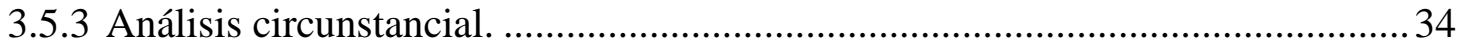

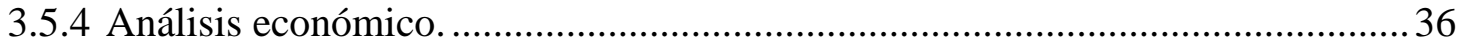

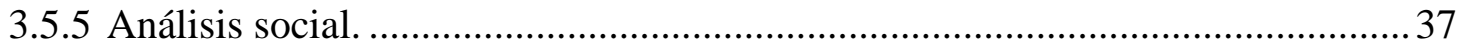

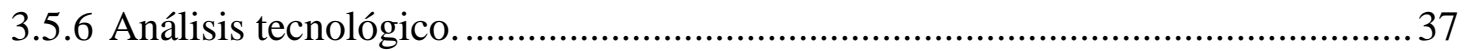

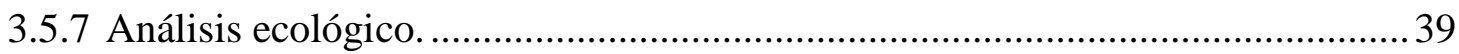

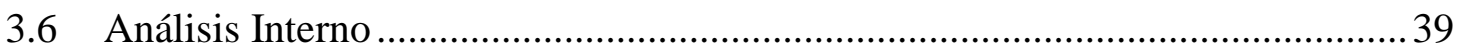

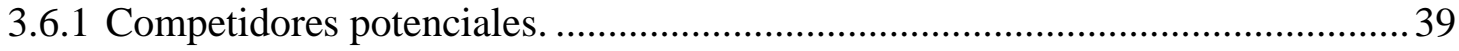

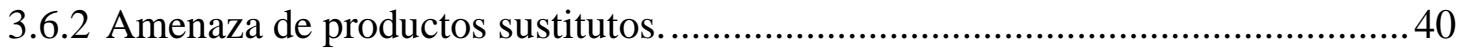

3.6.3 Poder de negociación de clientes. ..................................................................... 40

3.6.4 Poder de negociación de proveedores............................................................... 41

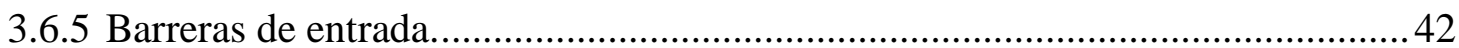

3.7 Análisis Sectorial e Identificación de Riesgos y Amenazas. Análisis FODA .... 42

3.8 Estrategia de Éxito (FODA cruzado). ……................................................... 44 
4.1 Planteamiento de Objetivos Generales de Marketing ..................................... 46

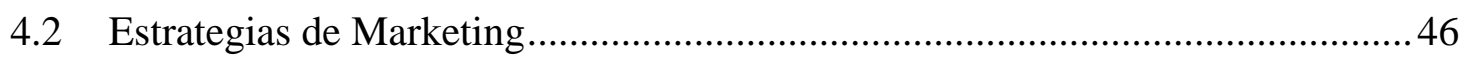

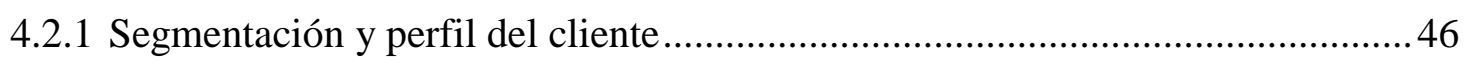

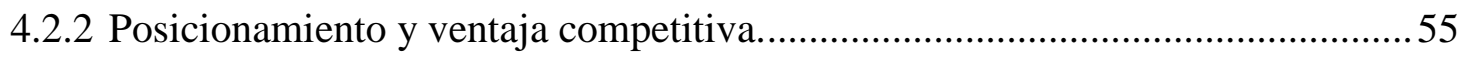

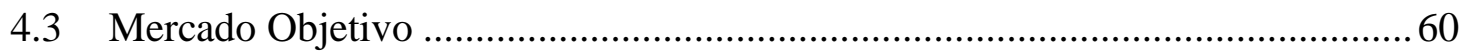

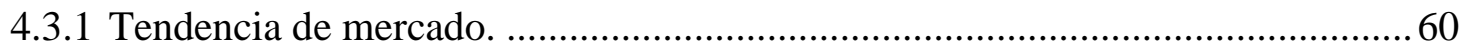

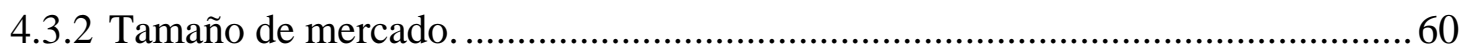

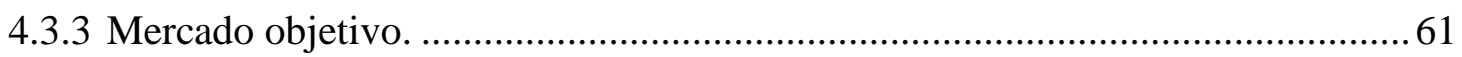

4.3.4 Identificación de agentes (clientes, usuarios, compradores, prescriptores, intermediarios, mayoristas, minoristas, comisionistas). ..................................6 61

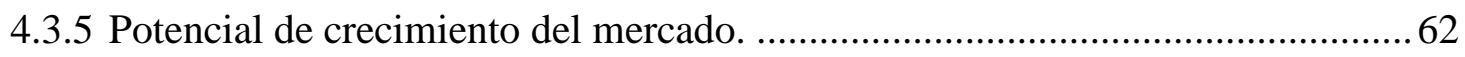

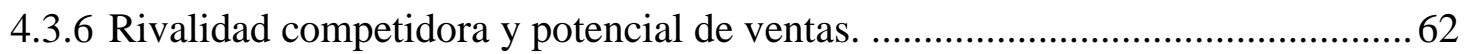

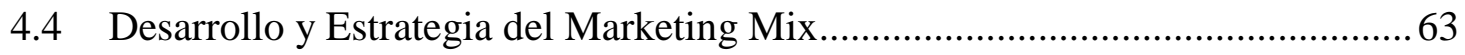

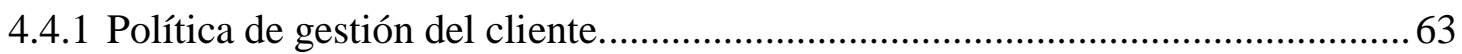

4.4.2 Estrategia de producto: especificaciones, calidad, variabilidad y

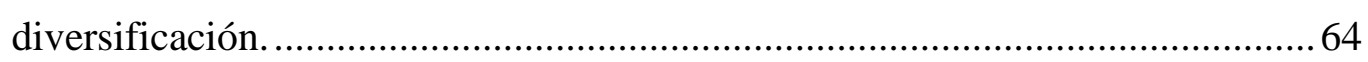

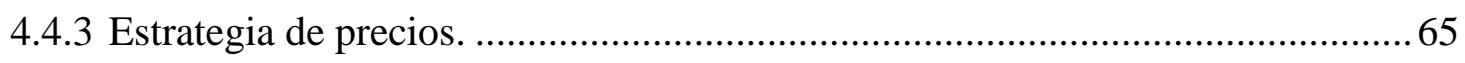

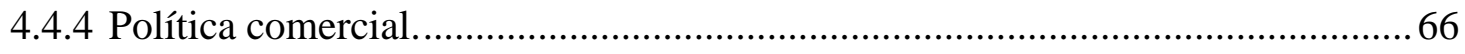

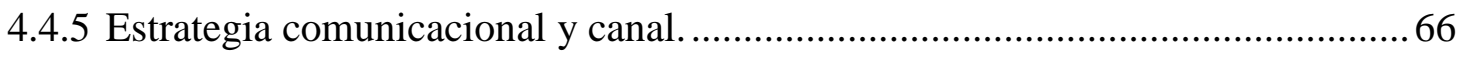

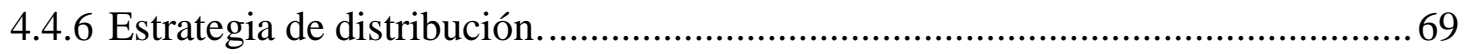

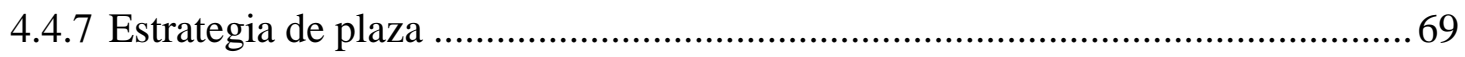

4.5 Plan de Ventas (objetivos anuales, alcance de la oferta) y Proyección de la Demanda (crecimiento y desarrollo) ............................................................ 72

CAPÍTULO V: PLAN DE OPERACIONES..........................................................76

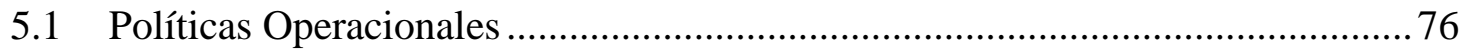

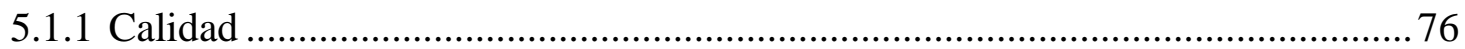

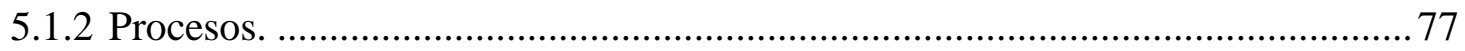

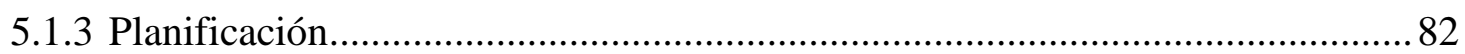

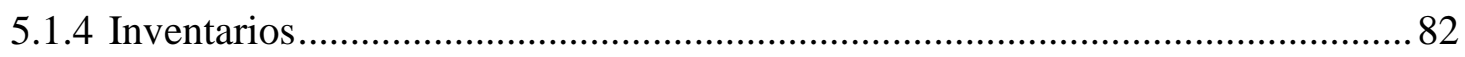

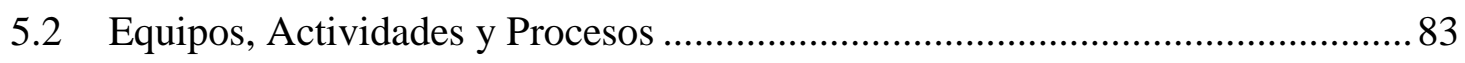

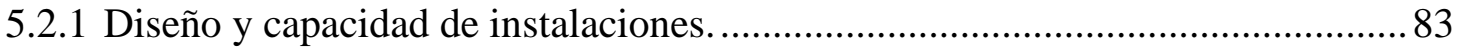

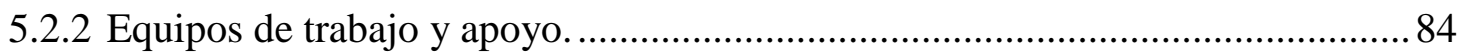


5.2.3 Gestión de proveedores, compras y stock. 86

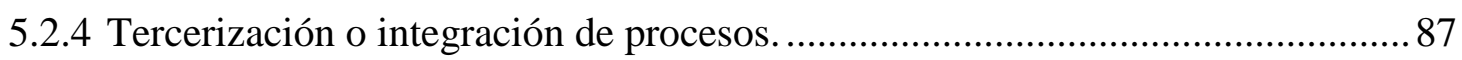

5.2.5 Implementación de las actividades por fases. Cadena de valor ......................... 87

5.2.6 Proceso de elaboración de bienes y/o prestación de servicio...............................8 88

5.2.7 Políticas de transformación de la actividad......................................................96

5.2.8 Flujograma de la actividad y diagrama de decisiones PERT.............................97

5.2.9 Balance scorecard: control de gestión por indicadores .................................... 99

\section{CAPÍTULO VI: ESTRUCTURA ORGANIZACIONAL Y RECURSOS}

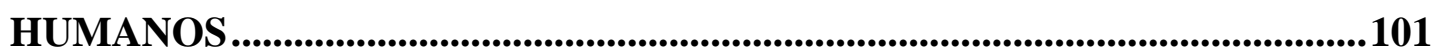

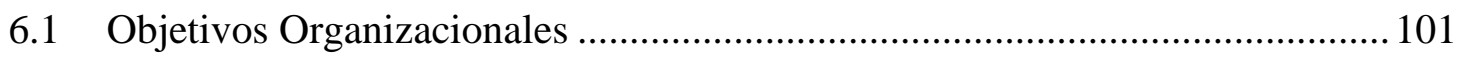

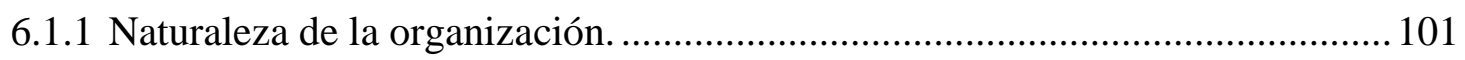

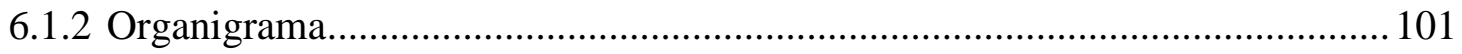

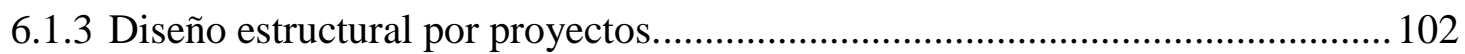

6.2 Diseño de Puestos y Responsabilidades.......................................................... 102

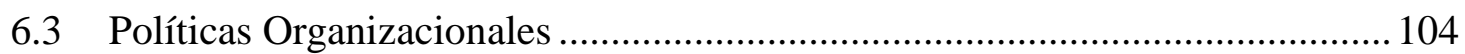

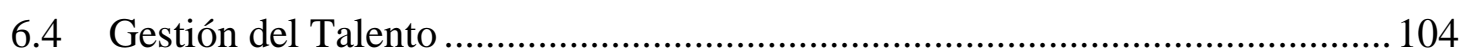

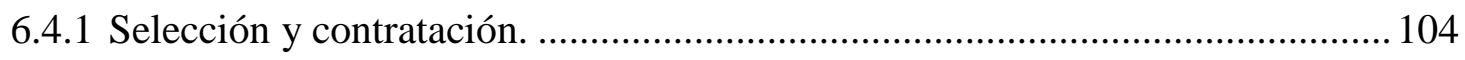

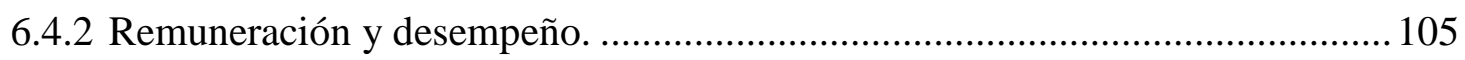

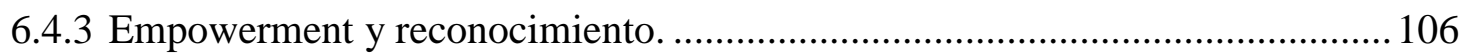

6.4.4 Capacitación, motivación y desarrollo............................................................ 106

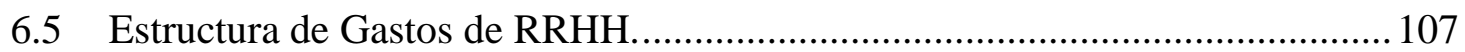

CAPÍTULO VII: PLAN ECONÓMICO - FINANCIERO....................................109

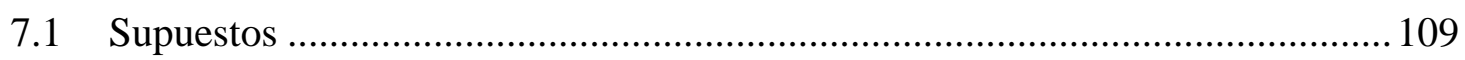

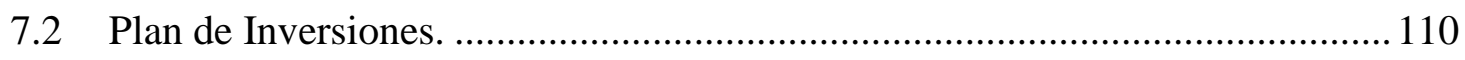

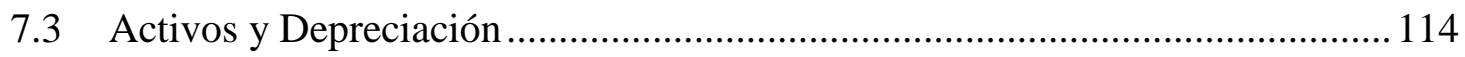

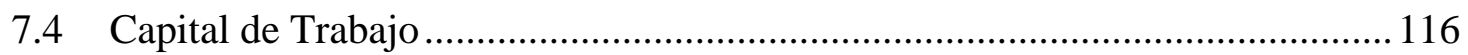

7.5 Fuentes de Financiamiento y Amortización.......................................................... 116

7.6 Balances Previsionales (Balance General) ...................................................... 117

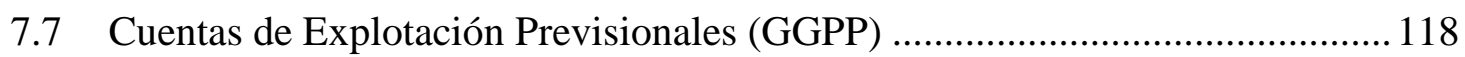

7.8 Proyección de Ventas y Flujo de Tesorería (Cash flow) ................................. 120

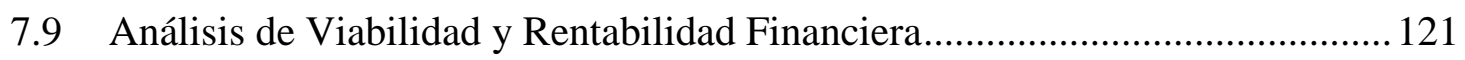

7.10 Políticas de Aplicación de Resultados ............................................................ 121 
7.11 Tasa de Descuento del Accionista .....

7.12 Indicadores de Rentabilidad Representativos ................................................. 122

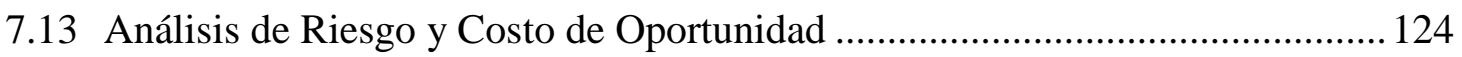

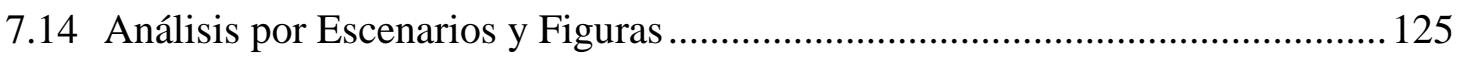

7.15 Principales Riesgos del Proyecto (cualitativos)............................................. 125

7.16 Plan de Contingencia y Disolución ................................................................... 126

Conclusiones.............................................................................................................................................. 127

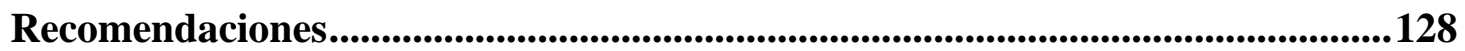

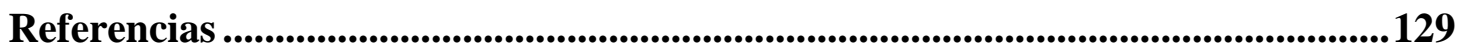

Bibliografía........................................................................................................................131 


\section{ÍNDICE DE TABLAS}

Tabla 2.1 Canvas del modelo de negocio

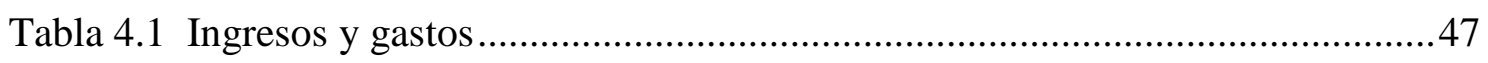

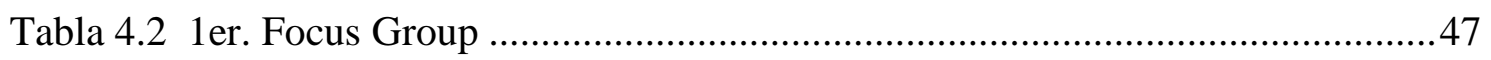

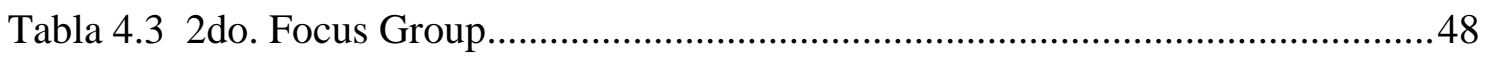

Tabla 4.4 Frecuencia de visitas a restaurantes ...........................................................50

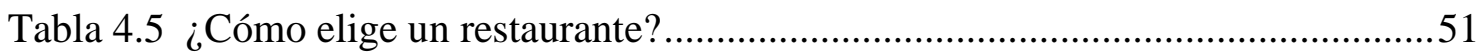

Tabla 4.6 ¿Cuánto tiempo esperaría para que le asignen una mesa? ..............................51

Tabla 4.7 ¿Cuál es la preferencia por tipo de comida? ..................................................52

Tabla 4.8 ¿Cuánto tiempo esperaría para que le traigan su pedido?..............................52

Tabla 4.9 ¿Cuánto tiempo esperaría para que le tomen el pedido .................................53

Tabla 4.10 ¿Cuánto está dispuesto a pagar por un plato saludable? …...........................53

Tabla 4.11 ¿Cómo le gustaría que fuera el local? .......................................................54

Tabla 4.12 ¿Cómo te enteras si se ha abierto un nuevo restaurante?.............................54

Tabla 4.13 ¿Usarías cupones de descuento para este restaurante? ................................55

Tabla 4.14 ¿Dónde le gustaría que estuviera ubicado este restaurante? .........................55

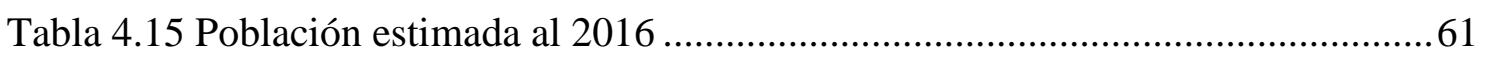

Tabla 4.16 Indicadores para establecer la microlocalización del restaurante ..................71

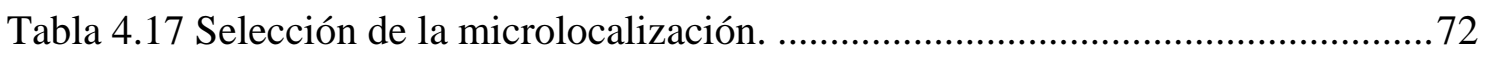

Tabla 4.18 Demanda de visitas al restaurante por comensales, sólo en los fines de

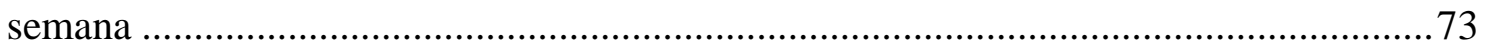

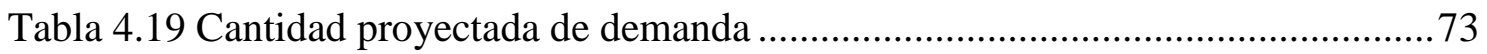

Tabla 4.20 Promedio de visitas en un día cualquiera, menos sábado y domingo, al

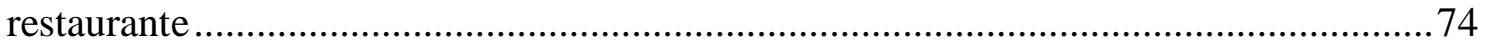

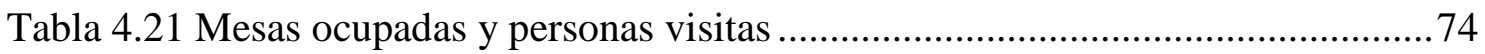


Tabla 4.22 Cantidad de mesas ocupadas. Mensual y anual .75

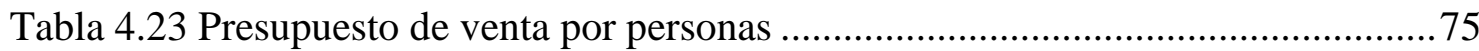

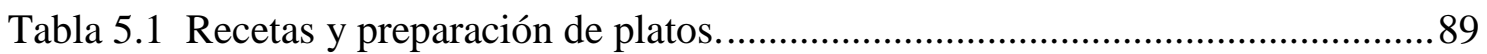

Tabla 5.2 Política de transformación de actividad ........................................................96

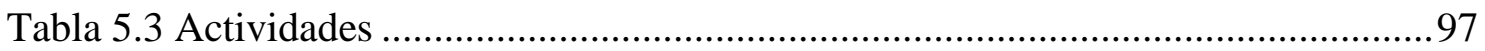

Tabla 5.4 Indicadores del balance scorecard, para seguimiento ............................... 100

Tabla 6.1 Comparación de sueldo en Bumerán el 20/10/2017 .................................... 105

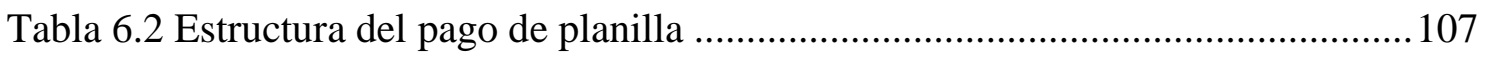

Tabla 6.3 Presupuesto de pago de planilla........................................................... 108

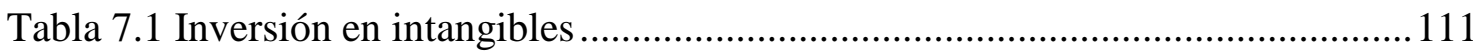

Tabla 7.2 Inversión en máquinas y equipos........................................................... 112

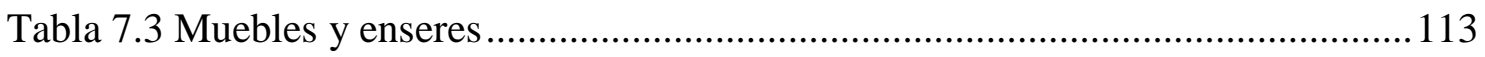

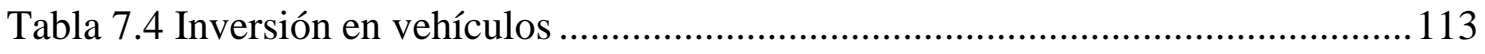

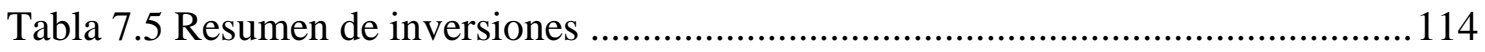

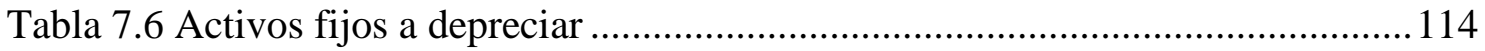

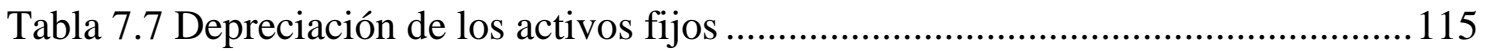

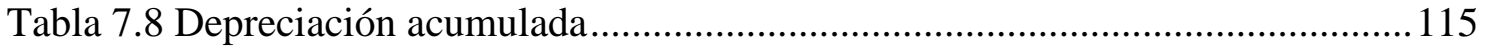

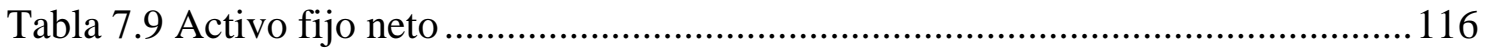

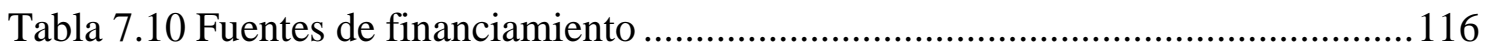

Tabla 7.11 Condiciones del préstamos bancario ......................................................... 117

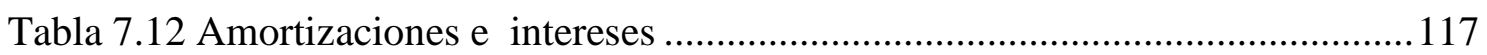

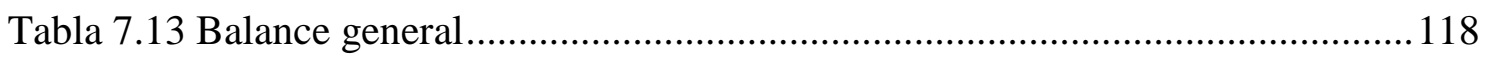

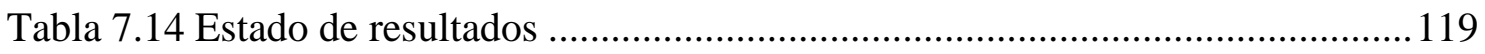

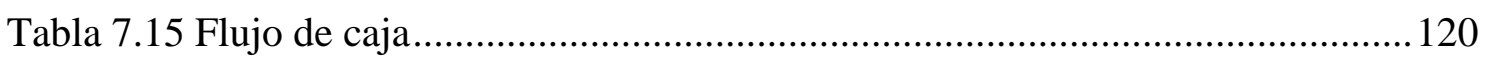

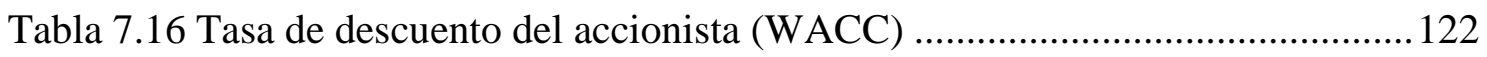

Tabla 7.17 Indicadores de rentabilidad representativos........................................... 123 


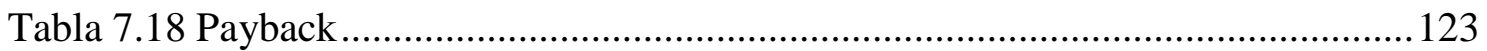

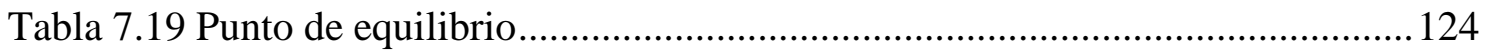

Tabla 7.20 Escenario ante una variación de las ventas ................................................ 125 


\section{ÍNDICE DE FIGURAS}

Figura 1.1 El plato para comer saludable de Harvard...............................................

Figura 1.2 El círculo de oro de Simon Zinek.......................................................... 12

Figura 3.1 Estructura del gasto real per cápita según grupos 2012 ............................. 34

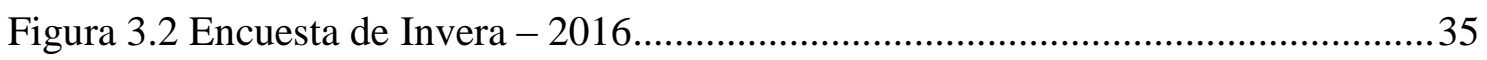

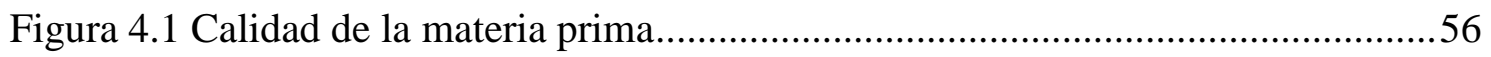

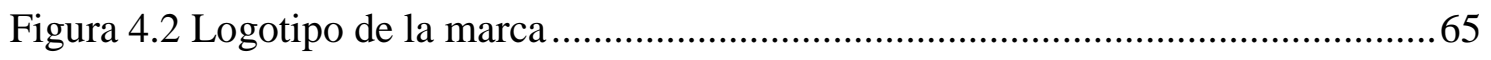

Figura 5.1 Procesos de compra y almacén.............................................................. 78

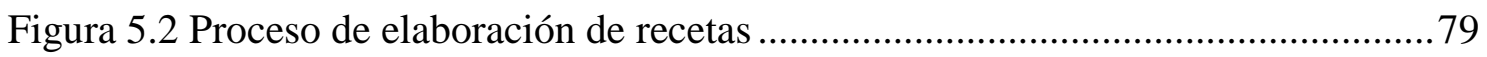

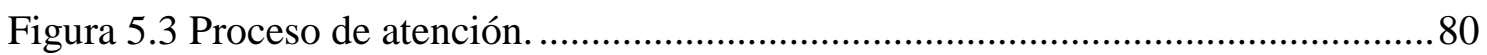

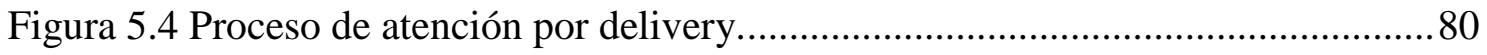

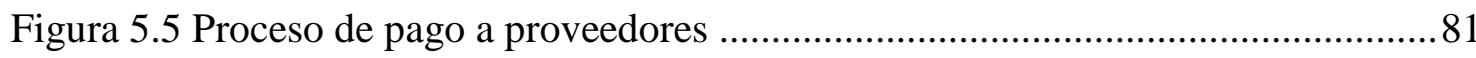

Figura 5.6 Procesos de selección y reclutamiento de recursos humanos.........................82

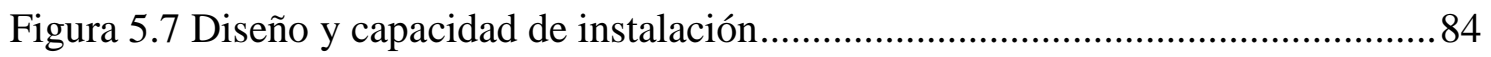

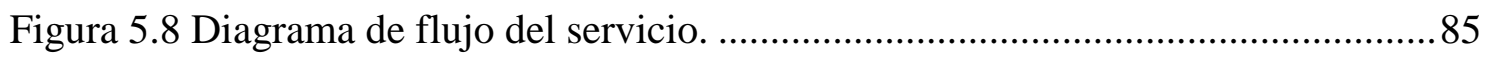

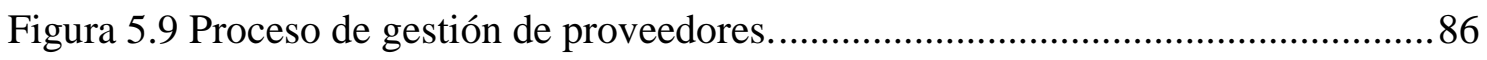

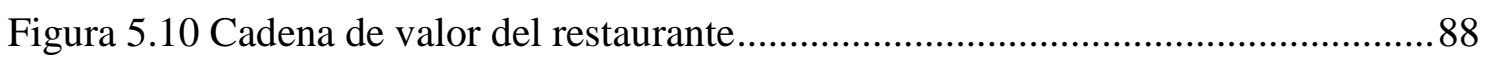

Figura 5.11 Diagrama PERT - De las actividades de implementación......................... 98

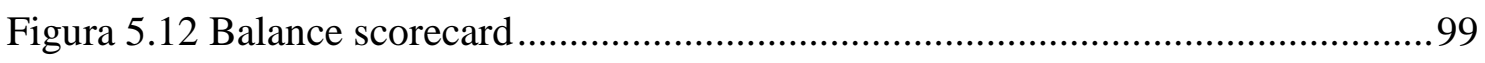

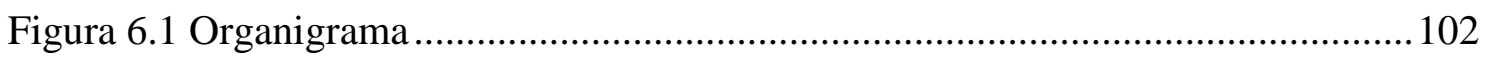




\section{ÍNDICE DE ANEXOS}

ANEXO 1: Descripción de puestos, competencias y perfil ........................................ 133 


\section{RESUMEN EJECUTIVO}

En el Capítulo I, se da a conocer el proyecto de alimentación saludable de un restaurante que se ubicará en el distrito de Surquillo, en las inmediaciones de la Urbanización La Aurora del distrito de Miraflores, provincia de Lima. El restaurante ofrecerá la experiencia de comer saludablemente, con productos mayormente orgánicos, abasteciéndose de insumos vegetales que provienen del uso preferente de la llamada agricultura en ambiente controlado ("Indoors Farming") - considerada como la agricultura del futuro porque permite producir todos los días del año, con un conjunto de estantes verticales, con un sistema mecatrónico que conecta sensores con computadoras, brindándole a cada planta las condiciones ideales de temperatura, iluminación, humedad, salinidad, ph, ventilación, nutrientes y minerales para que se desarrollen productos saludables e inocuos, con una productividad 100 veces mayor a la de la agricultura en suelo, ahorrando $90 \%$ del uso de agua y haciendo que los productos puedan comerse muy frescos, dado que no hay que transportarlos desde la chacra hasta el restaurante. Este sistema es el que explicamos en el presente capítulo. Así también se da a conocer el concepto sobre el plato saludable, según la Escuela de Salud Pública de Harvard, el cual es la base de nuestro restaurante. Damos una motivación y justificación de nuestro proyecto, el cual creemos que es importante para el desarrollo de la vida saludable de las personas.

En el Capítulo II, damos a conocer cómo vamos a desarrollar y validar nuestro proyecto partiendo del concepto de evaluación y formulación de proyectos de inversión, así como también, valiéndonos de la investigación de mercado.

Luego presentaremos el modelo de negocio de CANVAS, en donde estarán las principales actividades a realizar, cómo es que generamos valor para nuestros clientes. Así mismo, presentamos otros conceptos importantes que nos ayudan a dilucidar sobre la viabilidad de nuestro proyecto, para finalmente rematar el capítulo presentando nuestras conclusiones.

En el Capítulo III, se realiza un análisis más detallado del entorno, con la técnica de PESTEL y las 5 fuerzas de Michael Porter, a través de las cuales vamos incidiendo en 
cómo el entorno puede afectar a nuestro negocio y, en función de ello, planteamos una estrategia a emprender.

Un análisis político, económico y legal nos permite incluso ver que nuestra propuesta está encaminada hacia un servicio de restaurante de comida saludable. Asimismo, indicamos que, en el año 2017, el Estado peruano ha aprobado una ley muy favorable para la población peruana en lo referido al tipo de nutrición que se debe considerar para disfrutar de buena salud, Ley de Promoción de la Alimentación Saludable (Ley 30021).

También realizamos un análisis FODA, y las estrategias a utilizar para disminuir o eliminar las amenazas o deficiencias que se puedan presentar, tales como: ajustar precios al poder adquisitivo del cliente objetivo, colaborar en la diferenciación del sector turístico limeño, diferenciar el producto de aquél de la competencia para mejorar la competitividad, dada la alta rivalidad del sector de comidas.

En el Capítulo IV, se analiza el plan de marketing y los objetivos a alcanzar, teniendo un mayor conocimiento de nuestro mercado objetivo, su tendencia y tamaño, así como la macrolocalización y microlocalización del restaurante, en la que se justifica la ubicación del local en el distrito de Surquillo, en las inmediaciones de la Urbanización La Aurora del distrito de Miraflores, provincia de Lima. La zona fue elegida luego de analizar diferentes factores que se explican en este capítulo. Asimismo, se desarrollan las estrategias del marketing mix, incluyendo la política de gestión de clientes, la política comercial, la definición de los precios y productos, así como las estrategias comunicacionales y de distribución. Acorde a ello y a nuestro mercado objetivo, establecemos un plan de venta anual y una proyección de la demanda.

En el Capítulo V, analizamos los planes operativos implementando políticas de calidad, procesos necesarios para asegurar la atención, elaboración y gestión de los proveedores, que son pilares para el servicio en el restaurante.

Se desarrollan los flujos y el diagrama de operación del servicio a brindar, un diagrama PERT para implementar el proyecto, con sus principales fases. Así mismo, se da una serie de indicadores en el balance scorecard, teniendo como objetivo estratégico el ser innovador, sobre todo con la mira de ofrecer una experiencia única.

En el Capítulo VI, analizamos los planes de recursos humanos, los procesos de selección y la estructura organizativa que hará funcionar y poner operativo los servicios 
a brindar dentro de la empresa. Se indican las funciones principales y los gastos de planilla considerando el precio del mercado salarial.

En el Capítulo VII, analizamos la viabilidad económica y financiera del proyecto, en la cual se realizan varios supuestos, considerando de fuentes confiables los precios del mercado, los datos de inflación, tipo de cambio, riesgo, país -entre otros- para finalmente determinar el WACC. Para tal fin, se consideran cuatro productos principales de toda la carta, para así calcular sus costos de venta y los ingresos, a través del ticket promedio por persona.

En consecuencia, se trata de un proyecto de negocio perfectamente realizable, innovador y rentable, con una propuesta pionera para el Perú al ofrecer una bioexperiencia única de deleite con platos saludables y nutritivos, basados en el llamado "Plato Saludable" de la Universidad de Harvard, que sintetiza lo último en alimentación saludable y nutritiva, con un restaurante que aplica la que es considerada como agricultura del futuro mediante un laboratorio de "Indoors Farming", que estará dentro del restaurante y servirá como medio para abastecerse de vegetales y frutos frescos e inocuos y que estará expuesto a los comensales para que aprecien como crecen y se desarrollan los vegetales y frutos que consumen. 


\section{CAPÍTULO I: ASPECTOS GENERALES DEL NEGOCIO}

\subsection{Presentación del Proyecto}

Como parte de una propuesta de alimentación nutritiva y saludable para los peruanos, implementaremos un restaurante que se ubicará en el distrito de Surquillo, en las áreas circundantes a la Urbanización La Aurora del distrito de Miraflores, provincia de Lima. El restaurante tendrá un área de cocina y salones de comensales, complementadas con áreas artísticas de educación nutricional, un laboratorio de agricultura en ambiente controlado - "Indoors farming" y en donde el comensal viva una experiencia singular.

El restaurante tiene como objetivo ofrecer una experiencia multisensorial de aprendizaje en salud y nutrición, al mismo tiempo que interioriza la importancia de una alimentación saludable (orgánica y no orgánica) utilizando técnicas de cultivo de la agricultura en ambiente controlado, así como de la agricultura tradicional, siguiendo las recomendaciones del plato saludable de la Escuela de Salud Pública de la Universidad de Harvard. Se espera que los comensales se deleiten degustando platos de dos tipos de servicio: buffet y platos a la carta. Se planea que este servicio de comida pueda ser también ofrecido bajo la modalidad de "delivery" a centros educativos y oficinas.

\subsection{Marco Teórico y Mercado (benchmark y mejores prácticas empresariales)}

\subsubsection{Agricultura en ambiente controlado ("Indoors farming").}

La agricultura en ambiente controlado, también conocida como "indoors farming", en inglés, es considerada como la agricultura del futuro. Es una agricultura bajo techo que produce cien veces más alimentos por hectárea que la agricultura regular y utiliza 95\% menos de agua, con cero pesticidas. Los cultivos crecen en un ambiente controlado y, por ello, pueden cultivarse los 365 días del año, creciendo sin ningún pesticida. Con ello, se obtienen alimentos completamente limpios e inocuos. Los cultivos crecen a más del doble de velocidad que los cultivos en el campo. Según el experto Irving Fain, en comparación con este último tipo de cultivo, pueden lograrse más ciclos de cultivo por año, con más cosechas por ciclo. (I. Fain, comunicación personal, 09 de julio del 2017) 
Hoy en día, al abordar los desafíos del sistema de la agricultura moderna sabemos que el $70 \%$ de la oferta global del agua es destinada para la agricultura. Solamente en Estados Unidos se utilizan 317,000 toneladas de pesticidas. En términos demográficos, la agricultura en ambiente controlado constituye una respuesta eficiente y ambientalmente sostenible para dotar de alimentos frescos a los ambientes urbanos, ello tomando en cuenta que para el 2050 la población mundial estará entre los 9 y 10 mil millones de habitantes, con el $70 \%$ u $80 \%$ de esa población viviendo en ciudades.

La agricultura en ambiente controlado se suele localizar en las proximidades del ambiente urbano. Con ello los productos llegan a la mesa del restaurante o del consumidor en menos de un día después de ser cosechados, en comparación con los productos de la agricultura regular, que llegan a la mesa después de dos o tres semanas, dado el tiempo que demora el transporte desde la chacra a su destino final. Al prescindirse de los largos recorridos de camiones para transportar los productos se evita que el transporte de los productos genere emisiones de monóxido de carbono que inciden en el calentamiento global y en el cambio climático. Mediante el uso de esta tecnología se optimizan las condiciones de crecimiento de cada planta con un sistema computarizado y de sensores que recolectan cientos de datos de cada planta, lo que permite analizar y entender cuáles son las condiciones óptimas del crecimiento y la salud de las mismas e incluso del sabor y así poder replicar el más saludable y nutritivo ecosistema que cada planta necesita para crecer de la manera más fuerte y apropiada. La agricultura en ambiente controlado hace un uso intensivo y eficiente del espacio al colocar dispositivos, estantes, plataformas y repisas, unas sobre otras y en donde las plantas crecen aprovechando al máximo el espacio, sin depender de las aptitudes agrícolas disponibles del suelo.

La agricultura hidropónica, puede ser considerada como una tecnología predecesora de la agricultura en ambiente controlado. Se divide en hidroponía convencional e hidroponía orgánica. El sistema utiliza una fuente de agua que es impulsada por bombeo a través de recipientes que contienen los nutrientes concentrados (soluciones madre) con cabezales de riego y canales construidos en donde están los sustratos, las plantas, los conductos para aplicación del fertirriego y el recibidor del efluente. (¿Qué es hidroponía?, 2017)

El cansancio de los suelos por la alta carga de patógenos tras cultivos repetidos o la acumulación de iones que conllevan alcalinidad y/o elevación del tenor de sodio ha 
empujado a muchos productores a realizar cultivos sin suelo. En cultivos comerciales en cuanto a su superficie- se hace obligatorio seguir normas ambientales amigables con el ambiente, así como el emplear métodos de recirculación de las soluciones que regresen al cultivo tras equilibrarlas y desinfectarlas o buscándoles un lugar de descarga que evite la llegada de los nutrientes efluentes al suelo, cursos de agua y a los acuíferos.

La implementación de cultivos sin suelo, como la agricultura en ambiente controlado es considerada como la agricultura del futuro, no sólo por su alta productividad y rendimiento económico, sino también por la inocuidad y calidad de sus productos. Actualmente los cultivos que son aptos para el uso de esta tecnología son el tomate, la lechuga, el repollo, el pimiento, el pepino, la espinaca, entre otros. Sin embargo, se espera que, con el avance de la tecnología, otros cultivos también puedan progresivamente ser cultivados utilizando la agricultura en ambiente controlado. Aunque este cultivo en circunstancias normales no es orgánico, ya que utiliza sustancias químicas para la solución nutritiva que alimenta la planta, puede volverse orgánico utilizando sustancias naturales.

\subsubsection{Ventajas de la agricultura en ambiente controlado.}

De acuerdo a una entrevista llevada a cabo por nosotros al experto mundial, Dr. Wei Fang (Mayo, 2017), Profesor del Departamento de Ingeniería Mecatrónica Bioindustrial y Director del Centro de Excelencia para la Agricultura en Ambiente Controlado de la Universidad Nacional de Taiwán, las ventajas de la agricultura en ambiente controlado son las siguientes:

- Las computadoras y sensores de los sistemas mecatrónicos utilizados por esta tecnología hacen posible la automatización casi completa del proceso de cultivo de las plantas, así como el análisis y seguimiento de las condiciones óptimas de desarrollo de cada planta, incluyendo la temperatura, humedad, salinidad, tipo de iluminación, ventilación, $\mathrm{pH}$, minerales o nutrientes específicos, incrementando la productividad por hectárea hasta en 100 veces. (Ojo: no es en $100 \%$ sino en 100 veces).

- Genera una reducción de costos de transporte respecto a la agricultura en el campo. 
- Inicialmente los costos de inversión en máquinas y equipos pueden ser mayores que en la agricultura de suelo, pero los costos de operación pueden luego reducirse progresivamente, dependiendo del capital de trabajo a ser empleado.

- Permite producir cosechas fuera de estación, independientemente de los cambios en el clima.

- Emplea poco espacio y capital para una mayor producción.

- Genera ahorro de hasta un $90 \%$ en el uso del agua, pues ésta se recicla y se usa en la cantidad exacta que cada planta requiere.

- Genera ahorro de fertilizantes e insecticidas, pues la planta no entra em contacto con los agentes externos que se encuentran en el cultivo en suelo.

- No se requiere maquinaria agrícola.

- Mayor limpieza e higiene en el manejo del cultivo, desde la siembra hasta la cosecha.

- Cultivo libre de parásitos, bacterias, hongos y contaminación.

- $\quad$ Rápida recuperación de la inversión si se produce a gran escala.

- Mayor precocidad de los cultivos.

- No provoca los riesgos de erosión que se presentan en la tierra.

- Soluciona el problema de producción en zonas áridas o frías.

- Se puede cultivar en ciudades.

- Se obtiene uniformidad en los cultivos.

- Permite ofrecer mejores precios en el mercado.

- Se utilizan nutrientes naturales y limpios.

\subsubsection{Desventajas de la agricultura en ambiente controlado.}

En la agricultura en ambiente controlado, la planta es dependiente completamente del cuidado del sistema mecatrónico, a diferencia del cultivo en suelo en donde la planta se puede desarrollar por cuenta propia. No todas las plantas se pueden sembrar utilizando la 
tecnología de agricultura en ambiente controlado, especialmente los árboles. Contempla un principio simple: Colocar a la planta en un ambiente inerte y, a partir de ahí, controlar su nutrición, así como las condiciones ambientales óptimas.

La técnica de raíz flotante solamente sirve para las lechugas; sin embargo, dicha técnica puede funcionar con la mayoría de plantas cuyo desarrollo sea superficial y no subterráneo. En ese sentido, la técnica puede funcionar con plantas como el melón, la sandía, el pepino, la fresa, el tomate, etc., no estando aun completamente desarrollada la tecnología para producir óptimamente los cultivos de papa, cebolla, zanahoria, entre otros.

\subsubsection{La nutrición: el plato para comer saludable de acuerdo con la Escuela de Salud Pública de la Universidad de Harvard.}

Figura 1.1

El plato para comer saludable de Harvard.

\section{EL PLATO PARA COMER SALUDABLE}

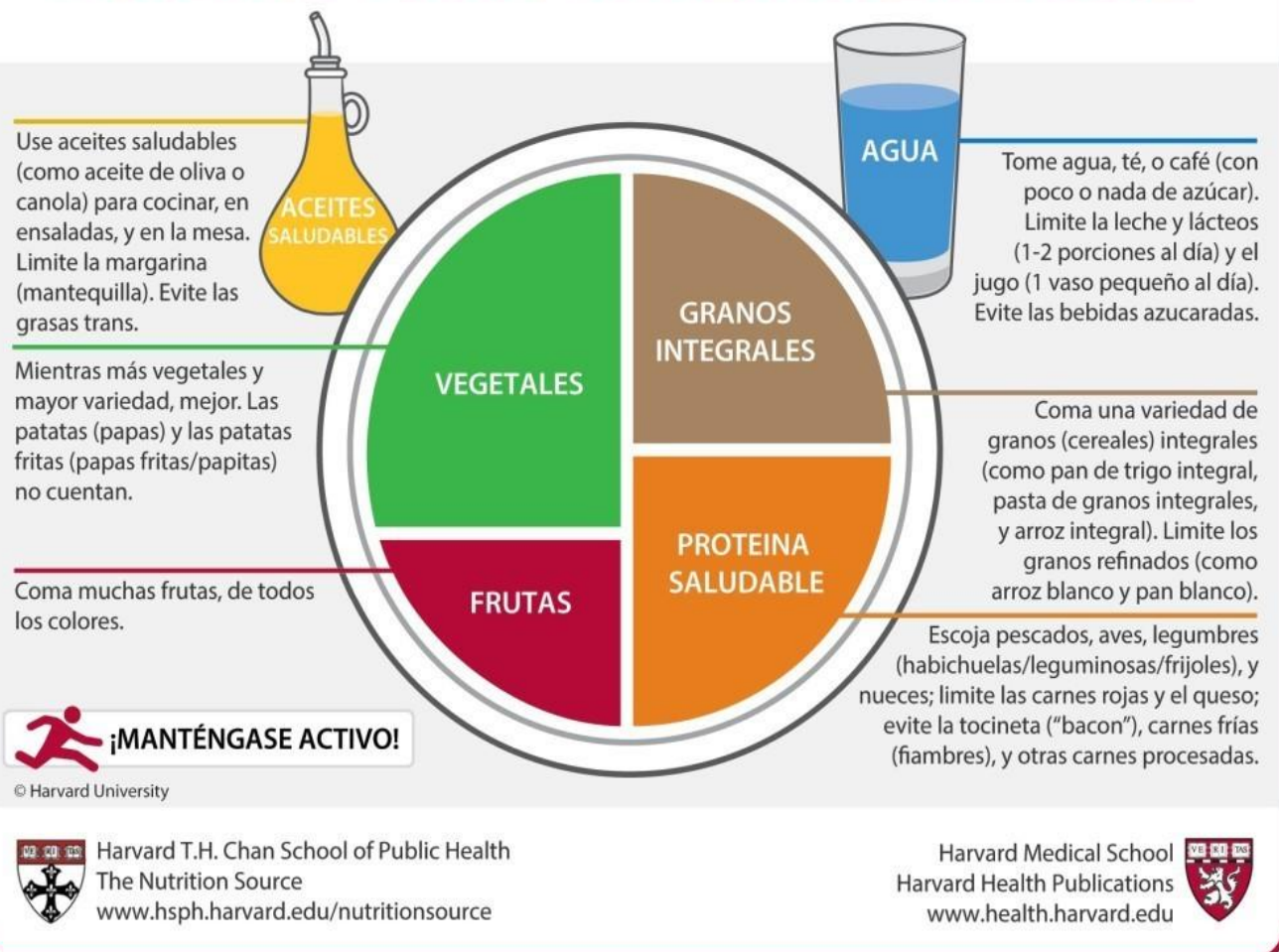

Fuente: Escuela de Salud Pública de la Universidad de Harvard (s.f) 
"El Plato para Comer Saludable", creado por expertos en nutrición de la Escuela de Salud Pública de Harvard y los editores en Publicaciones de Salud de Harvard, es una guía para crear comidas saludables y balanceadas - ya sean servidas en un plato o empacadas para llevar en la merienda o almuerzo. Coloque una copia en su refrigerador/nevera para que recuerde a diario preparar comidas saludables $\mathrm{y}$ balanceadas.

- Haga que la mayoría de sus comidas sean vegetales y frutas - $1 / 2$ de su plato: Intente incorporar color y variedad, y recuerde que las patatas (papas) no cuentan como un vegetal en El Plato para Comer Saludable por su efecto negativo en la azúcar en la sangre.

- Escoja granos integrales - 1/4 de su plato: Granos integrales e intactos - trigo integral, cebada, granos de trigo, quinua, avena, arroz integral, y las comidas preparadas con estos ingredientes como pasta de trigo integral - tienen un efecto más moderado en la azúcar en la sangre y la insulina que el pan blanco, arroz blanco, y otros granos refinados.

- El valor de la proteína - 1/4 de su plato: Pescado, pollo, legumbres (habichuelas/leguminosas/frijoles), y nueces son fuentes de proteínas saludables y versátiles - pueden ser mezcladas en ensaladas, y combinan bien con vegetales en un plato. Limite las carnes rojas, y evite carnes procesadas como tocineta ("bacon") y embuditos (salchichas).

- Aceites de plantas saludables - en moderación: Escoja aceites vegetales saludables como aceite de oliva, de canola, de soya, de maíz, de girasol, de maní (cacahuate), u otros y evite los aceites parcialmente hidrogenados, los cuales contienen las grasas trans no saludables. Recuerde que "bajo en grasa" no significa "saludable".

- Tome agua, café, o té: Omita las bebidas azucaradas, limite la leche y productos lácteos a una o dos porciones al día, y limite el jugo (zumo) a un vaso pequeño al día.

- Manténgase activo: La figura roja corriendo sobre el mantel de El Plato para Comer Saludable es un recordatorio de que mantenerse activo también es importante en el control de peso. El mensaje principal de El Plato para Comer Saludable es enfocarse en la calidad de la dieta. 
- El tipo de carbohidratos en la dieta es más importante que la cantidad de carbohidratos en la dieta, porque algunas fuentes de carbohidratos, (otros que no sean patatas/papas), granos integrales, y legumbres (habichuelas/leguminosas/frijoles)- son más saludables que otros.

- El Plato para Comer Saludable también aconseja a los consumidores a evitar las bebidas azucaradas, una fuente principal de calorías, usualmente con poco valor nutricional.

- El Plato para Comer Saludable anima a los consumidores a usar aceites saludables, y no establece un máximo en el porciento de calorías de fuentes saludables de grasa que las personas deben obtener cada día.

\subsubsection{Educación nutricional utilizando el marketing experiencial y el "Círculo de Oro" de Simon Sinek.}

Uno de los rasgos distintivos del servicio de comida que ofreceremos es que buscaremos llegar al consciente y subconsciente de la mente del consumidor a través del uso de dos metodologías de marketing que se complementan. La primera será el marketing experiencial, entendido como un conjunto de principios y acciones que se basan en la premisa de que el cliente elige un producto o servicio por la experiencia que se le ofrece antes y durante su consumo. Es decir, que el producto o servicio es mejor vivirlo a que sólo te lo cuenten. Lo que se busca esencialmente es provocar en el cliente emociones y sentimientos de modo que éste se conecte afectivamente con la marca.

La segunda metodología de marketing que utilizaremos para conseguir conquistar y fidelizar a nuestros clientes será "El Círculo de Oro" de Simon Sinek. Según esta estrategia, la manera de llegar a tener clientes "inspirados" y muy fieles a una marca se deriva del orden y la forma en que se estructura un mensaje. La figura 1.3: El Círculo de Oro describe tres círculos concéntricos que guardan un paralelo con la anatomía del cerebro. En la parte externa del círculo, al igual que en la parte más externa del cerebro, el neocórtex, es en donde se procesan los mensajes racionales, es decir el "qué"; más adentro, en la zona del círculo concéntrico del medio, se procesa el "cómo" y, finalmente, en la zona más interna del cerebro, el "por qué". Lo que sostiene el experto en neuromarketing Simon Sinek es que -usualmente- la comunicación tradicional va de 
afuera hacia adentro. Es decir, primero se suele enviar un mensaje que habla del "qué" (mensaje racional), luego del "cómo", pero raramente se llega a la zona del " por qué". Sin embargo, según Sinek, de acuerdo a su modelo del "Círculo de Oro", para que un mensaje sea "inspirador", el orden en que se presenta un mensaje debe ser inverso. Es decir, que el mensaje debe presentarse primero estimulando el círculo concéntrico más interno (respondiendo al "por qué"), luego estimular el "cómo", para recién -finalmenteestimular la zona racional del cerebro, es decir, la zona que responde al "qué".

Para la implementación de nuestro primer restaurante bio-experiencial de educación nutricional según la Escuela de Salud Pública de la Universidad de Harvard en Perú la diversión, la creatividad, el arte y la fantasía estarán entrelazados con la educación, la nutrición y la salud, gracias a un enfoque en el que el buscaremos inicialmente un contenido emocional (motivación lúdica y artística del individuo) que nos permita llegar a estimular rápidamente al sistema límbico, que es el conjunto de estructuras del cerebro en donde se interiorizan las emociones. (Esto lo haremos a través de un conjunto de medios artísticos en los que se fusionen videos multimedia con música, pintura, fotografía, entre otros.) Luego, siempre dentro del sistema límbico, encontramos ciertas estructuras como la amígdala, que es responsable de determinar qué recuerdos se almacenan y en qué parte del cerebro, para que luego el hipocampo envíe estos recuerdos a la parte apropiada del hemisferio cerebral, que los almacenará a largo plazo, para cuando se necesite recuperarlos. Luego, las decisiones se procesarán en el córtex órbitofrontal del cerebro, para finalmente estimular también la zona externa del cerebro, el neocórtex (componente racional) con los conocimientos sobre nutrición y la salud. Aplicando de esta manera, la teoría del Círculo de Oro de Simon Zinek lograremos que los consumidores se inspiren e interioricen los beneficios del consumo de las frutas y vegetales, como parte de una dieta agradable, saludable y nutritiva. 
Figura 1.2

El círculo de oro de Simon Zinek

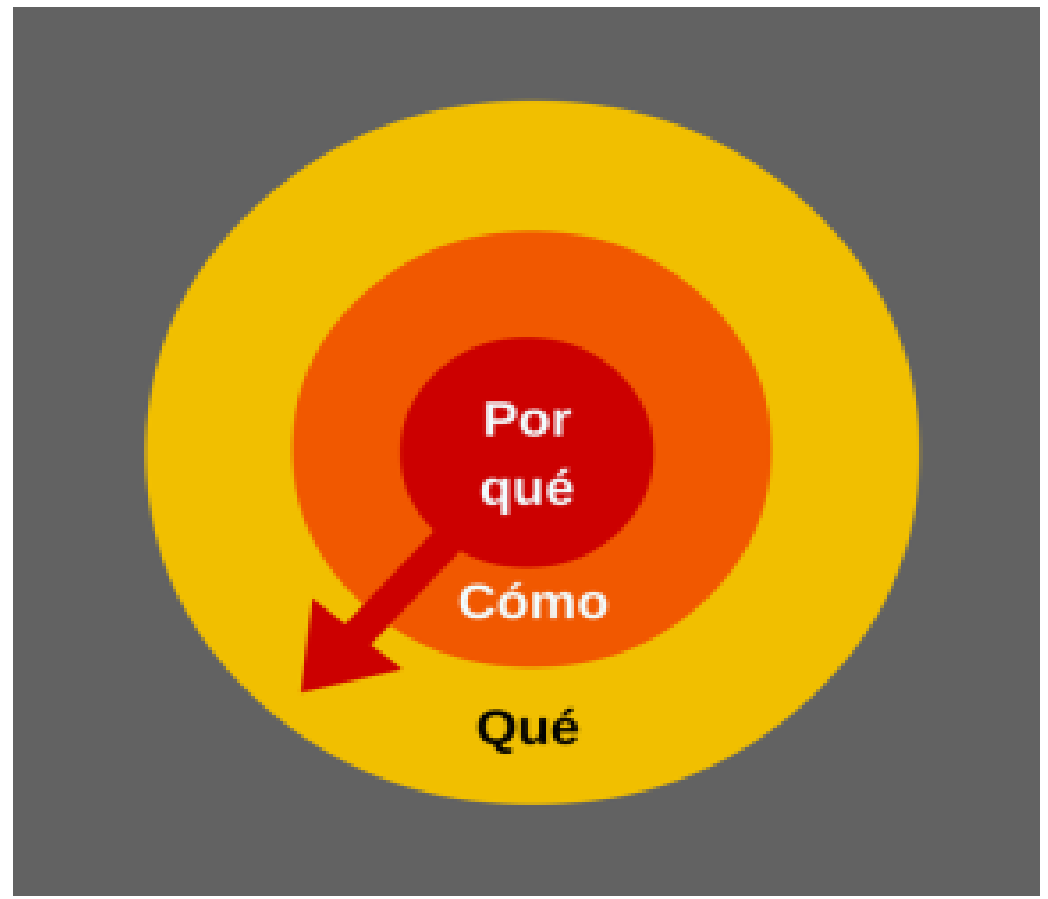

Fuente: Guimerá, A. (2016)

El modelo del "Círculo de Oro" de Simon Sinek (2009) consiste en tres circulos concéntricos que se asemejan a cómo se vería el cerebro humano si lo cortáramos como quien corta a una naranja. Las zonas definidas por los tres círculos concéntricos guardan una correspondencia con las zonas en las que se llevan a cabo los diferentes tipos de proceso del cerebro humano. La forma de comunicación más frecuente es seguir el orden de afuera hacia adentro.

Sin embargo, Sinek sostiene que la forma más efectiva de inspirar y fidelizar a nuestros clientes es comunicándose empezando desde adentro y yendo hacia fuera. Es decir, primero hablando del "por qué", luego del "cómo", para finalmente hablar del “qué”. Según Sinek es éste el orden en que los líderes más efectivos piensan, actúan y comunican.

Pensar, actuar y comunicar desde el centro del círculo (por qué) hasta la periferia (qué) pasando por el cómo es lo que hace todo líder inspirador, así como las marcas que logran fidelizar a sus clientes. 


\subsubsection{Evaluación y formulación de proyecto de inversión.}

Este proceso comprende realizar 4 estudios: un estudio de mercado, un estudio técnico, un estudio financiero, un estudio de organización.

Todo ello para evaluar la factibilidad y viabilidad de realizar el proyecto de tener un restaurante con productos orgánicos, utilizando el plato saludable de Harvard.

\subsubsection{Benchmark}

Escogeremos como benchmark un proyecto de María Cedeño (2006), en donde se hace mención a un proyecto que se realizó en la ciudad de Guayaquil - Ecuador y fue concebido como un restaurante de encuentro familiar y personal, en donde el cliente estaría el mayor tiempo posible en sus instalaciones disfrutando de un ambiente distinto al que puede encontrar en otro punto de la ciudad. Conviene aclarar que el propósito inicial era tener unos precios bajos y que la calidad del producto no fuera a variar. El servicio de restaurante se ofrecería los fines de semana y feriados, es decir de viernes a domingo, así como feriados abierto al público. La diferencia con nuestro proyecto es que el nuestro, entre semana, funcionaría además para el delivery a centros educativos y oficinas en los siete días de la semana.

Este proyecto que escogimos como benchmark, se realizó en la ciudad de Guayaquil, en donde un chef con conocimiento en la preparación de platos de mariscos, se encargó de elaborar los platillos en forma nutritiva y saludable para el segmento socioeconómico medio y medio alto. La materia prima incluyó vegetales, frutas, verduras y mariscos, todos ellos frescos y cumpliendo con las normas sanitarias y de higiene. La empresa a crear fue "Delicias del Mar".

\subsection{Motivación del Proyecto.}

La motivación de nuestro proyecto surgió a partir de una reflexión sobre lo que constituye el hábitat para la arquitectura, y que lo fundamental no es lo formal o lo espacial, sino los modos de vida de las personas que lo habitan. Chen, L. (2016). Es más, ello se puede reflejar-inclusive- en lo más cotidiano, como en la comida. El acto de comer es en sí una experiencia relacionada con nuestros sentidos y el placer. Además, siempre implica cumplir el papel social de unir personas, familiares y amigos. Y esta función social no se 
limita sólo a comer, sino también a la producción y a la cocción de alimentos. Las reflexiones sobre el espacio para cocinar y el lugar para cultivar influyen cada vez más en nuestros modos de vida. La cocina ya no es un sitio de trabajo sólo para la madre, sino que es en donde todos los miembros de la familia podrían cocinar juntos y hablarse unos a otros. Así mismo, la relación del jardín de cultivo con la cocina es fundamental para tener alimento sano y fresco, además de constituir una alternativa con implicancias de carácter económico y volver a introducir los valores sociales al replantear nuestro estilo de vida. Palabras claves: habitar, persona, comida, relación social, cocina, jardín, huerto urbano, ecología urbana, agricultura urbana, desarrollo sostenible.

La motivación del proyecto nació también a partir de una necesidad no cubierta en el mercado nacional, que es la de contar con un restaurante que ofrezca comida de alta calidad (como la que estamos acostumbrados) pero baja en grasas y carbohidratos, con productos orgánicos y que sea saludable y nutritiva. Los consumidores de este nicho de mercado están preocupados por la alimentación que ellos y sus hijos reciben día a día. Y es que en los restaurantes muchas veces es difícil encontrar platos nutritivos que vengan con las proporciones debidas para una alimentación saludable. Adicionalmente, los aportes de la agricultura en ambiente controlado (Indoors farming), sumados a los de comida orgánica y súper alimentos como la quinua, kiwicha, maca, tarwi, más de 2 mil variedades de papa, y una enorme variedad de frutos, verduras y hierbas medicinales constituyen una trilogía perfecta de alimentación saludable, estilo de vida y cuidado del medio ambiente. Todo esto en un solo restaurante en donde la experiencia del comer, esté ligada al modo de vida del ser humano del futuro, que esperamos viva en armonía con el medio ambiente y con su cuerpo.

\subsection{Percepción de la Necesidad: Análisis-Problema-Solución.}

\subsubsection{Análisis}

El Perú es considerado como uno de los diez países mega diversos del mundo. Esta es nuestra ventaja comparativa para el desarrollo económico y social. Y es que, según la Estrategia Nacional de Biodiversidad Biológica del Perú, nuestro país concentra 11 ecoregiones naturales, 84 zonas de vida natural, una enorme biodiversidad de flora con unas 25,000 especies (10\% del total mundial). 
La Asociación Peruana de Gastronomía, APEGA, ha venido trabajando con diversas organizaciones agrarias en el forjamiento de cadenas agroalimentarias gastronómicas inclusivas, que parten de reconocer que los pequeños agricultores son el primer eslabón de la cadena gastronómica. En esa línea, APEGA ha implementado, como gran atracción, que cada año se lleve a cabo la feria gastronómica Mistura, que convoca a medio millón de visitantes del llamado Gran Mercado, el cual incluye a productores agropecuarios emblemáticos de las diversas regiones del Perú y ha reconocido anualmente a los más destacados con el Rocoto de Oro. Paralelamente ha promovido reportajes en los principales medios de comunicación, sobre el trabajo en el campo, con el aporte de los productores. APEGA, con el lema "como rico, coma sano, coma peruano", busca que los productos naturales de una zona sean frescos, de estacionalidad, saludables, nutritivos y a buen precio.

Perú es uno de los centros de origen de recursos genéticos de plantas y animales, ocupando el primer lugar en especies nativas domesticadas (128 especies), así como poseedor de una alta diversidad genética en los cultivos de papa y maíz (dos de los cuatro cultivos más importantes para la alimentación mundial). Todo esto se ha mantenido en el tiempo gracias a la sabiduría y las habilidades del agricultor peruano que, a través de una ingeniería ancestral -como los andenes y avanzados sistemas de riego- ha hecho perdurar a especies que hoy asombran al mundo.

Aun así, tenemos problemas de alimentación muy graves con casos de desnutrición en niños y adultos anémicos. Por la falta de una dieta saludable en sus platos, los peruanos tienen una mayor proclividad hacia las enfermedades.

Nuevas técnicas de cultivo como la agricultura en ambiente controlado que todavía no se han desarrollado en el Perú, pueden ser los proveedores de frutas y vegetales orgánicos y que generen la base para una alimentación nutritiva y saludable. (Sociedad Peruana de Gastronomía, s.f.).

\subsubsection{Problema}

El público en general está preocupado por la alimentación que ellos y sus hijos reciben día a día. Y es que en los restaurantes muchas veces es difícil encontrar platos nutritivos que vengan con las proporciones debidas para una alimentación saludable. Este problema 
se hace más preocupante por los efectos que una alimentación poco saludable pueda luego generar en la salud.

Asimismo, no se tiene una suficiente oferta de productos saludables, existiendo pocos centros de cultivo con riego tecnificado, sin pesticidas químicos. La mayoría de los productos agrícolas se riegan con agua de río, que está inclusive contaminada. En la actualidad existen muchos restaurantes, pollerías, chifas (restaurantes de comida china) que vienen ofreciendo una comida con productos poco saludables y que no siguen las recomendaciones de nutrición más adecuadas. Por ello es que planteamos ofrecer unos platos que se basen en el llamado Plato Saludable de la Escuela de Salud Pública de la Universidad de Harvard.

Una buena alimentación es esencial para mantenerse sano física y mentalmente. A continuación, se menciona algunos de los problemas más comunes generados por una mala alimentación:

El primer problema es la obesidad. Algunas personas sufren la obesidad por causas genéticas, pero la mayoría de las personas la sufre debido a una mala alimentación y al sedentarismo. Según el Instituto Nacional de Estadística e Informática (INEI, 2016) en el año 2016, en el Perú, el 35.5\% de las personas mayores de 15 años sufría de obesidad. Cada año, el número de obesos en el mundo aumenta considerablemente; así, según la Organización Mundial de Salud (OMS, 2017) desde 1980 hasta el 2017, el número de obesos en el mundo se ha duplicado.

El segundo problema es la alta presión arterial. La cual se deriva mayormente por casos de alcoholismo, alimentación con mucha sal o sodio, por el tabaco y por una dieta malsana que puede ocasionar sufrir de hipertensión. Según la OMS, anualmente mueren 9.4 millones de personas debido a una alta presión arterial, siendo ésta la causante de al menos el $45 \%$ de otras patologías o enfermedades.

El tercer problema son las enfermedades cardiovasculares. Que son ocasionadas por una mala alimentación o un excesivo consumo de sal. De allí que la recomendación sea comer raciones de fruta y hortalizas para evitar riesgos de infartos al miocardio y accidentes cardiovasculares.

El cuarto problema es la depresión. Comer en exceso puede desencadenar un cuadro depresivo que puede inclusive llevar al suicidio. Según cifras de la OMS en el 2017, más de 300 millones de personas en el mundo sufren de depresión. 
(http://www.who.int/campaigns/world-health-day/2017/es/). Entonces una dieta saludable contribuye a obtener una mejor salud mental.

El quinto problema es la diabetes. La forma de prevenir la diabetes tipo 2 es mediante actividades físicas, por un mínimo 30 minutos diarios, acompañadas de una dieta saludable. La diabetes tipo 1, no se puede prevenir. Para el 2030 se prevé que será la séptima causante de muerte.

El sexto problema es el cáncer. Más del $30 \%$ de los cánceres se pueden evitar comiendo sanamente, realizando actividad física, moderando el uso del alcohol, evitando fumar y eliminando el consumo de drogas ilegales. Menores serán las probabilidades de tener cáncer si se consume más de los siguientes alimentos: ajo, brócoli, té verde, pan integral, cereales, granos, tomate, lechuga, espinaca, frijoles, uvas, nueces, naranjas y limones.

El séptimo problema es el mal funcionamiento cerebral. En ese sentido, las grasas trans aceleran el envejecimiento cerebral. Un alto consumo de azúcar no es bueno para el cerebro y puede además provocar somnolencia, irritabilidad o incapacidad de concentrarse. Esto implicaría que comer sano y realizar actividad física, ayuda a irrigar el cerebro.

El octavo problema es la indigestión. Esto se percibe en el abdomen por comer productos con alto contenido de grasas, por ingerir bebidas con gas, alcohol o cafeína.

Todo lo anteriormente descrito justifica la importancia de implementar un restaurante que ayude a reducir los riesgos antes descritos con el objetivo de llevar el plato saludable de la Escuela de Salud Pública de la Universidad de Harvard a las mesas de padres y familias que desean consumir una dieta saludable, con pleno conocimiento de las implicancias positivas que ello trae consigo para sus vidas.

\subsubsection{Solución}

Como solución a estos males, proponemos implementar el primer restaurante bioexperiencial y de educación nutricional según las recomendaciones del denominado "Plato Saludable la Escuela de Salud Pública de la Universidad de Harvard". Para contribuir a lograr este objetivo, proponemos promover y utilizar la tecnología de la agricultura en ambiente controlado (también conocida como "indoors farming", en 
inglés) para la provisión progresiva de los insumos que utilizaremos en los platos de nuestro restaurante. Ello hará que más agricultores, poco a poco, prefieran el uso de esta tecnología, considerando sus grandes ventajas. Con el aumento en el uso de esta tecnología, los agricultores de la agricultura vertical podrán también establecer negociaciones comerciales con restaurantes y hoteles que tengan altas exigencias de calidad e inocuidad, al ofrecer productos saludables en forma permanente, y que formen parte de su carta.

Estos productos orgánicos son la base de los platos que se van a preparar en nuestro restaurante, teniendo como eje el plato saludable de la Escuela de Salud Pública de la Universidad de Harvard.

En la ciudad de Lima, existe un alto porcentaje de personas que no tienen suficiente tiempo para preparar alimentos sanos y amas de casa que, por lo general, trabajan y no cuentan con el debido tiempo para cocinar, dado el agitado ritmo de vida que viven en la actualidad y una carencia de establecimientos de comida nutritiva y saludable.

Por lo anteriormente mencionado, implementaremos el primer restaurante bioexperiencial de educación nutricional desarrollando un concepto novedoso en el que los clientes vivan una experiencia multisensorial única, en la que a través de la conjugación del arte y la ciencia interioricen una educación nutricional, al mismo tiempo que se deleitan de platos de un bufet y/o platos a la carta. Asimismo, proponemos una oferta por delivery, para aquellas personas, que describimos en el párrafo anterior.

\subsection{Descripción de la Idea y la Oportunidad}

La idea del negocio, nace por la necesidad que se tiene de comer de manera saludable en los restaurantes, partiendo de las recomendaciones del plato saludable de la Escuela de Salud Pública de la Universidad de Harvard así como de disfrutar del aprendizaje de una educación nutricional y de una experiencia multisensorial que actualmente no se tiene en Lima Metropolitana.

Dado que se necesita de empresas proveedoras de alimentos, carnes, pescados, vegetales, equipos industriales, enseres, etc., hay la necesidad de los Gobiernos, Municipalidades, APEGA y todas las entidades interesadas en la salud de la población 
que los agricultores que cultiven alimentos nutritivos y saludables sean parte de un clúster que les permita conocer nuevas tecnologías, como las de la agricultura en ambiente controlado.

\subsection{Justificación del Atractivo de la Propuesta}

La preocupación de muchas personas es acerca de cómo acceder a platos que contengan un alto valor nutricional, que sean atractivos y de agrado al paladar buscando evitar el consumo de alimentos chatarra, como las golosinas, bebidas gaseosas y jugos envasados, cuyo consumo en altas dosis genera obesidad y muchas veces una alimentación deficiente como lo hemos ya descrito.

En la gran mayoría de hogares de Nivel Socio Económico (NSE en adelante) "A" y "B", ambos padres trabajan fuera de casa de manera dependiente o independiente, por lo que se opta por preparar el contenido de los alimentos de la manera más fácil y simple, o delegar este trabajo al personal de servicio, dando por resultado que muchas veces no se obtiene una alimentación nutritiva, balanceada y con la porción adecuada y necesaria para la nutrición del cuerpo humano.

Se aprecia también la existencia de cierta preocupación por parte de las instituciones del Estado, como Ministerio de Salud (MINSA en adelante) y el Ministerio de Educación (MINEDU en adelante), en lo referente al contenido nutricional en las loncheras que los niños llevan a las escuelas, ofreciendo, en muchas ocasiones, sugerencias y recomendaciones para su elaboración.

Con el fin de superar esos inconvenientes es que se presenta la idea de implementar un restaurante en donde se ofrezcan alimentos saludables, la mayoría de ellos orgánicos y de acuerdo a las recomendaciones del plato saludable de la Escuela de Salud Pública de la Universidad de Harvard. Tanto para comer in situ y disfrutar de la experiencia multi-sensorial, así como también de envío de estos platos saludables por delivery, entregados, en la casa, oficina o colegio, este último está dirigido para los niños que los padres contraten el servicio de loncheras saludables, o mediante un convenio directo con el colegio para brindar lonchaeras saludables en los comedores.

Las alianzas estratégicas con centros de investigación de universidades nacionales y extranjeras contribuirán a generar ecosistemas de emprendimiento que promuevan la 
innovación científica y tecnológica, así como la diversificación productiva, gracias a la alianza entre la universidad, la empresa privada y el Estado.

\subsection{Estrategia Inicial y Objetivos de Alcance}

\subsubsection{Estrategia inicial.}

- Realizar las alianzas con agricultores de vegetales.

- Realizar las alianzas con los proveedores de carnes y pescados.

- Realizar las alianzas con los proveedores de equipos.

- Realizar las alianzas con los proveedores de enseres y menaje.

- Estar inscrito dentro de APEGA y el IPEH (Instituto Peruano del espárrago y las Hortalizas).

\subsubsection{Objetivos de alcance.}

El estudio de investigación toma como eje central los siguientes criterios:

(i) El análisis estratégico del sector, buscando determinar los factores de éxito.

(ii) El estudio de mercado para determinar las características del segmento elegido y el tamaño del mercado meta.

(iii) Propuesta de valor del plan de negocios para la demanda identificada.

\subsubsection{Objetivo general.}

Implementar un restaurante bio-experiencial de educación nutricional que ofrezca una experiencia multisensorial única, que combine el arte y la ciencia para interiorizar el conocimiento de la alimentación saludable y nutritiva, al mismo tiempo que deleite al comensal con alimentos en un bufet y/o platos a la carta que estén basados en el modelo del Plato Saludable de la Escuela Pública de la Universidad de Harvard y que proporcione beneficios económicos, satisfaciendo las necesidades de la población de Lima para los niveles socioeconómicos A y B (NSE A y B). 


\subsubsection{Objetivos específicos.}

- Investigar el interés de las personas por la comida saludable.

- Detectar la factibilidad de instaurar con éxito un establecimiento de comida saludable en las áreas alrededor del casco urbano de Lima.

- Implementar una serie de platos que se puedan preparar utilizando el modelo de Plato Saludable de la Escuela de Salud Pública de Harvard, que sean nutritivos, saludables y de muy buen sabor, para ofrecer a los habitantes de Lima Metropolitana del NSE A y B.

- Determinar todos los implementos, estudios y requerimientos que se requieren para instaurar un restaurante bio-experiencial de comida nutritiva y saludable.

- Encontrar los beneficios, ventajas y desventajas, que aportará un establecimiento de comida saludable en la ciudad de Lima.

- Implementar el reparto a domicilio u oficina de comida saludable.

\subsection{Impacto Comercial y Responsabilidad Social}

\subsubsection{El impacto comercial.}

El impacto comercial se espera que sea sostenible y de rápida expansión, debido a la creciente megatendencia para consumir productos orgánicos, saludables y nutritivos.

Los consumidores en muchas partes del mundo, cada vez más buscan productos saludables y muchos de ellos orgánicos en los supermercados y restaurantes, a la vez que más personas abren pequeños negocios vendiendo productos orgánicos, y que se puede apreciar en las calles de Lima.

\subsubsection{Responsabilidad social.}

Este proyecto es de vital importancia, dado que va a involucrar a todos los actores en un crecimiento sostenible y de expansión.

Algunos programas de responsabilidad social: 
Proyectos Productivos. Se promoverá la capacitación de los agricultores de productos naturales, frescos y sin preservantes para innovar en técnicas de cultivo, la crianza en granjas y la conservación del medio ambiente.

Alianzas con universidades y colegios. Dando el apoyo para que los estudiantes innoven en los diferentes procesos, equipos y menaje que necesita un restaurante. Se plantea desarrollar un concurso para la elaboración de platillos saludables con los estudiantes de los centros de capacitación en gastronomía.

Capacitación en comida saludable. En el mismo lugar en donde se ubicará el restaurante, se colocarán vallas, paneles o monitores con explicación de infofiguras sobre la nutrición, al cual los comensales podrán acceder en circuito cerrado con videos amigables, de corta duración. Así mismo, el uso de medios multimedia en presentaciones en las que se fusione la música, la fotografía, la escultura y las artes visuales, contribuirán a generar que los comensales vivan una bio-experiencia singular. 


\section{CAPÍTULO II: IDEA, INVESTIGACIÓN Y VALIDACIÓN DE SOLUCIÓN}

\subsection{Diseño y Metodología de la Investigación}

La metodología empleada en este proyecto de investigación se guía por dos criterios que funcionan como eje de la investigación:

(i) El análisis del sector: servicio de alimentación saludable con productos saludables.

(ii) La investigación del mercado: Características del segmento poblacional de los NSE “A” y "B” y de los distritos de Santiago de Surco, San Isidro, San Borja, La Molina y Miraflores.

A través de la información y conclusiones obtenidas de ambos ejes, se realizó un análisis estratégico con la finalidad de obtener los factores claves para el éxito del negocio propuesto y, a partir de ellos, elaborar un Plan de Negocios que contiene:

- El Plan Estratégico, en el que se define la visión, misión, objetivos estratégicos, las competencias genéricas, ventajas comparativas y propuestas de valor del modelo de negocio.

- El Plan de Marketing, a través del cual se identifica y caracteriza al segmento objetivo para luego comunicarles la propuesta de valor del negocio.

- El Plan de Operaciones, buscando desarrollar procesos eficientes y competitivos.

- El Plan de Recursos Humanos, en el que se establece la organización, designación de responsabilidades y gestión de los recursos humanos.

- La Evaluación Económica y Financiera, por medio de la cual se sustentará la viabilidad del modelo de negocio. 


\section{Metodología:}

Lo anteriormente descrito considera una metodología cuantitativa y cualitativa, con un tipo de investigación que utiliza estudios exploratorios, descriptivos y explicativos.

Las metodologías que aplicaremos en este trabajo nos permitirán ir construyendo el camino a seguir. Mediante una correcta selección y aplicación de distintos métodos de investigación, con la ayuda de las adecuadas herramientas técnicas y metodológicas para recabar la información lógica, objetiva y precisa, podremos cuantificar con exactitud los datos requeridos para diagnosticar y proponer soluciones en la creación de la nueva empresa de un restaurante bio-experiencial, a partir del modelo del Plato Saludable de la Escuela de Salud Pública de la Universidad de Harvard.

Métodos Analíticos. Se emplearán para investigar la naturaleza y preferencias del consumidor, así como las tendencias del mercado. Ello se canalizará a través del Estudio de Mercado, en donde se aplicarán encuestas, focus group, juicios de expertos, tomando en cuenta un tamaño de muestra representativo de la población que nos permita hacer una segmentación del mercado. Asimismo, se determinará la demanda potencial, real, efectiva e insatisfecha.

El Análisis Técnico se utilizará para encontrar el tamaño de la empresa, una localización adecuada, así como para definir el diseño arquitectónico más adecuado para el proyecto.

El Análisis Administrativo nos mostrará la viabilidad legal referida al negocio, así como el modelo de organización que se adecúe mejor a la empresa y el personal requerido. Finalmente, el Análisis Financiero permitirá determinar la rentabilidad del negocio y las condiciones de riesgo detrás del proyecto de negocio.

Métodos Estadísticos. Estos métodos permitirán que hallemos procedimientos adecuados para el manejo de datos cualitativos y cuantitativos al recolectar, elaborar, analizar, interpretar y presentar la información del mercado a través de números, tablas y figuras referidos a la población en estudio, la muestra seleccionada acompañada de las técnicas aplicadas con el único fin de poder interpretar los resultados y tomar las decisiones adecuadas referidas al presente proyecto de negocio.

Método Deductivo. Se aplicará para sacar conclusiones referidas a la interpretación racional y el análisis objetivo de los hechos o fenómenos que se 
encontraron en la obtención de datos y variables como demandas, precios, ingresos, costos, utilidades, etc.

Método Inductivo. El presente método se utilizará para determinar los resultados generales del proyecto, porque al momento de formular, analizar e interpretar los resultados de la información obtenida de las entrevistas, focus group y encuestas, se proporcionará información confiable para la toma de decisiones en cuanto a la creación de la empresa Restaurante Bio-Experiencial, utilizando el modelo de Plato Saludable de la Escuela de Salud Pública de la Universidad de Harvard en la ciudad de Lima Metropolitana.

\subsection{Validación de la Hipótesis}

La hipótesis sobre la viabilidad del proyecto de crear una empresa de Restaurante BioExperiencial aplicando el modelo del Plato Saludable de la Escuela de Salud Pública de la Universidad de Harvard se demuestra utilizando dos herramientas financieras: el VAN y la TIR. Se aceptará la hipótesis si los valores en el caso del VAN resulten positivos y en el caso de la tasa interna de retorno, cuando aquella sea la esperada por los inversionistas. En el caso del VAN, se hará utilizando la tasa de descuento del WACC.

Adicionalmente utilizaremos una serie de métodos cualitativos (entrevistas a expertos sobre la agricultura vertical y focus group) y cuantitativos (encuestas realizadas según los diversos distritos considerados), que se detallan en el punto 2.3 que apoyarán nuestra hipótesis.

\subsubsection{Hipótesis}

Es factible y rentable implementar un restaurante de educación nutricional bioexperiencial, multisensorial de alimentación saludable y nutritiva basado en el modelo de Plato Saludable de la Escuela de Salud Pública de la Universidad de Harvard, satisfaciendo la necesidad de una alimentación nutritiva y saludable. 


\subsection{Validación de la Solución}

A lo largo del presente proyecto de tesis se emplea una serie de herramientas de análisis, entre las cuales tenemos:

- El Análisis PESTE. El cual nos demuestra los factores externos que podrían influir en el comportamiento del mercado objetivo.

- El Análisis de Competitividad (cinco fuerzas de Porter). Identificando e investigando el mercado, barreras de entrada, los actores involucrados y su interrelación.

- La Investigación de Mercado. Que permite obtener información preliminar acerca de atributos a tener en cuenta en el producto a ofrecer al público, con expertos en gastronomía y nutrición, junto a atributos valorados por las personas. También se logrará recoger información cualitativa y cuantitativa que permita identificar los hábitos de consumo, frecuencia, la intención de compra, disposición de pago, la demanda potencial y el mercado meta.

- El Análisis de las Estrategias Competitivas. Para definir las estrategias generales y específicas a establecer en el servicio ofrecido por el modelo de negocio, junto a las estrategias de incremento de ventas del mismo.

- El Análisis del Marketing Mix. Que permite diseñar y definir estrategias funcionales para el modelo de negocio propuesto.

- El Flujo de Operaciones. Que determina el modelo óptimo de operaciones, permitiendo la eficacia en la puesta en práctica del servicio propuesto.

- La Evaluación Económica y Financiera del proyecto.

\subsection{Muestreo Poblacional}

El objetivo de la investigación de mercado y su respectiva encuesta es conocer si la creación del restaurante bio-experiencial tendría aceptación por parte de nuestros posibles consumidores, dado que este tipo de servicio aún no es conocido por la población, al ser un nuevo negocio. 
También se desea determinar la población o público objetivo del restaurante, conocer el perfil del consumidor y su frecuencia de consumo. Toda esta información es importante para determinar la demanda potencial del mercado.

Se utilizará la población de los 5 distritos de Lima Metropolitana que albergan a consumidores de los niveles socioeconómicos más altos, es decir, los niveles A y B. Estos distritos son: La Molina, San Isidro, San Borja, Miraflores y Santiago de Surco.

Con la siguiente fórmula de población finita, determinaremos el tamaño de la muestra de la encuesta a realizar. (Roberto Sampieri, 2006).

$$
n=\frac{N^{*} Z_{a}^{2} p^{*} q}{d^{2 *}(N-1)+Z_{a}^{2} p^{*} q}
$$

Donde:

$\mathrm{n}=$ tamaño de la muestra.

$\mathrm{N}=($ Total de la población $)$

$\mathrm{Z}=1.96$ (el Nivel de Confianza es de 95\%)

p=0.5 (Proporción Esperada, se tomó 0.5 que maximiza el tamaño muestral)

$\mathrm{q}=0.5(1-\mathrm{p})$

d=6\% (Precisión en la investigación).

\subsection{Análisis de Tendencias y Patrones}

Según Coquillat (2015) tenemos las siguientes tendencias:

Calidad del producto: Las nuevas tendencias manifiestan que la calidad de los productos y de las materias primas cobran cada vez mayor relevancia a la hora de elegir un restaurante.

Comer fuera de casa se está convirtiendo en un estilo de vida en muchos países. La experiencia va ligada al concepto de la calidad en detrimento del precio.

Los nuevos clientes prefieren pagar más por tener productos de primera calidad y vivir experiencias diferentes. 
Comer sano: Es una de las megatendencias que con mayor fuerza en la que los consumidores "vienen desde el otro lado del océano". Muchas de las medidas contra la epidemia de la obesidad, aditivos, transgénicos, productos químicos y las enfermedades cardiovasculares se están canalizando a través de los restaurantes.

Comer sano cada vez preocupa más a los gobiernos y a los ciudadanos. La calidad en los componentes nutricionales de aquello que comemos en los restaurantes se va a convertir en uno de los elementos de mayor impacto diferenciador y de sostenibilidad en el sector.

Formación: La industria de los restaurantes se está enfrentando al mayor proceso de transformación global de su historia. La tecnología está cambiando las formas, los métodos y los procesos de todo lo establecido, a una velocidad de vértigo. La manera de ser competitivo y eficaz en el sector ha cambiado. Como decía hace unos días Ferran Adrià “La gran revolución es la educación online". La industria no se puede quedar atrás en esta revolución, y el sector ha de ser consciente que ha de formarse en nuevas habilidades profesionales para dar una respuesta adecuada a los nuevos retos a los que se enfrenta.

La sostenibilidad: El camino hacia la sostenibilidad es una tendencia mundial imparable. Forma parte del sentido común y del respeto al entorno en el que se desarrolla una actividad. Cada vez son más los restaurantes que se inician en este sentido favoreciendo elementos como preservar el medio ambiente, crear un huerto propio, usar agua depurada, utilizar productos biodegradables, favorecer el ahorro energético y otras muchas acciones.

La experiencia móvil: El incremento en el uso de los teléfonos celulares inteligentes (smartphones) ha provocado una digitalización de experiencia móvil en los clientes. Cada vez son más las personas que utilizan este dispositivo para localizar un restaurante, hacer una reserva, pedir comida a domicilio y, en breve, hacer el pago por el consumo. Se está produciendo una traslación desde los entornos webs habituales o de escritorio a los entornos móviles.

Este elemento es especialmente importante en el caso de la industria de los restaurantes donde un porcentaje muy elevado de los clientes son de proximidad, convirtiéndose en el complemento perfecto para conseguir conversiones digitales en el restaurante. 


\subsection{CANVAS del Modelo de Negocio.}

Tabla 2.1

Canvas del modelo de negocio

\begin{tabular}{|c|c|c|c|c|}
\hline 8.Socios Clave & $\begin{array}{l}\text { 7.Actividades } \\
\text { Clave }\end{array}$ & $\begin{array}{l}\text { 2.Propuesta } \\
\text { Valor }\end{array}$ & $\begin{array}{c}\text { 4.Relación } \\
\text { Clientes }\end{array}$ & $\begin{array}{l}\text { 1.Segmentos } \\
\text { de Clientes }\end{array}$ \\
\hline $\begin{array}{l}\text { Alianza con } \\
\text { Proveedor de } \\
\text { Vegetales } \\
\text { Orgánicos. } \\
\text { Alianza con } \\
\text { proveedor de } \\
\text { insumos de carne } \\
\text { y pescado. } \\
\text { Alianza con } \\
\text { proveedor de } \\
\text { equipos, utensilios } \\
\text { de cocina y } \\
\text { menaje. } \\
\text { Alianza con } \\
\text { proveedores de } \\
\text { mueblería y } \\
\text { decoración. } \\
\text { Alianzas con } \\
\text { futuros } \\
\text { franquiciados y } \\
\text { distribuidores }\end{array}$ & $\begin{array}{l}\text { Compra y control de } \\
\text { calidad de los } \\
\text { insumos, equipos y } \\
\text { utensilios de cocina. } \\
\text { Compra y Control } \\
\text { de calidad de } \\
\text { alimentos y bebidas. } \\
\text { Preparación de } \\
\text { recetas por plato. } \\
\text { Degustación y } \\
\text { aprobación de los } \\
\text { platos y buffet. } \\
\text { Control del personal } \\
\text { y capacitación en } \\
\text { salubridad de los } \\
\text { alimentos } \\
\text { 6.Recursos Clave }\end{array}$ & $\begin{array}{l}\text { Brindar comida } \\
\text { saludable, partiendo } \\
\text { del plato saludable } \\
\text { de la Escuela de } \\
\text { Salud Pública de la } \\
\text { Universidad de } \\
\text { Harvard, con } \\
\text { productos que sean } \\
\text { mayormente } \\
\text { orgánicos. } \\
\text { Brindar una } \\
\text { capacitación } \\
\text { interactiva y de } \\
\text { forma amigable } \\
\text { sobre la comida } \\
\text { saludable. } \\
\text { Brindar } \\
\text { capacitación y } \\
\text { promover los súper } \\
\text { alimentos }\end{array}$ & $\begin{array}{l}\text { Directo en el } \\
\text { Restaurante y a } \\
\text { través de } \\
\text { distribuidores, } \\
\text { franquicias. } \\
\text { Además, como } \\
\text { servicio de delivery } \\
\text { y para llevar. } \\
\text { Convenio con los } \\
\text { Colegios Top de } \\
\text { Lima }\end{array}$ & $\begin{array}{l}\text { Son los NSE A } \\
\text { y B de Lima } \\
\text { Metropolitana. }\end{array}$ \\
\hline \multicolumn{3}{|c|}{ Estructura de costos } & \multicolumn{2}{|l|}{ 5.Fuente de Ingresos } \\
\hline \multicolumn{3}{|c|}{$\begin{array}{l}\text { Los costos son los asociados al personal, materia prima de los } \\
\text { platos, como son los vegetales, carnes, pescado, etc. Insumos } \\
\text { de aceite, sal, condimentos y otras especies. Otros costos son la } \\
\text { electricidad, agua, servicio de internet, cable tv. Mantenimiento } \\
\text { y conservación del área del restaurante. }\end{array}$} & \multicolumn{2}{|c|}{$\begin{array}{l}\text { Se hará a través de la venta de platos } \\
\text { a la carta y de un servicio de buffet a } \\
\text { pago diferenciado entre niños y } \\
\text { adultos. Así también sobre las ventas } \\
\text { de productos orgánicos. }\end{array}$} \\
\hline
\end{tabular}

\subsection{Conclusiones}

En este capítulo se presentaron las ideas básicas del Plan de Negocios, teniendo en cuenta la motivación, los antecedentes del sector y la elección de la población, segmento al que va dirigido. Para ello, se planteó la interrogante del Plan de Negocios centrada en la viabilidad y sostenibilidad de la ejecución del mismo, junto a la metodología a seguir, 
considerando las variables extrínsecas e intrínsecas que podrían influir en nuestro negocio.

El modelo de negocio y sus atributos, buscan que el producto sea una solución para las personas que buscan alimentarse en forma saludable. 


\section{CAPÍTULO III: PLANEAMIENTO ESTRATÉGICO}

\subsection{Visión}

La visión consiste en ser la empresa líder proveedora de platos saludables con alimentos orgánicos para los NSE “A” y "B”, siendo reconocida por la variedad de su contenido, valor nutricional, precio justo y puntualidad en su entrega. Tanto para consumir en el restaurante como por delivery y llevar.

\subsection{Misión}

Somos una empresa de elaboración de platos saludables, que ofrece una solución a la falta de tiempo y conocimientos nutricionales de los padres y las familias, al brindar una experiencia multisensorial y un producto variado, sano y divertido para sus familias, ofreciéndoles siempre valor agregado como charlas y capacitación en nutrición y salud.

\subsubsection{Valores y ética.}

Nuestra empresa está regida por los siguientes valores institucionales:

- Excelencia en el servicio que brindamos a nuestros clientes, desde la selección de insumos, elaboración, conservación, venta, post venta y servicios adicionales de nutrición y asesoría médica.

- Compromiso, en brindar un producto saludable, fresco, a un precio asequible para nuestros clientes.

- Garantía de que nuestros platos saludables, desde la selección de sus insumos, en su manipulación, elaboración y conservación, son seguros y han seguido estándares de higiene y sanidad, encontrándose libres de agentes que causen infecciones o enfermedades.

- Innovación, porque siempre buscamos experimentar, aplicando nuevas tecnologías como la agricultura en ambiente controlado que nos proporcionen productos nuevos, inocuos y de alta calidad nutricional. 


\subsection{Cultura Organizacional}

Sin intención de delimitarla y enmarcarla por completo, se puede decir que la cultura organizacional tiene 4 aspectos:

- Filosofía corporativa (misión, visión, objetivos estratégicos).

- Valores (características identificadoras de la organización).

- El ambiente o lugar (siempre cambiante, pero con ánimos de inducirla al ámbito positivo con todos los colaboradores, creando un ambiente saludable).

- Comportamiento del personal, que se traduce en la forma de actuar en el interior y exterior de la empresa. Con Responsabilidad, Transparencia e Integridad.

\subsection{Objetivos Estratégicos}

Nuestros objetivos estratégicos son a largo plazo (5 años).

- Posicionarla como la empresa más rentable proveedora de platos saludables para las familias de los NSE “A” y "B”.

- Lograr el reconocimiento del 20\% del mercado meta como el mejor proveedor de platos saludables, al quinto año de operación.

- Ser la empresa proveedora de platos saludables para las familias de los NSE "A" y "B" de los distritos de San Isidro, Santiago de Surco, San Borja, La Molina y Miraflores con el mejor posicionamiento de marca entre los consumidores.

\subsection{Análisis Externo}

Político, legal, circunstancial, económico, geográfica, social, demo-figura, cultural, tecnológico, ambiental (PESTEL). 


\subsubsection{Análisis político.}

El Estado peruano ejerce una débil fiscalización a través de sus organismos reguladores e instituciones públicas. La propuesta de descentralización regional tampoco cumple sus objetivos debido a que los funcionarios regionales no se encuentran suficientemente capacitados para realizar una gestión pública eficiente en la asignación de sus recursos.

Sin embargo, a pesar de la situación política a la que el país se enfrenta, encontramos un marco legal establecido plenamente, compuesto por legislaciones alimentarias, de sanidad y permisos administrativos municipales que tienen su respectiva reglamentación.

\subsubsection{Análisis legal}

La legislación contempla una serie de requisitos para un mejor manejo de los alimentos preparados.

El Reglamento de Restaurantes (Decreto Supremo 025 - 2004 Mincetur), obliga a los negocios a cumplir una serie de normas de salud.

Asimismo, tenemos la Norma Sanitaria para el Funcionamiento de Restaurantes y Servicios Afines (Resolución Ministerial No 363-2005/Minsa) que busca encauzar las responsabilidades en materia sanitaria que tienen las municipalidades locales, dado que son que las encargadas de dar licencias de funcionamiento o clausurar negocios a los infractores.

Las siguientes son las dos principales disposiciones legales para llevar un buen manejo del negocio. Conviene siempre estar alertas con su fiel cumplimiento para así evitar multas o perder clientes.

La Ley N ${ }^{\circ}$ 30021, Ley de Promoción de la Alimentación Saludable, para Niños, Niñas y Adolescentes, que se promulgó mediante Decreto Supremo Nº 017 -2017 - SA ha sido reglamentada y tiene como objetivo "la promoción y protección efectiva del derecho a la salud pública, al crecimiento y desarrollo adecuado de las personas a través de las acciones de educación, al fortalecimiento y fomento de la actividad física, a la implementación de kioscos y comedores saludables en las instituciones de educación básica regular y a la supervisión de la publicidad y otras prácticas relacionadas con los alimentos, bebidas no alcohólicas dirigidas a niños, niñas y adolescentes para reducir y 
eliminar las enfermedades vinculadas con el sobrepeso, la obesidad y las enfermedades crónicas conocidas como no transmisibles"

\subsubsection{Análisis circunstancial.}

- Industria Alimentaria

La industria de alimentos ha sido impulsada por el incremento de la demanda interna y el mayor poder adquisitivo de la población, este último compuesto por mayores ingresos salariales y el aumento del crédito de consumo que proveen las entidades financieras.

El estudio Evolución de la Pobreza Monetaria 2007-2012 en el Perú, elaborado por el INEI indica: "En el 2012 el 41,1\% del gasto per cápita se destinó a alimentos (S/. $243,4)$, seguido de alquiler de vivienda y combustible con 16,8\% (S/.99,6), transportes y comunicaciones con 11,7\% (S/. 69,5), cuidados de la salud con 8,7\% (S/.51,8), esparcimiento, diversión y cultura con $8,5 \%$ (S/. 50,5); vestido y calzado con 4,6\% (S/.27,2); muebles y enseres con 4,2\% (S/. 25,1) y otros gastos acumulan 4,3\% (S/. 25,4)" (INEI, 2007). Ver figura 3.1

Figura 3.1

Estructura del gasto real per cápita según grupos 2012

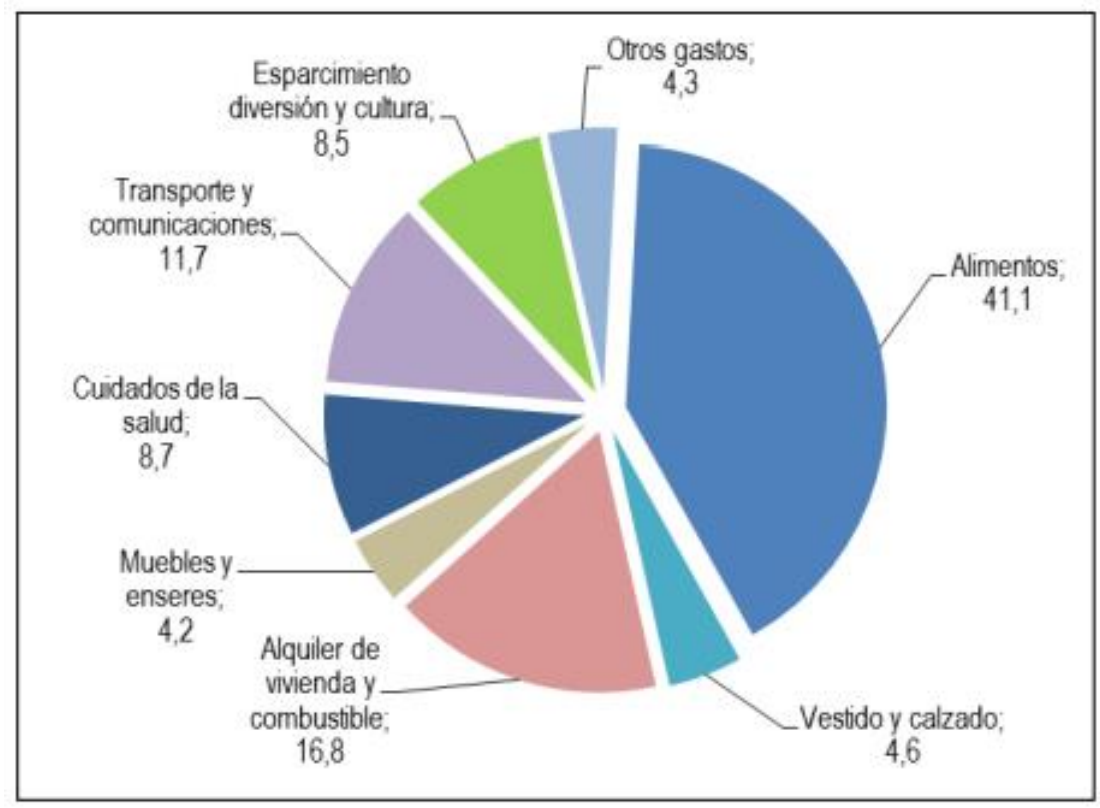

Fuente: Instituto Nacional de Estadística e Informática, INEI (2014) 
En este estudio, podemos observar que el rubro alimentos tiene una mayor importancia dado su alto porcentaje $(41,1 \%)$.

Es preciso indicar que las familias limeñas $\mathrm{y}$, especialmente, las de mayores ingresos buscan ahora comer de manera saludable. Según una encuesta de la firma Invera, "la mayoría de los limeños (59\%) considera que su alimentación es medianamente saludable, autopercepción que, de algún modo, se condice con sus hábitos”.

Los limeños preferimos las proteínas y los lácteos en el desayuno, tomamos un promedio de cuatro tasas de agua diarias y consideramos que la cena es la comida menos saludable del día.

Estas conclusiones se desprenden de una encuesta realizada por la firma Invera. La metodología fue vía web, en el año 2016 y fue aplicada a 400 personas, entre 17 y 70 años, de todos los niveles socioeconómicos y que viven en Lima Metropolitana. En cuanto a la autopercepción de la calidad de alimentación, el 59\% de los encuestados reconoce que su alimentación es medianamente saludable, el $28 \%$ percibe que es saludable y solo el 1\%, totalmente saludable. Ver figura 3.2.

Figura 3.2

Encuesta de Invera - 2016

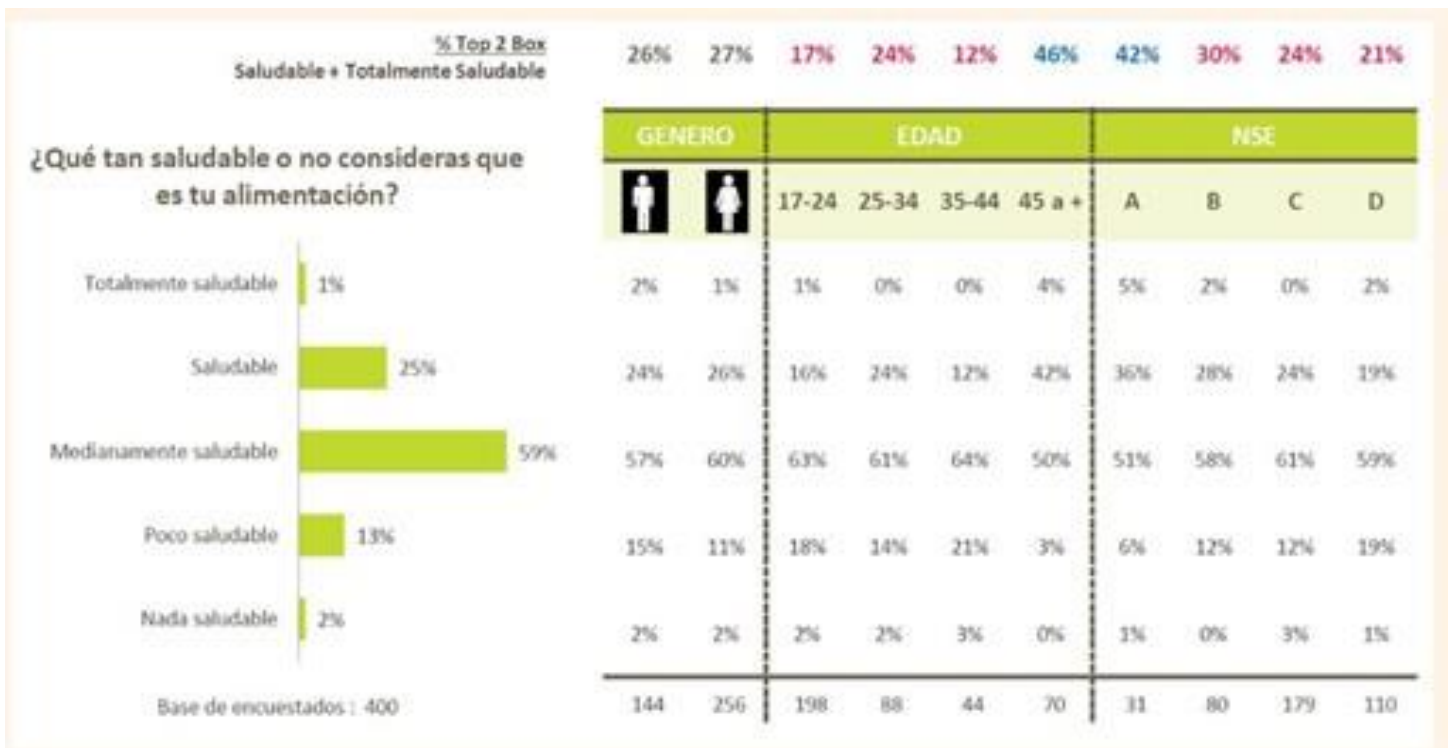

Fuente: "Solo el 26\% de limeños considera que su alimentación es saludable" (2016) 
"Sí hay un reconocimiento, hay una conciencia que se tiene oportunidades para aprender, eso nos da una oportunidad de mercado. Ya hay una conciencia. Hace unos diez años, ni siquiera pensábamos mucho en esto. Más pensábamos en si estábamos gordos o flacos, no en la salud, es un chip distinto", indica Silvia Díaz, Gerente General de Invera.

Para los limeños que participaron en la encuesta, la cena es la comida menos 'sana' que ingieren. La mayoría relaciona la alimentación saludable a alimentos sin elementos químicos. En el desayuno, los encuestados registran una tendencia de consumir menos frutas y menos cereales y a darle más prioridad a las proteínas y los lácteos.

Con esta figura 3.2, podemos concluir que existe un mercado en los NSE A y B que va creciendo y que prefiere comida saludable.

\subsubsection{Análisis económico.}

- Crecimiento Sostenido de la Economía:

La economía peruana demuestra un panorama favorable respecto a la región, con una tasa de crecimiento de 4\%, según el Reporte de Inflación a diciembre del 2016 del Banco Central de Reserva del Perú (BCRP en adelante) y con una inflación en un rango de 2.6 a 3.1, lo cual es bajo y con estabilidad en los precios.

La proyección del PBI peruano muestra una perspectiva de crecimiento aceptable para los siguientes años.

En términos generales según el BCRP, podemos resaltar un gran crecimiento económico del Perú y una tendencia inflacionaria a la convergencia hacia el 2,0\% manteniéndose, a diciembre 2016, cerca del rango meta entre 3.0 a 3.3\%. Los resultados inflacionarios nos muestran una estabilidad en la economía.

- Entorno económico en Lima Metropolitana.

Como veremos más adelante, los distritos en donde se encuentran las familias de mayores ingresos son: San Isidro, La Molina, Santiago de Surco, San Borja y Miraflores, conformada por consumidores perteneciente al NSE "A" y NSE "B", con un total de 98.4\% de concentración de ambos niveles en dicho distrito. 


\subsubsection{Análisis social.}

En la actualidad el país se encuentra dividido en 24 departamentos y una provincia constitucional, con una población nacional de aproximadamente 30 millones de habitantes, de los cuáles el 30\% se encuentra únicamente en el departamento de Lima. Dentro de la población nacional existen más de 6.5 millones de hogares (APEIM, 2016).

En lo referido a las familias de hoy en día, encontramos que, en muchas de ellas, hay una creciente tendencia a que ambos padres de familia trabajen, sea en negocios familiares o para terceros, por lo cual cuentan con menor tiempo para dedicarse a los quehaceres del hogar y, entre ellos, a la preparación de alimentos. Destinan gran cantidad de sus horas despiertos, sea al trabajo y/o estudios, por lo que muchas veces los miembros de familia deben alimentarse cerca de su centro de labores. A partir de esta realidad, surge la aparición de muchas propuestas de empresas de comida saludable y comida "chatarra" con formato "delivery", que satisfacen la creciente demanda de alimentación.

Según IPSOS Apoyo en Perfiles Zonales de la Gran Lima, si bien el ingreso familiar mensual de Lima Moderna (San Isidro, San Borja, Miraflores, San Borja y Santiago de Surco) asciende en promedio a S/. 4,790, sus principales gastos están orientados a la educación, al transporte y a la alimentación, tanto dentro como fuera del hogar (IPSOS Apoyo, 2013).

Según APEIM en el 2016. El NSE A, tiene un gasto mensual promedio en alimentación de S/.997 soles y el NSE B de S/.787 soles.

Se evidencia también, que el crecimiento económico del país, propicia un mayor consumo familiar, especialmente en los NSE "A" y "B", los cuales se caracterizan por acceder al consumo de bienes suntuarios. Actualmente, nos encontramos frente a un consumidor altamente informado y exigente con nivel de educación superior el cual se muestra influenciable por tendencias de consumo de sus pares.

\subsubsection{Análisis tecnológico.}

Según el ranking Mundial de Ciencia y Tecnología del 2013 del World Economic Forum (WEF), el Perú se encuentra ubicado en el puesto 15 de 21 países en Latinoamérica y en la ubicación 103 a nivel global, subiendo tres puestos frente al ranking anterior (WEF, 2013). 
Dicho ranking evalúa cuatro aspectos, dentro de los cuales el Perú destaca en el aspecto relacionado al impacto económico y social. Sin embargo, en los rubros de redes y accesibilidad a las nuevas tecnologías y en los subíndices que evalúan la calidad del sistema educativo y la efectividad de proceso de elaboración de leyes que faciliten la penetración de las Tecnologías de Información y Comunicaciones (TICs), las puntuaciones son considerablemente bajas.

Frente a ello, el Colegio de Ingenieros del Perú, ha diseñado el plan "Perú 2040" con la finalidad de lograr un mayor desarrollo del país durante los próximos 30 años, basado en mayor inversión en infraestructura, ciencia, tecnología e innovación (Colegio de Ingenieros del Perú, 2013).

En lo referente a la conectividad, encontramos que, según los datos de la empresa de logística inteligente Celistics, al 2014 se evidencia una mayor importación de teléfonos inteligentes (smartphones), pasando de un 20\% en el 2013, a un 35\%, en el 2014 (Celistics, 2014). Esto quiere decir que, de cada 3 celulares, uno tiene conectividad, posibilidad de uso de las redes sociales, jugar en línea, entre otros.

Hallamos también en el estudio Perfiles Zonales 2012 de IPSOS Apoyo, que entre los usuarios más frecuentes de internet en Lima Moderna está la población de edades promedio de 28 años, los cuales se conectan desde el hogar, en un tiempo aproximado entre 2 y 4 horas diarias, con una frecuencia de 23 veces al mes. Así, el gasto mensual promedio en soles, por hogar, destinado al servicio de internet en Lima Moderna es de S/.73 y el gasto por celular es de S/.94 (IPSOS Apoyo, 2012).

Nuestra propuesta considera muy importante el desarrollo tecnológico para así poder encontrarnos comunicados con nuestros clientes finales, ofreciéndoles una variedad de platos saludables y recibiendo comentarios y sugerencias de los mismos. Adicionalmente, esto nos permitirá tener un mejor servicio de delivery, a través de llamadas telefónicas o mediante una app de pedidos.

En lo referente a la industria alimentaria, encontramos madurez tecnológica para el cultivo, elaboración y conservación de alimentos lo que nos beneficiaría para innovar en el campo de la preparación de los platos saludables con vegetales orgánicos, respaldados por una marca y registro de empresa. 


\subsubsection{Análisis ecológico.}

Es imprescindible considerar todos los elementos necesarios para una alimentación nutritiva y balanceada. Estos elementos son: carbohidratos, grasas, proteínas, vitaminas y minerales, los cuáles serán combinados y formarán parte de nuestra propuesta alimenticia, en una medida adecuada y balanceada, gracias al apoyo de una nutricionista especializada y usando como referencia básica el Plato Saludable de la Escuela de Salud Pública de la Universidad de Harvard.

El consumidor de hoy en día, poco a poco va tomando conciencia ecológica. Por ello, se preocupa que los productos que consume no vayan a contaminar el ambiente, ni antes ni después de ser consumidos. Por ello, se recomendará que los envases empleados en toda la cadena de valor de los productos de nuestro negocio sean, en lo posible, biodegradables. Por ejemplo, buscaremos utilizar los envases y empaques que se pueden inclusive comer, como es el caso de las botellas de agua con envases que se pueden comer (http://www.eltiempo.com/vida/ciencia/envases-de-agua-que-se-pueden-comer-y-nocontaminan-90724), (http://www.mujerkiik.com/estas-bolsas-de-plastico-no-solo-sonbiodegradables-se-pueden-comer/). Asimismo, será necesario tener en cuenta la trayectoria de los proveedores de insumos para la elaboración de los platos saludables. Se les exigirá credenciales de buenas prácticas ambientales y de responsabilidad social.

\subsection{Análisis Interno}

Competidores potenciales, clientes, proveedores, productos sustitutos, barreras de entrada (PORTER).

\subsubsection{Competidores potenciales.}

El sector de servicio de Platos Saludables, con vegetales orgánicos, no cuenta con competidores potenciales que ofrezcan el producto en presentaciones del plato saludable de acuerdo a la Escuela de Salud Pública de la Universidad de Harvard.

Los platos saludables sólo se venden en las cadenas de supermercados, pero por separado, en una góndola, tal es el caso de los supermercados Wong y Vivanda, en donde no encontramos un plato saludable completo ni que específicamente haga mención al llamado Plato Saludable de Harvard. 
Existen otros restaurantes que venden comida saludable, en su mayoría son cafés o fuentes de soda, pero que tampoco hacen referencia específica al plato saludable de la Escuela de Salud Pública de la Universidad de Harvard y sus insumos no son orgánicos.

Por ello, consideramos que en un corto plazo no se tiene competidores directos.

Las características de cada competidor, se detallan a continuación:

- Tapun Wasi, comida criolla, pescados y mariscos a precios de 40 a 80 soles el plato.

- El Otro Parrillón, comida criolla, parrillas, a precios de 40 a 150 soles el plato o la parrilla.

- Huancahuasi, comida típica del centro (Huancayo), a precios de 30 a 100 soles el plato.

- Restaurante Gloria, comida nacional e internacional, a precios de 40 a 100 soles el plato.

- Restaurante alrededor de la zona de nuestro mercado objetivo. Tienen venta de menú y platos a la carta desde S/. 10 y S/. 25 soles, respectivamente.

\subsubsection{Amenaza de productos sustitutos.}

El producto sustituto aparecería si es que las personas, dentro de sus casas, comienzan a producir el contenido del plato saludable de la Escuela de Salud Pública de la Universidad de Harvard, llegando a ser similar, e inclusive complementándolo con otros productos de los cuales tienen conocimiento y son aceptados por sus familias. Otra amenaza sería la entrada de replicadores del negocio.

\subsubsection{Poder de negociación de clientes.}

El público objetivo está compuesto por las personas de los NSE “A” y “B”. Es con ellos con quienes se tendrá un poder de negociación de manera directa y quienes aportarán los factores para valorar la propuesta respecto a las características del "Plato Saludable de Harvard". La propuesta será una alternativa para las personas que podrán acceder a ellas 
y disfrutar del restaurante con sus instalaciones, a disposición de sus hijos y de una manera ágil y accesible.

\subsubsection{Poder de negociación de proveedores.}

El poder de negociación con los proveedores de insumos para la elaboración de los platos se dará a través de los proveedores de las tiendas de venta al por mayor de insumos y productos MAKRO (Makro Mayorista S.A. tiene varios locales en Lima Metropolitana). En dicha tienda existen promociones de descuento según la cantidad solicitada de productos, lo cual permitirá tener facilidades de compra y disponer de las cantidades necesarias para la operatividad de la compañía.

También se consideran proveedores a los recursos humanos que apoyan en el funcionamiento y las operaciones de la empresa, los cuales se encuentran en un nivel medio, ya que su relevancia para otorgar un buen producto de platos nutritivos y servicios complementarios está directamente relacionada con una propuesta exitosa que pueda mantenerse en el tiempo, de acuerdo a las exigencias del segmento objetivo.

En el caso de los cocineros, actualmente se encuentra un alto nivel de oferta de los mismos y dado que se debe seguir un esquema nutricional previamente establecido, se requieren profesionales capacitados con amplia experiencia para atender dicho requerimiento, lo cual es favorable en el momento de seleccionar al candidato, ya que la calidad del producto final es de alta valoración por las personas.

El nutricionista ejerce un rol de asesoría que permite otorgar valor y respaldo a la propuesta de Platos Saludables según la Escuela de Salud Pública de la Universidad de Harvard y tendrá la posibilidad de generar un nexo entre los clientes y nuestro restaurante bio-experiencial.

En el caso de los insumos de vegetales (orgánicos y no orgánicos) producidos a través de la agricultura en ambiente controlado (Indoors farming), estos se pueden producir dentro de las instalaciones del restaurante y estarán a cargo de agricultores, previamente capacitados en esta técnica, con lo cual sus productos serán vendidos al restaurante y luego a los clientes del restaurante. Con ello reduciríamos el costo de transporte de mercancía, además de obtener vegetales frescos, dado que estarían en la mesa en el mismo día de la cosecha. 


\subsubsection{Barreras de entrada.}

Las personas son quienes toman la decisión de compra para la alimentación saludable de sus familias, con lo cual vemos que en principio el consumo en el restaurante bio experiencial se daría todos los días de la semana.

La zonificación ha permitido identificar un nicho de mercado orientado a los NSE A y B y en ciertos distritos de la ciudad de Lima Metropolitana. Sin embargo, la propuesta se maneja bajo un esquema modular con la posibilidad de migrar a otros distritos en función al éxito de la idea de negocio, por lo que este punto será muy importante, si es que no se encontrara una zonificación favorable o que la distancia resulte una limitante respecto a la ubicación de la oficina. Tanto para el consumo en el mismo restaurante, como las entregas por "delivery" y para llevar.

\subsection{Análisis Sectorial e Identificación de Riesgos y Amenazas. Análisis FODA}

El análisis FODA, consta de un análisis interno acerca de la empresa y un análisis externo, referido al entorno en donde se desenvuelve la empresa.

En el análisis interno, vamos a identificar las fortalezas y debilidades de la empresa y en el análisis externo, vamos a identificar las oportunidades y amenazas.

\section{Matriz FODA}

\section{Fortalezas}

- Utilización de la agricultura en ambiente controlado (Indoors Farming) que permite producir verduras y hortalizas inocuas y saludables, reduciendo el consumo de agua e incrementando la productividad hasta en 100 veces.

- Aprovechamiento al máximo del área destinada a la producción de verduras y hortalizas.

- El uso del plato saludable de Harvard, para la elaboración de las recetas.

- Bajo costo logístico por uso de insumos orgánicos, producidos dentro de las instalaciones del restaurant.

- Ofrecimiento de productos altamente nutritivos y saludables. 
- El carácter formativo y educativo en nutrición que se ofrece a padres, hijos y consumidores en general, que podrán inclusive apreciar a través de los vidrios de la estación de agricultura vertical que estará en el restaurante.

- El uso del arte, juegos y videos multimedia en la formación nutricional que se ofrece a los consumidores.

- La posibilidad de que el cliente reciba la comida saludable en su casa, centro educativo u oficina.

- Contaremos también con paquetes mensuales de comida saludable, que incluirán el desayuno, snack de media mañana, almuerzo, snack de media tarde y cena. Distribuidos en entregas diarias, de lunes a sábados por 4 semanas.

\section{Debilidades}

- No existen cadenas logísticas de productos orgánicos para todos los productos que se necesitan para la elaboración de las recetas.

- Costos elevados para la implementación de un local perfectamente ubicado, con zonas amplias para los salones de cocina, y para el Indoors farming.

- Demora en la obtención de la licencia de funcionamiento y autorización de INDECI por parte del municipio local y Defensa Civil, respectivamente.

- Alto costo de retención del personal calificado por elevada competencia.

- Dificultad para encontrar y retener el talento humano del área de cocina, con conocimientos en el plato saludable de Harvard.

\section{Oportunidades}

- La tendencia global a comer productos orgánicos, saludables y nutritivos.

- El auge de la gastronomía peruana a nivel nacional e internacional.

- El apoyo del gobierno a la industria gastronómica.

- La biodiversidad del Perú, ofrece una gran variedad de alimentos altamente nutritivos y saludables (los llamados Superalimentos Peruanos, un concepto de 
marketing, más que un concepto científico y por ello no común entre los expertos en nutrición).

- Posicionarse como la marca líder de la gastronomía peruana saludable.

- Abrir restaurantes franquiciados.

\section{Amenazas}

- Riesgo de que otros negocios se copien el modelo.

- La megatendencia de comida saludable y nutritiva puede llevar a que muchos competidores ingresen al mercado.

- El cambio climático puede afectar la provisión de los insumos para la elaboración de las recetas, así como una fluctuación en los precios y en la cantidad de insumos, inclusive generando escasez y desabastecimiento de los mismos. (Por ejemplo: desabastecimiento de productos hidrobiológicos, elevados costos del limón u otros productos).

- Aumento de la delincuencia y criminalidad.

- Que los competidores se lleven los recursos humanos.

\subsection{Estrategia de Éxito (FODA cruzado).}

\section{Afrontar las Amenazas}

- En el caso del cambio climático, usar productos sustitutos y adaptar la carta del restaurant.

- En el caso de delincuencia y criminalidad, estableceremos alianzas estratégicas con la policía nacional y el serenazgo.

- Ante el ingreso de nuevos competidores mantener el liderazgo de la marca, innovando y renovándonos constantemente. 


\section{Convirtiendo las debilidades en fortalezas}

- Establecer alianzas estratégicas con universidades y centros de investigación no sólo del Perú, sino de Estados Unidos, Taiwán y España, países líderes en la agricultura en ambiente controlado, para desarrollar estudios conjuntos en los campos de la gastronomía, nutrición y salud.

- Establecer convenios con universidades o institutos de gastronomía para la captación, capacitación, retención y promoción del talento humano.

- Establecer alianzas estratégicas y convenios con restaurantes competidores, empresas abastecedoras, entidades gubernamentales, entidades académicas, y gremios del sector agropecuario para la conformación y fortalecimiento de un clúster de la gastronomía peruana saludable.

- Fomentar el negocio del delivery y la comida para llevar, lo cual nos permitirá generar grandes ahorros en infraestructura y personal contratado.

\section{Explotar las Oportunidades}

- Aprovechar la ventaja competitiva de la gastronomía peruana que cada vez es más reconocida a nivel internacional.

- Contactar con las agencias de turismo para poder ofrecer el servicio del restaurante bio-experiencial a los viajeros durante su estancia en la ciudad.

- Aprovechar las ventajas de las modalidades de contratación de personal y los beneficios que se otorgan en Promperú, así como en los Ministerios de Salud y Comercio Exterior y Turismo.

- Desarrollar la promoción y venta directa por internet utilizando las plataformas existentes.

- Desarrollar convenios con centros educativos para los NSE A y B, para proveer a los comedores de loncheras saludables.

- Ampliar las rutas de reparto de comida saludable en horarios de madrugada (4:00am a 7am) para evitar el tráfico y repartir la comida saludable a más puntos, con menor cantidad de tiempo y combustible. 


\section{CAPÍTULO IV: PLAN DE MARKETING}

\subsection{Planteamiento de Objetivos Generales de Marketing}

Los objetivos que se plantean para lograr la participación de mercado son los siguientes:

- Lograr un 5\% de participación de mercado de los NSE A y B en el primer año de lanzamiento.

- Lograr la identificación y reconocimiento de la marca en un $20 \%$ del mercado meta al primer año, que permita alcanzar la participación de mercado propuesta.

- Consolidar la marca como un concepto de comida saludable, nutritiva y orgánica de alta calidad para las familias.

- Lograr la atención del 20\% del mercado meta al término del quinto año.

- Alcanzar una rentabilidad promedio anual de $35 \%$.

- Lograr el reconocimiento del total del mercado meta como el mejor proveedor de comida saludable orgánica, al quinto año.

- Posicionar a la marca en la Lima Moderna, de modo que ello permita posteriormente aplicar un esquema modular de expansión hacia otros distritos ligados al segmento de los NSE A y B.

\subsection{Estrategias de Marketing}

\subsubsection{Segmentación y perfil del cliente}

Segmentación.

Para el presente estudio, se escoge el NSE A y NSE B (APEIM - 2016). Ver tabla 4.1. Se tiene que en este segmento hay una alta demanda por productos saludables y nutritivos y que el segmento desea alimentarse sano. Según la encuesta de Invera, mostrada anteriormente en el punto 3.6.2, este segmento está en capacidad de pagar por este tipo de alimentación teniendo presente el Plato Saludable de la Escuela de Salud Pública de la Universidad de Harvard, en toda su carta. 
Tabla 4.1

Ingresos y gastos

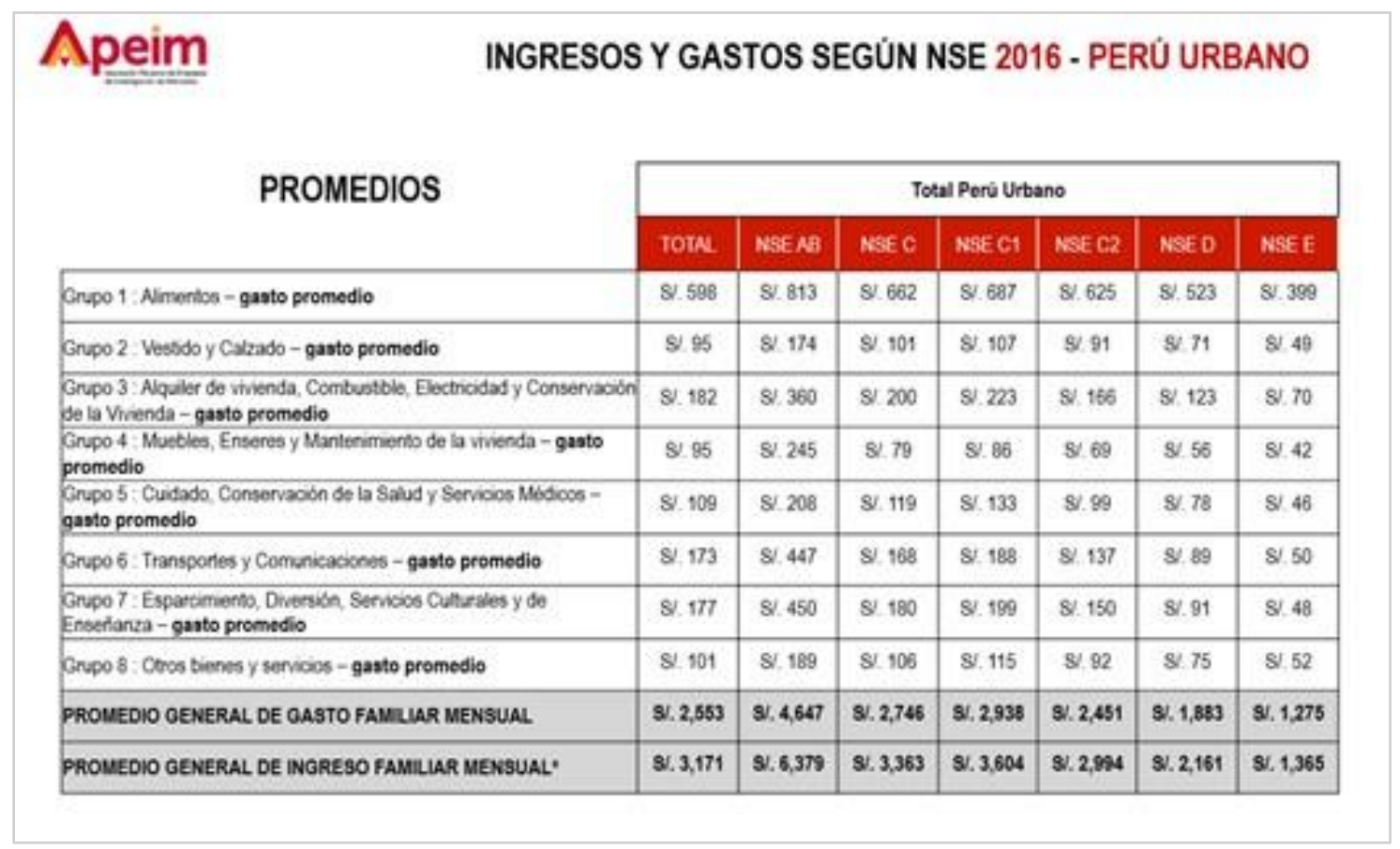

Fuente: Asociación Peruana de Empresas de Investigación de Mercados, Apeim (2016)

Perfil de cliente.

Se realizaron dos focus group para determinar el perfil del cliente del NSE A y B, teniendo como objetivo el determinar los hábitos de consumo, conocer lo que consumen y sus características para considerarlos en el servicio a ofrecer. Ver tabla 4.2 y 4.3 para ver los participantes.

Tabla 4.2

1er. Focus Group

Lugar: San Isidro

Fecha: 26.05 .2017

Moderador: Carmen Barba/ Abogada

Asistentes al Focus Group:

\begin{tabular}{lll} 
Nombre y Apellido & Edades hijos & Ocupación \\
\hline Analía Pigati/ 28 años & 3 años & Publicista \\
Janine Rivera/33 años & 2 años & Administradora \\
Fiorella Amasifuen/38 años & 12 años & Diseñadora
\end{tabular}




\begin{tabular}{lll}
\hline Ana María Escobal/34 años & 3 años & Analista \\
María Zavala/35 años & $4 / 6$ años & Productora \\
Claudia Chang /46 años & 14 y 16 años & Publicista \\
Anahí Ruiz/28 años & 6 años & Ama de casa \\
Heyni Schneider/37 años & 10 años & Administradora \\
\hline
\end{tabular}

Elaboración propia

Tabla 4.3

2do. Focus Group

\begin{tabular}{lll} 
Lugar: La Molina & & \\
Fecha: 20.06 .2014 & & \\
Moderador: Diana Gibaja / Comunicadora & & \\
Asistentes al Focus Group: & & \\
Nombre y Apellido & Edades hijos & Ocupación \\
\hline Verónica García / 28 años & $3 / 10$ años & Administradora \\
Andrés Cruz / 28 años & 3 años & Administrador \\
Adriana Contreras / 33 años & 9 años & Administradora \\
Aura Rojas / 26 años & 4 años & Contadora \\
Faride del Águila / 38 años & 12 años & Administradora \\
Mariella Zoppi / 27 años & $2 / 8$ años & Ingeniera
\end{tabular}

Elaboración propia

Hábitos de compra. Respecto a la frecuencia de compra de insumos para la preparación de los alimentos, la mayoría indicó que las compras las realizan una vez por semana. Sin embargo, dos de ellas indicaron que las compras las realizan una vez al mes. El gasto promedio de las compras por los alimentos es de 400 a 600 soles a la semana. Esto depende del contenido diario y el estimado se obtiene en función al monto de las compras semanales o mensuales, según sea el caso.

Preparación de los platos. El 70\% de las asistentes generalmente delega la elaboración de los platos, así como la elección del contenido de la alimentación, a la empleada, a la cocinera o a la encargada de la alimentación del hogar. En líneas generales, en su mayoría indicaron que la participación de la madre de familia se limita a un rol de 
guía o referencia para indicar qué alimentos se encuentran restringidos para sus hijos. Una respuesta disonante fue cuando el padre se encarga de dicha actividad. Sin embargo, su participación se da sólo en momentos cuando se ha producido un imprevisto. Asimismo, en su totalidad las encuestadas indicaron que el tiempo invertido para la preparación de los alimentos es de 40 a 120 minutos.

Contenido de los platos actuales. Todas las madres coincidieron en que uno de los temas más relevantes y de mayor preocupación es que, por un factor de practicidad y falta de tiempo, existe una alta incidencia de alimentos con bajo contenido de aporte nutricional (productos envasados y/o con químicos-preservantes).

Dentro de los productos que usualmente se utilizan, la mayoría concuerda que un sándwich y una bebida son los elementos principales, así como se percibe la carencia de frutas, lácteos, vegetales, pescados, carnes y cereales.

Apreciación acerca del servicio. Se procedió con la descripción de la idea del negocio y la percepción fue positiva dentro de todas las asistentes, al considerarse una alternativa para solucionar el problema de realizar platos no saludables o abundantes en carbohidratos, pero sin proteínas.

Dentro de las características más apreciadas por todas las asistentes, resalta que la preparación contemple un esquema nutricional y que los padres de familia reciban información del tema para poder tener un mayor conocimiento sobre nutrición.

Bajo un consenso se determinó que el beneficio adicional fuera que hubiera un feedback cada cierto tiempo que permitiera saber si su hijo/a está consumiendo el plato saludable según la Escuela de Salud Pública de la Universidad de Harvard, de manera parcial o en su totalidad.

Se realizó una encuesta para ver los perfiles del consumidor, teniendo presente la fórmula para calcular el tamaño de la muestra. (Sampieri, 2006)

$$
n=\frac{N^{*} Z_{z}^{2} p^{*} q}{d^{2} *(N-1)+Z_{a}^{2} p^{*} q}
$$

Donde:

$$
\mathrm{n}=\text { tamaño de la muestra. }
$$


$\mathrm{N}=($ Total de la población $)=546990$

$Z=1.96$ (el Nivel de Confianza es de 95\%)

p=0.5 (Proporción Esperada, se tomó 0.5 que maximiza el tamaño muestral)

$\mathrm{q}=0.5(1-\mathrm{p})$

d=6\% (Precisión en la investigación)

$\mathrm{n}=266$

De acuerdo a la encuesta realizada tenemos algunas conclusiones.

De la tabla 4.4, vemos que dentro de este nivel socioeconómico A y B, un $32 \%$ gusta ir una vez por semana a comer a un restaurante, lo cual encaja con el concepto que deseamos, por lo que siendo un restaurante bio - experiencial funcionaría todos los día de semana, de lunes a domingo.

Tabla 4.4

Frecuencia de visitas a restaurantes

\begin{tabular}{|l|c|c|}
\hline $\begin{array}{l}\text { Frecuencia de visita a } \\
\text { restaurantes }\end{array}$ & Cantidad & $\%$ \\
\hline 1 vez cada 15 dias & 101 & $\Im \% \%$ \\
\hline 1 vez por semana & 86 & $32 \%$ \\
\hline 2 veces por semana & 48 & $18 \%$ \\
\hline 3 veces por semana & 19 & $7 \%$ \\
\hline Mas de 3 veces por semana & 13 & $5 \%$ \\
\hline Total & 266 & $100 \%$ \\
\hline
\end{tabular}

Elaboración propia

De la Tabla 4.5, se desprende que un $27 \%$ del segmento analizado elige el lugar a donde ir a comer por el tipo de comida. Y un $23 \%$ por el ambiente, esperando sea agradable y así poder disfrutar una experiencia agradable e inolvidable. 
Tabla 4.5

¿Cómo elige un restaurante?

\begin{tabular}{lcc} 
¿Cómo elige un restaurante? & Cantidad & $\%$ \\
\hline Si tiene anfitrionas & 43 & $16 \%$ \\
Tipo de comida & 72 & $27 \%$ \\
Ambientación del local & 61 & $23 \%$ \\
Estacionamiento & 43 & $16 \%$ \\
diferentes canales de atención & 48 & $18 \%$ \\
\hline Total & $\mathbf{2 6 6}$ & $\mathbf{1 0 0 \%}$ \\
\hline
\end{tabular}

Elaboración propia

De la Tabla 4.6, este NSE A y B gusta y espera a que le asignen su mesa, y están dispuestos a esperar por ello en forma prudente de 6 a 10 minutos, más de eso les puede ocasionar incomodidad.

Tabla 4.6

¿Cuánto tiempo esperaría para que le asignen una mesa?

\begin{tabular}{lcc}
\hline ¿Cuánto esperaría para que le asignen una mesa? & Cantidad & $\%$ \\
\hline No esperaría & 16 & $6 \%$ \\
1 a 5 minutos & 80 & $30 \%$ \\
6 a 10 minutos & 141 & $53 \%$ \\
11 a 15 minutos & 19 & $7 \%$ \\
16 a 30 minutos & 11 & $4 \%$ \\
\hline Total & $\mathbf{2 6 6}$ & $\mathbf{1 0 0 \%}$ \\
\hline
\end{tabular}

Elaboración propia

De esta Tabla 4.7, podemos analizar que un $34 \%$ gusta de la comida saludable, la cual vamos a brindar, siguiendo la recomendación del Plato Saludable según la Escuela de Salud Pública de la Universidad de Harvard. 
Tabla 4.7

¿Cuál es la preferencia por tipo de comida?

\begin{tabular}{lcc}
$\begin{array}{l}\text { ¿Cuál es la preferencia por tipo de } \\
\text { comida? }\end{array}$ & Cantidad & $\%$ \\
Comida saludable & 90 & $34 \%$ \\
Pescados & 52 & $20 \%$ \\
Chifas & 44 & $17 \%$ \\
Típicas & 27 & $10 \%$ \\
Pollos a la brasa & 34 & $13 \%$ \\
Otros & 19 & $7 \%$ \\
\hline Total & 266 & $100 \%$ \\
\hline
\end{tabular}

Elaboración propia

De la Tabla 4.8, podemos indicar que un tiempo prudencial de espera para tener servido el plato elegido es entre 11 a 15 minutos, en donde tranquilamente se espera por aquél. Muchos platos que se preparan, al tener todo picado, pueden realizarse en ese tiempo y a gusto del cliente.

Tabla 4.8

¿Cuánto tiempo esperaría para que le traigan su pedido?

\begin{tabular}{lcc}
$\begin{array}{l}\text { ¿Cuánto tiempo esperaría para que le } \\
\text { traigan su pedido? }\end{array}$ & Cantidad & $\%$ \\
\hline 1 a 5 minutos & 8 & $3 \%$ \\
6 a 10 minutos & 27 & $10 \%$ \\
11 a 15 minutos & 130 & $49 \%$ \\
16 a 20 minutos & 98 & $37 \%$ \\
20 a 30 minutos & 3 & $1 \%$ \\
\hline Total & $\mathbf{2 6 6}$ & $\mathbf{1 0 0 \%}$ \\
\hline
\end{tabular}

Elaboración propia 
De la Tabla 4.9, les gustaría que en un tiempo prudencial para revisar la carta, se le tome su pedido, considerando este tiempo de 3 a 5 minutos; pasado este tiempo se puede ocasionar incomodidad al cliente.

Tabla 4.9

¿Cuánto tiempo esperaría para que le tomen el pedido

\begin{tabular}{lcc}
$\begin{array}{l}\text { Cuánto tiempo esperaría para que le tomen } \\
\text { el pedido }\end{array}$ & Cantidad & $\%$ \\
\hline 1 a 2 minutos & 82 & $31 \%$ \\
3 a 5 minutos & 130 & $49 \%$ \\
6 a 10 minutos & 37 & $14 \%$ \\
11 a 15 minutos & 13 & $5 \%$ \\
16 a 30 minutos & 3 & $1 \%$ \\
\hline Total & $\mathbf{2 6 6}$ & $\mathbf{1 0 0 \%}$ \\
\hline
\end{tabular}

Elaboración propia

De la Tabla 4.10, podemos señalar que el rango de precios a pagar por los platos elegidos para el $41 \%$ de los entrevistados está en el rango de 31 a 50 soles, lo cual consideran que es adecuado por el nivel de contenido nutricional que contiene cada plato.

Tabla 4.10

¿Cuánto está dispuesto a pagar por un plato saludable?

\begin{tabular}{lcc}
\hline ¿Cuánto está dispuesto a pagar por un plato saludable? & Cantidad & $\%$ \\
\hline 15 a 20 soles & 8 & $3 \%$ \\
21 a 30 soles & 32 & $12 \%$ \\
31 a 50 soles & 109 & $41 \%$ \\
51 a 80 soles & 88 & $33 \%$ \\
80 a 100 soles & 29 & $11 \%$ \\
\hline Total & $\mathbf{2 6 6}$ & $\mathbf{1 0 0 \%}$ \\
\hline
\end{tabular}

Elaboración propia 
De la Tabla 4.11, podemos indicar que el 99\% de los clientes encuestados prefiere que el local esté ambientado en forma adecuada, considerando que este ambiente es importante para el impacto de la experiencia del cliente, creando sensaciones que los inviten a sentirse placenteramente. Así también, valoran que el personal del restaurante, esté correctamente uniformado.

\section{Tabla 4.11}

¿Cómo le gustaría que fuera el local?

\begin{tabular}{lcc} 
¿Cómo le gustaría que fuera el local? & Cantidad & $\%$ \\
\hline Que tenga infraestructura adecuada & 263 & $99 \%$ \\
Con personal uniformado & 253 & $95 \%$ \\
Con música de fondo & 192 & $72 \%$ \\
Con juegos para niños & 200 & $75 \%$ \\
Con Shows en vivo & 80 & $30 \%$ \\
\hline Total & $\mathbf{2 6 6}$ & \\
\hline
\end{tabular}

Elaboración propia

De la Tabla 4.12, observamos que las redes sociales han logrado una mayor presencia como medio para llegar a los nuevos negocios. Por ello, nuestro proyecto propone que se llegue a los consumidores, a través de las redes sociales y, a través de la radio también.

Tabla 4.12

¿Cómo te enteras si se ha abierto un nuevo restaurante?

\begin{tabular}{lcc} 
¿Cómo te enteras si se ha abierto un nuevo restaurante? & Cantidad & $\%$ \\
\hline Volantes & 13 & $5 \%$ \\
Radio & 80 & $30 \%$ \\
TV & 8 & $3 \%$ \\
Redes sociales & 146 & $55 \%$ \\
Revistas & 19 & $7 \%$ \\
\hline Total & 266 & $100 \%$ \\
\hline
\end{tabular}

Elaboración propia 
De la Tabla 4.13, podemos indicar que, a un $40 \%$ de los clientes encuestados les da lo mismo utilizar o no los cupones de descuento. Sin embargo, vemos que un importante $60 \%$ los usaría, motivo por el cual es importante tomar en cuenta que la comercialización de los platos especiales puede venir acompañada de promociones con cupones de descuento para el subsegmento que sí tiene interés en utilizarlos. Para buscar una mayor eficiencia en la repartición de cupones de descuento, la clave estará en identificar a los clientes que sí utilizan este incentivo de consumo.

\section{Tabla 4.13}

¿Usarías cupones de descuento para este restaurante?

\begin{tabular}{lcc}
\hline ¿Usarías cupones de descuento para este restaurante? & Cantidad & $\%$ \\
$\mathrm{Si}$ & 160 & $60 \%$ \\
No & 106 & $40 \%$ \\
\hline Total & 266 & $100 \%$ \\
\hline
\end{tabular}

Elaboración propia

Tabla 4.14

¿Dónde le gustaría que estuviera ubicado este restaurante?

\begin{tabular}{lll}
\multicolumn{1}{c}{ Distrito } & \multicolumn{1}{c}{ Cantidad } \\
Surquillo (límite con & 89 & $33 \%$ \\
Miraflores) & 58 & $22 \%$ \\
Miraflores & 69 & $26 \%$ \\
San Isidro & 50 & $19 \%$ \\
Magdalena & $\mathbf{2 6 6}$ & $\mathbf{1 0 0 \%}$ \\
\hline Total & &
\end{tabular}

Elaboración propia

\subsubsection{Posicionamiento y ventaja competitiva.}

\subsubsection{Posicionamiento.}

El posicionamiento propuesto para el negocio se rige bajo las siguientes premisas: 
- Servicio de elaboración de platos saludables partiendo del Modelo del Plato Saludable según la Escuela de Salud Pública de la Universidad de Harvard.

- Los elementos diferenciadores son variedad, valor nutritivo, calidad de los insumos ver Figura 4.1, área de educación nutricional, área de entretenimiento familiar, laboratorio experiencial de agricultura en ambiente controlado.

Figura 4.1

Calidad de la materia prima

CALIDAD DE LA MATERIA PRIMA

\begin{tabular}{|c|c|c|}
\hline ALIMENTO & $\begin{array}{l}\text { CARACTERISTICAS } \\
\text { ACEPTABLES }\end{array}$ & $\begin{array}{l}\text { CARACTERISTICAS } \\
\text { INACEPTABLES }\end{array}$ \\
\hline PESCADOS & $\begin{array}{l}\text { Ojos prominentes } \\
\text { y brillantes, agallas } \\
\text { rojas y humedas, } \\
\text { escamas } \\
\text { firmemente } \\
\text { adheridas, carne } \\
\text { firme al tacto y olor } \\
\text { caracteristico (a } \\
\text { algas marinas). }\end{array}$ & $\begin{array}{l}\text { Ojos hundidos } \\
\text { opacos, agallas } \\
\text { pálidas verdosas o } \\
\text { grises, escamas } \\
\text { que se } \\
\text { desprenden } \\
\text { fácilmente, carne } \\
\text { blanda que se } \\
\text { desprende del } \\
\text { espinazo y olor } \\
\text { desagradable. }\end{array}$ \\
\hline MARISCOS & $\begin{array}{l}\text { Moluscos (almejas, } \\
\text { conchas de } \\
\text { abanico): las valvas } \\
\text { deben estar } \\
\text { cerradas y producir } \\
\text { un sonido macizo } \\
\text { cuando se golpea. } \\
\text { Cefalópodos (pulpo, } \\
\text { calamar, pota): deben } \\
\text { tener piel suave y } \\
\text { húmeda, ojos } \\
\text { brillantes, carne firme } \\
\text { y elástica. }\end{array}$ & $\begin{array}{l}\text { Moluscos (almejas, } \\
\text { conchas de } \\
\text { abanico): valvas } \\
\text { abierta, mal olor y } \\
\text { contenido seco. } \\
\text { Cefalópodos } \\
\text { (pulpo, calamar, } \\
\text { pota): olor } \\
\text { repulsivo, } \\
\text { coloraciones } \\
\text { oscuras (rojizas, } \\
\text { pardas), ojos } \\
\text { opacos y } \\
\text { hundidos. }\end{array}$ \\
\hline
\end{tabular}

(Continúa) 
(Continuación)

\begin{tabular}{|c|c|c|}
\hline & $\begin{array}{l}\text { Caracoles: deben estar } \\
\text { vivos, llenar } \\
\text { completamente la } \\
\text { envoltura y presentar } \\
\text { movilidad a la excitación. } \\
\text { Crustáceos } \\
\text { (camarones, } \\
\text { langostinos y } \\
\text { cangrejos): deben tener } \\
\text { carne firme y elástica; el } \\
\text { cangrejo debe } \\
\text { presentar rigidez en las } \\
\text { patas; el camarón debe } \\
\text { ser de color verde } \\
\text { azulado y su cola debe } \\
\text { replegarse bajo el tórax }\end{array}$ & $\begin{array}{l}\text { Caracoles: olor } \\
\text { desagradable, } \\
\text { ausencia de respuesta } \\
\text { a cualquier tipo de } \\
\text { acción. } \\
\text { Crustáceos } \\
\text { (camarones y } \\
\text { cangrejos): coloración } \\
\text { oscura, falta de rigidez } \\
\text { en las patas. }\end{array}$ \\
\hline HORTALIZA & $\begin{array}{l}\text { Adecuado estado de } \\
\text { madurez. Las verduras } \\
\text { de hojas no deben } \\
\text { haber florecido. }\end{array}$ & $\begin{array}{l}\text { Atacadas por insectos } \\
\text { o larvas, cubiertas de } \\
\text { barro u otras materias } \\
\text { extrañas en la } \\
\text { superficie }\end{array}$ \\
\hline $\begin{array}{l}\text { TUBÉRCULOS, } \\
\text { BULBOSY } \\
\text { RAICES }\end{array}$ & $\begin{array}{l}\text { Con coloración homogé. } \\
\text { nea }\end{array}$ & $\begin{array}{l}\text { Cubiertos de } \\
\text { barro o tierra, con } \\
\text { presencia de } \\
\text { golpes o } \\
\text { manchas. No } \\
\text { deben adquirirse } \\
\text { picados. }\end{array}$ \\
\hline
\end{tabular}

(Continúa) 
(Continuación)

\begin{tabular}{|c|c|c|}
\hline HUEVOS & $\begin{array}{l}\text { Cáscara limpia en } \\
\text { forma natural (sin } \\
\text { lavar), sin rajaduras ni } \\
\text { olores extraños. } \\
\text { Clara firme, } \\
\text { transparente, } \\
\text { homogénea; y yema } \\
\text { firme y entera, sin } \\
\text { pigmentos extraños. }\end{array}$ & $\begin{array}{l}\text { Cáscara rajada, rota o } \\
\text { de aspecto anormal. } \\
\text { Clara muy fluida, con } \\
\text { pérdida de } \\
\text { consistencia al ser } \\
\text { extendida en un plato. } \\
\text { Presencia de } \\
\text { pigmentos de sangre. }\end{array}$ \\
\hline $\begin{array}{l}\text { GRANOS } \\
\text { (Menestras, } \\
\text { mani, } \\
\text { cereales) }\end{array}$ & integros y limpios. & $\begin{array}{l}\text { Presencia de granos } \\
\text { deteriorados, picados } \\
\text { por insectos o } \\
\text { roedores, rotos, } \\
\text { húmedos, } \\
\text { hongueados y con } \\
\text { residuos de tierra o } \\
\text { piedra. } \\
\text { Olores raros o } \\
\text { manchas de aceite o } \\
\text { kerosene. }\end{array}$ \\
\hline HARINAS & $\begin{array}{l}\text { Olor caracteristico al } \\
\text { cereal sobre la base } \\
\text { del cual se ha } \\
\text { elaborado. } \\
\text { Debe de encontrase } \\
\text { en polvo en su } \\
\text { totalidad. }\end{array}$ & $\begin{array}{l}\text { Olor a rancio o a } \\
\text { húmedad, presencia } \\
\text { de trozos solidificados } \\
\text { o apelmazados y con } \\
\text { evidencia de insectos } \\
\text { (gorgojo, politla). }\end{array}$ \\
\hline
\end{tabular}

$\begin{array}{lll}\text { FIDEOS } & \begin{array}{l}\text { Enteros, integros, secos, } \\ \text { sin presencia de insectos; } \\ \text { las bolsas deben estar } \\ \text { intactas, }\end{array} & \begin{array}{l}\text { Olor a humedad, } \\ \text { manchas, gorgojos o } \\ \text { cuerpo extraños. }\end{array} \\ \text { FRUTAS } & \begin{array}{l}\text { Color, olor y textura } \\ \text { caracteristicos del estado } \\ \text { de madurez. }\end{array} & \begin{array}{l}\text { Con picaduras de } \\ \text { insectos, aves y } \\ \text { roedores. }\end{array} \\ \begin{array}{l}\text { Limpias y sin cuerpos } \\ \text { extraños adheridos a su } \\ \text { superficie. }\end{array} & \begin{array}{l}\text { Con parásitos, } \\ \text { hongos, residuos de } \\ \text { polvo y barro o } \\ \text { cualquiler sustancia } \\ \text { extraña. }\end{array} \\ & \begin{array}{l}\text { Indicios de } \\ \text { fermentación }\end{array} \\ \end{array}$

Fuente: Calidad de los alimentos

- Un lugar con acceso a la educación en nutrición, al entretenimiento, al conocimiento y capacitación interactiva, con un laboratorio de agricultura 
en ambiente controlado, para dar a conocer sus procesos de siembra, crecimiento y cosecha.

En cuanto a los atributos:

- Calidad del servicio.

- Variedad de contenido (nutritivo).

- Diseño de los platos saludables (atractivos).

- Precio justo, sobre la base de lo que el consumidor está dispuesto a pagar (según encuesta).

- Un lugar con entretenimiento para grandes y chicos.

- Un lugar con acceso a la educación en nutrición.

- Un laboratorio de agricultura en ambiente controlado y monitores con explicación fácil y sencilla.

- Cocina - Mostrador, para que los clientes vivan la experiencia de la adrenalina que existe en la cocina a la hora de preparar los alimentos.

\subsubsection{Ventaja competitiva}

El plan de negocios de nuestro restaurante bio-experiencial brinda una solución a los ajetreados padres de familia que hay en la actualidad, en donde el tiempo les apremia y, por ello, muchas veces elaboran platos no variados, que no son saludables y son carentes de valor nutricional. En ese sentido, nuestro restaurante bio-experiencial ofrece una experiencia innovadora, única y creativa en educación nutricional, con platos saludables conforme los lineamientos de la Escuela de Salud Pública de la Universidad de Harvard, con elementos diferenciadores como un precio asequible a lo que está dispuesto a pagar por un producto de alta calidad, de contenido variado, nutritivo y con un componente educativo que se adquiere a través de una experiencia vivencial en la que la agricultura vanguardista del futuro, la llamada la agricultura en ambiente controlado (Indoors Farming) pueda ser apreciada.

Las ventajas competitivas son:

- Manejo eficiente de la cadena de producción y elaboración. 
- Manejo eficiente de la información de hábitos, consumos, gustos y preferencias del sector.

- Adecuada estrategia de marketing y comunicación que permita captar nuevos clientes.

\subsection{Mercado Objetivo}

\subsubsection{Tendencia de mercado.}

Las megatendencias deben ser tomadas en cuenta para proyectarnos al futuro y estar preparados satisfacer las necesidades de los consumidores. Más aún, considerando que en los próximos años, ya no seremos los mismos consumidores. Vamos hacia un proceso selectivo del consumo, una preferencia más por la calidad que por la cantidad. Será cada vez más difícil acceder al nuevo consumidor y se aplicarán estrategias diferenciadas para cada segmento de mercado. La clave para alcanzar el éxito dependerá de la capacidad para dejar de lado las viejas prácticas y aprender de los nuevos métodos: Productos creativos, educativos, vanguardistas, nutritivos, impecable presentación del plato, ingenio, estilo, descuentos, servicios. Esto de acuerdo al punto 2.5 visto anteriormente.

\subsubsection{Tamaño de mercado.}

El tamaño del mercado estará dado de acuerdo a lo revisado anteriormente para los NSE A y B de los distritos de San Borja, San Isidro, Miraflores, Santiago de Surco y La Molina. Según se vio anteriormente en el punto 2.4. (Ver Figura 3.2 y Figura 4.1). Esto nos aporta un total de $27.2 \%$ del NSE A y B, lo cual se traduce en 2`442,979 personas.

En la Tabla 4.15, se tiene la población de los cinco distritos asciende a 780,300 habitantes. De esa población, el 70.1\% pertenece a los NSE A y B, lo que nos aporta un tamaño del mercado de 546,990 personas. 
Tabla 4.15

Población estimada al 2016

\begin{tabular}{cc}
\hline & Población 2016 \\
\hline Surco & 351,200 \\
La Molina & 175,100 \\
San Borja & 114,400 \\
Miraflores & 84,000 \\
San Isidro & 55,600 \\
\hline Total & $\mathbf{7 8 0 , 3 0 0}$ \\
\hline
\end{tabular}

Fuente: Compañía Peruana de Estudios de Mercado y Opinión Pública SAC, CPI (2016)

\subsubsection{Mercado objetivo.}

El mercado objetivo estaría dado por los clientes que al menos van una vez al restaurante, esto según el punto 4.2.1, de la Tabla 4.3, resultando un 32\%. Esto equivaldría a tener un mercado objetivo de 175,036 personas.

\subsubsection{Identificación de agentes (clientes, usuarios, compradores, prescriptores, intermediarios, mayoristas, minoristas, comisionistas).}

\subsubsection{Clientes}

Son todas las personas de más de 18 años que, por sí solos, pueden ir al restaurante o estar acompañados y pagar por un plato saludable o un paquete mensual por delivery. Estos clientes según nuestro estudio son del NSE A y B, y que pertenecen a los distritos de Santiago de Surco, San Borja, San Isidro, La Molina y Miraflores.

\subsubsection{Usuarios.}

Son los hijos menores de 18 años y sus padres y cualquier consumidor que vaya al restaurante y que pertenecen al NSE A y B principalmente y que estén dispuestos a comprar un plato saludable. 


\subsubsection{Mayoristas.}

Los mayoristas, son los proveedores de menestras, cereales, carnes, pescado, etc., de acuerdo a la cantidad a comprar. Estos proveedores pueden ser principalmente Makro y Mayorsa.

\subsubsection{Minorista.}

Los minoristas, van a ser los proveedores directos de los productos nutritivos, por ejemplo, los agricultores.

\subsubsection{Comisionistas.}

Serán las personas que realicen actividades de venta de eventos a empresas y las personas que se encarguen del área de educación nutricional.

\subsubsection{Encargados del laboratoio bio-experiencial de agricultura en ambiente controlado.}

Se establecerá un joint venture con participación del sector empresarial no gubernamental, con el Instituto Peruano del Espárrago y Hortalizas (IPEH), con la Universidad Agraria de Lima y con la Asociación de Gremios Productores Agrarios del Perú (AGAP).

\subsubsection{Potencial de crecimiento del mercado.}

El crecimiento estará dado en relación al crecimiento del PBI, el cual estará en un 3\%, al 2016 y se espera que crezca, para los siguientes años, entre el 4\% y 5\% en forma anual. Esto hará que más personas o familias alcancen un mayor nivel socioeconómico, como ha venido sucediendo en nuestro país. Las expectativas nos conducen a que suba el PBI, según lo visto en el punto 3.6.4

\subsubsection{Rivalidad competidora y potencial de ventas.}

Dado el formato sobre plato saludable con contenido de insumos saludables de alta calidad, se prevé que al inicio o al primer año no se tenga rivalidad directa, dado que se 
tiene otro enfoque ya sea como experiencia única en general, así como en la preparación y el contenido de los platos.

El Potencial de venta. Es auspicioso debido a la creciente tendencia a preferir productos saludables en la alimentación. Esto se vio en el punto 2.5, en donde los comensales y los restaurantes están cambiando sus formas de atención y le están prestando mayor atención a los alimentos de alta calidad, ricos en nutrientes. Un ejemplo es el café orgánico, el cual lo podemos encontrar en la siguiente página web: www.compadres.pe. Otro ejemplo sería el de la empresa Shiwi, que vende a domicilio productos naturales como la miel de abeja, la castaña, la panela, entre otros, a la cual podemos acceder a través de la siguiente página web: www.shiwi.pe. El caso de esta empresa es notable, porque hoy en día ya se encuentran exportando a mercados internacionales muy competitivos.

\subsection{Desarrollo y Estrategia del Marketing Mix}

\subsubsection{Política de gestión del cliente.}

El personal administrativo supervisará y atenderá la gestión de cualquier inconformidad del cliente respecto del servicio recibido. Las condiciones de atención se sujetarán a las responsabilidades y alcances legales de nuestros servicios puestos en conocimiento de la población en general a través de nuestra página web.

En ese sentido se recurrirá a los siguientes medios de comunicación con el cliente, que no representan costo adicional para la empresa:

- Se aceptará regularmente reclamaciones y sugerencias a través de nuestra página web, correo electrónico o directamente con el personal administrativo.

- Se medirá la satisfacción del cliente a través de encuestas realizadas a los clientes y consumidores.

- Se examinará a fondo cada queja, con la finalidad de lograr mejoras en el servicio y la atención al cliente.

Se permitirá que los comensales puedan ver la cocina y el laboratorio de agricultura en ambiente controlado (Indoors farming) dentro del local de la empresa, dado que todas las paredes dentro del recinto serán de vidrio. Asimismo, videos instructivos y 
recursos de multimedia complementarán la bio-experiencia de los clientes. De esa forma, los comensales podrán verificar las buenas condiciones de ubicación, espacio, infraestructura e higiene del lugar en donde se preparan los platos saludables para los comensales.

Asimismo, se mostrarán videos de corta duración y paneles informativos con gráficos, los que se complementarán con videos multimedia, que serán mezclados con las artes visuales y musica, para poder dar a conocer los productos y platos saludables de nuestro restaurante.

\subsubsection{Estrategia de producto: especificaciones, calidad, variabilidad $y$ diversificación.}

El servicio consiste en brindar una experiencia multisensorial de aprendizaje en salud y nutrición en donde el arte y la ciencia se conjuguen para que el cliente se alimente con una variedad de platos saludables y nutritivos, (orgánicos y no orgánicos) en un restaurante bio-experiencial, para ser degustados por toda la familia. Platos con el concepto de variedad de contenido (nutritivo), diseño atractivo del plato y precio asequible. Se ha planeado que la población en general cuente con acceso a la página web para ver la carta de alimentación semanal y apreciar el balance en nutrición de los variados platos siguiendo las recomendaciones del "Plato Saludable de Harvard". Adicionalmente al servicio del restaurante, se implementará el pedido a domicilio o por "delivery" de paquetes mensuales o pedidos individuales. El producto contempla 5 alternativas para otorgar una mayor variedad de oferta, alternativas que serán cambiadas una vez al mes.

Los insumos y platos serán colocados en paneles o monitores, dando una infografía y propiciando la educación para la alimentación saludable. 
En cuanto a la propuesta se muestra la identidad de la marca según la figura 4.2

Figura 4.2

Logotipo de la marca

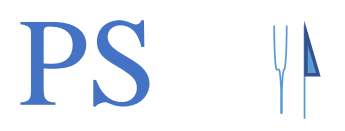

Elaboración propia

a) Marca

La marca establecida es "Plato Saludable" que engloba el concepto de nutrición innovadora, concepto asociado a "sentirse bien de salud", que se comercializa generalmente en el restaurante bio-experiencial, destacando los beneficios y atributos altamente valorados por el segmento de clientes de comida saludable y los subsegmentos de comensales en familia, comensales de oficinas y empresas, estudiantes y, en el futuro, para comensales de malls, aeropuertos, clínicas, hospitales y establecimientos de hospedaje.

b) Slogan

La frase propuesta es "Una manera diferente, de disfrutar los sabores de un plato saludable". Con este enfoque se quiere interiorizar la asociación de ideas que comiendo el mismo plato que deleita al paladar, lo disfruto de una manera diferente por el alto contenido de aporte nutricional, siendo no sólo saludable sino de un sabor delicioso.

\subsubsection{Estrategia de precios.}

De acuerdo a los resultados obtenidos en el punto 4.2.1, se observa que el rango de precios que está dispuesto a pagar el público objetivo se encuentra entre los 31.00 a 55.00 Soles, por lo que, tomando ventaja de la innovación del servicio y la amplitud del mercado potencial, se deben resaltar los beneficios previamente identificados que agregan valor a la propuesta de modelo de negocio, para tener una relación de 
precio/calidad adecuada que justifique un precio asequible para el público en general y para el cliente en general.

A partir de la información recopilada en el estudio cualitativo y cuantitativo se determina que el precio promedio de los platos es S/.40.50 Soles (se considera el [((máximo + mínimo) / 2)]. Dado que el segmento está dispuesto a pagar hasta S/. 50 soles, por un plato saludable.

El precio al cliente se ha proyectado como parte de un ajuste en precios por la inflación anualizada de 2 a 3\% para los próximos años, con una inflación anualizada que está en el rango meta del Estado Peruano, según los estimados que maneja el BCRP.

\subsubsection{Política comercial.}

La política comercial está dada por las comisiones de venta en forma corporativa, en donde la fuerza de ventas podrá tener como acciones comerciales el ofertar un descuento por volumen.

Los precios dados en el restaurante por cada plato sólo se modificarán cuando haya un cambio sustancial en los precios de los productos e insumos usados en la preparación del plato saludable.

Se realizará una temática diferente cada mes, en donde se dará a conocer desde la siembra, la cosecha y la preparación del producto principal. Así también cada mes la carta de 5 platos se podrá cambiar para darle un mayor valor agregado.

Se colocará un video en nuestra página web o app para que las personas puedan ver los cambios y conocer los datos o la preparación de los platos, así como los las nuevas delicias culinarias.

Ofreceremos paquetes mensuales por delivery que incluirán las 5 comidas al día (desayuno, snack de la mañana, almuerzo, snack de la tarde y cena) por un costo promedio de $S / 1,850.00$ por las comidas señaladas de lunes a sábado, por 4 semanas.

\subsubsection{Estrategia comunicacional y canal.}

La promoción y publicidad del "Plato Saludable de Harvard" se basará en la comunicación a través de diversos medios de comunicación y de publicidad que hagan 
posible que la difusión de los atributos y beneficios, sean los esperados por el público objetivo. La estructura que se plantea es la siguiente:

- Página Web: Consta de una plataforma amigable para que, los clientes en general, puedan ingresar su pedido online, hacer una reserva y realizar las consultas que consideren pertinentes, así como brindar comentarios o enviarnos una retroalimentación que pueda ser útil para aportar valor agregado adicional al producto final. La web cuenta con la descripción del servicio, ubicación, zona de reparto, salones o áreas, muestra de la oferta y la información de contacto. Es utilizable desde cualquier dispositivo con conexión a internet.

- Redes Sociales: La herramienta principal será un fan page en Facebook que permita promocionar la participación del "Plato Saludable de Harvard" en eventos, como por ejemplo, a través de promociones que puedan lanzarse o cualquier otra actividad que sea de interés de los clientes en general o de personas interesadas en la salud y la calidad nutritiva de los alimentos. Asimismo, se ha contemplado un anuncio en Facebook para fomentar el tráfico en la página.

- Adwords: Inversión en anuncios con palabras claves asociadas al concepto de "Plato Saludable de Harvard" que permita un posicionamiento estratégico y para poder conocer qué producto de las búsquedas constantes en la website de la compañía es primera alternativa, algo que no estará limitado a un posicionamiento alimenticio general.

- Mailing: El correo electrónico se usa como parte de una herramienta de gran alcance a bajo costo. Los mails del público se recopilan en los eventos, en las ferias y mediante el llenado de formularios. Los clientes realizan el pedido o las reservas en la página web, manteniéndose una base de datos actualizada.

- Dípticos y Brochure: Los volantes servirán para ser repartidos en los eventos en que se participe. El contenido es resumido destacando algunos datos de la página web, contemplando un concepto gráfico y atractivo. En el caso del brochure se ha contemplado como pack de presentación a manera institucional.

- Stickers: Como parte de un concepto práctico y de difusión masiva, el logotipo de la marca, mostrado en la Figura 4.1, es parte de los artículos o souvenirs a fin de consolidar la recordación de la marca, los que serán adheridos en dichos objetos a 
la salida del restaurante o en un evento en donde se participe. Por ejemplo, se espera que los ornamentos imantados con nuestro logo sean colocados en los refrigeradores de las casas de nuestros clientes.

- Programas especializados: En canal de señal por cable, como Plus TV, se manejan conceptos de programas que fomentan la alimentación saludable y el cuidado en la alimentación, estando alineados al concepto de "Plato Saludable de Harvard", por lo que la participación en dichos programas se podría realizar bajo un concepto de "lobby" y que no representan un alto costo, puesto que el concepto se maneja como parte de las relaciones públicas de la compañía.

- Prensa escrita: En revistas como Somos del diario El Comercio existen artículos relacionados a la buena alimentación, empleando publicación tanto escrita como digital o en programas de empresas, así como en publirreportajes. Un ejemplo podría ser el del "Programa en la Mira", transmitido por Panamericana Televisión.

- Eventos: Participación activa en jornadas deportivas o charlas sobre nutrición dadas por el Ministerio de Salud o por las Municipalidades de Santiago de Surco, San Borja, San Isidro, Miraflores y La Molina. En dichos eventos se contempla la instalación de un módulo (stand) en donde se entregarán los brochures y dípticos, y en los que se podrá degustar muestras de algunos platos saludables.

- Elementos visuales: Vehículo acondicionado al concepto "Plato Saludable de Harvard" para que sea expuesto por las calles y avenidas de alto tránsito en los distritos antes mencionados, así como vallas de publicidad.

- Charlas nutricionales: Dirigidas a las personas, a las familias y al público en general sobre el "Plato Saludable de Harvard" y así corregir la falta de conocimiento en temas nutricionales, charlas que podrían también estar a cargo de la nutricionista perteneciente al staff de la compañía, y que serían parte de la difusión de un concepto de alimentación saludable, así como de los atributos del servicio.

- Colocación de paneles o monitores: Para dar a conocer los beneficios y ventajas, los que serán plasmados en una infografía y video de fácil comprensión y entendimiento completamente amigable y de corta duración, como medio de capacitación interactiva. 
- Inbound Marketing o Marketing de contenido: Donde se desarrollará contenido orientado a la alimentación saludable, estilo de vida, cuidado del medio ambiente a través del Indoors farming, etc. Con llamadas de acción (estas llamadas de atención, nos permitirán obtener su email y nombre) para que los clientes que están buscando dicha información la encuentren en nuestra web, a través de las cuales se les otorgará información de calidad, mediante concejos y recomendaciones, con la finalidad que recuerden nuestro restaurante y que éste sea un referente a la hora de elegir comida saludable.

\subsubsection{Estrategia de distribución.}

El producto "Plato saludable de Harvard", se entregará en el mismo local del restaurante Bio-experiencial y por delivery en la comodidad del hogar u oficina.

\subsubsection{Estrategia de plaza}

La localización tendrá como propósito encontrar el mejor lugar para realizar el restaurante y que cumpla con las exigencias de un restaurante Bio-experiencial.

La macrolocalización. El restaurante se ubicará en la región Lima, perteneciente al Perú.

La microlocalización. Se va a utilizar el método de Brown y Gibson, ya que utiliza factores cuantitativos y subjetivos, dándoles un peso para determinar su elección.

De los 2 distritos que se vio en el estudio de mercado, se procederá a elegir uno de ellos.

Los distritos pre-seleccionados fueron Surquillo y Magdalena del Mar, por ser distritos en los que el precio del metro cuadrado no es tan caro, pero que están muy próximos a los distritos residenciales de Miraflores, San Isidro, San Borja y Surco, que es donde habitualmente, los segmentos y subsegmentos de los NSE A y B, asiste a restaurantes los fines de semana. Y es que existen zonas de Surquillo que están en los límites con el distrito de Miraflores, que pareciera que son de Miraflores, pero a un costo por metro cuadrado mucho menor. Algo similar ocurre con zonas del distrito de Magdalena del Mar que están próximas a los distritos de San Isidro y Miraflores. 
Asimismo, el servicio de entrega por delivery, exige que los distritos en donde se localice el restaurante esté en el casco urbano consolidado, próximo a los distritos de Surco, La Molina, San Borja, Miraflores y San Isidro y, especialmente próximo al mayor número de centros educativos de los NSE A y B, así como a oficinas y universidades.

Entonces para proceder a la elección entre uno de los dos distritos (microlocalización), tenemos los siguientes criterios:

- Costo de terreno en US\$ por m2 visto en la página web www.urbania.pe

- Proximidad a distritos con población de los NSE A y B

- Número de centros educativos top y universidades en proximidades

- Densidad en el número de oficinas de empresas en las proximidades

- Accesibilidad para llegar al restaurante.

- Disponibilidad de terrenos en venta.

- Presencia de competidores.

- Preferencia de los clientes.

En la tabla 4.16 se muestran los puntajes de ambos distritos al ser evaluados los criterios de microlocalización.

En la tabla 4.17 se muestran los puntajes finales para la selección de la microlocalización.

Tenemos la tabla 4.16, con sus puntajes respectivos. De acuerdo a la tabla 4.17 se tiene el resultado final (ver la tabla 4.17). Para elegir la microlocalización entre ambos distritos se procedió a sumar los puntajes de todos los ítems considerados. Viendo la tabla 4.18, se elige el distrito de Surquillo por ser el que tiene mayor puntaje. 
Tabla 4.16

Indicadores para establecer la microlocalización del restaurante

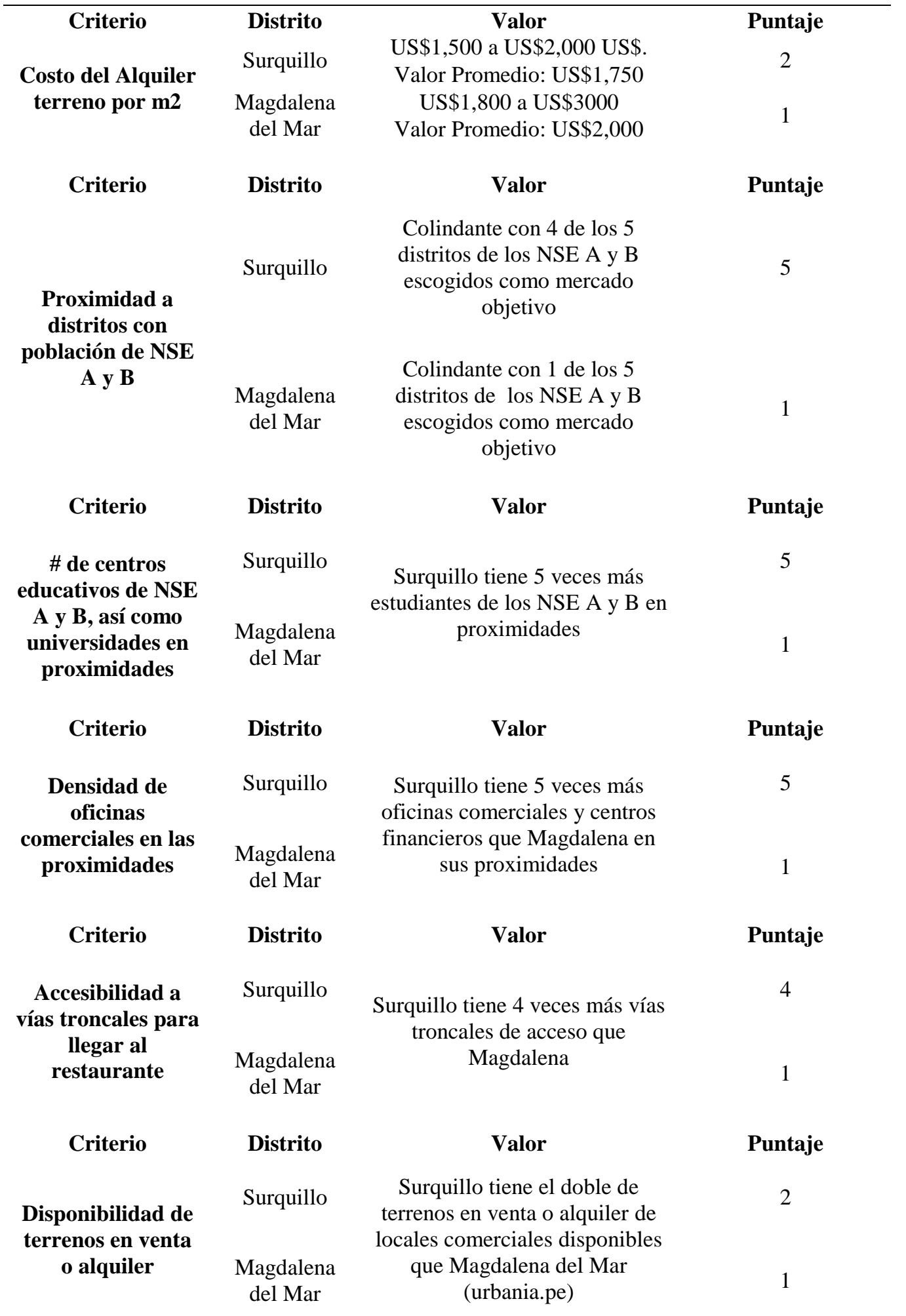




\begin{tabular}{|c|c|c|c|}
\hline Criterio & Distrito & Valor & Puntaje \\
\hline \multirow{2}{*}{$\begin{array}{l}\text { Presencia de } \\
\text { competidores }\end{array}$} & Surquillo & \multirow{2}{*}{$\begin{array}{c}\text { Ambos distritos tienen el mismo } \\
\text { número de restaurantes } \\
\text { competidores }\end{array}$} & 1 \\
\hline & $\begin{array}{l}\text { Magdalena } \\
\text { del Mar }\end{array}$ & & 1 \\
\hline Criterio & Distrito & Valor & Puntaje \\
\hline \multirow{3}{*}{$\begin{array}{l}\text { Presencia de } \\
\text { competidores }\end{array}$} & Surquillo & \multirow{3}{*}{$\begin{array}{l}\text { Ambos distritos tienen el mismo } \\
\text { número de restaurantes }\end{array}$} & 1 \\
\hline & & & \\
\hline & $\begin{array}{l}\text { Magdalena } \\
\text { del Mar }\end{array}$ & & 1 \\
\hline Criterio & Distrito & Valor & Puntaje \\
\hline \multirow{2}{*}{$\begin{array}{l}\text { Preferencia de } \\
\text { clientes (de la } \\
\text { encuesta } \\
\text { realizada) }\end{array}$} & $\begin{array}{l}\text { Surquillo, en } \\
\text { límite con } \\
\text { Miraflores }\end{array}$ & $33 \%$ & 0.63 \\
\hline & $\begin{array}{l}\text { Magdalena } \\
\text { del Mar }\end{array}$ & $19 \%$ & 0.37 \\
\hline
\end{tabular}

Elaboración propia

Tabla 4.17

Selección de la microlocalización.

\begin{tabular}{lc}
\hline Distrito & Puntaje final \\
\hline Surquillo & 25.63 \\
Magdalena del Mar & 9.37 \\
\hline
\end{tabular}

Elaboración propia

\subsection{Plan de Ventas (objetivos anuales, alcance de la oferta) y Proyección de la Demanda (crecimiento y desarrollo)}

De acuerdo a los datos de la población y las encuestas realizadas, tenemos la cantidad de visitas que se realizan a los restaurantes. (Ver tabla 4.18). La cantidad de demanda. 
Tabla 4.18

Demanda de visitas al restaurante por comensales, sólo en los fines de semana

\begin{tabular}{|c|c|c|c|c|c|c|c|c|c|}
\hline Frecuencia & $\%$ & Población & $\begin{array}{c}\text { Sem } \\
1\end{array}$ & $\begin{array}{c}\text { Sem } \\
2\end{array}$ & $\begin{array}{c}\text { Sem } \\
3\end{array}$ & $\begin{array}{c}\text { Sem } \\
4\end{array}$ & $\mathrm{Fr}$ & $\begin{array}{l}\text { Demanda } \\
\text { mes }\end{array}$ & $\begin{array}{c}\text { Demanda } \\
\text { Anual }\end{array}$ \\
\hline 1 vez cada 15 días & $38 \%$ & 296514 & 1 & & 1 & & 2 & 593028 & 7116336 \\
\hline 1 vez por semana & $32 \%$ & 249696 & 1 & 1 & 1 & 1 & 4 & 998784 & 11985408 \\
\hline 2 veces por semana & $18 \%$ & 140454 & 2 & 2 & 2 & 2 & 8 & $\begin{array}{l}1123 \\
632\end{array}$ & 13483584 \\
\hline 3 veces por semana & $7 \%$ & 54621 & 3 & 3 & 3 & 3 & 12 & 655452 & 7865424 \\
\hline $\begin{array}{l}\text { Más de } 3 \text { veces por } \\
\text { semana }\end{array}$ & $5 \%$ & 39015 & 4 & 4 & 4 & 4 & 16 & 624240 & 7490880 \\
\hline Total & $100 \%$ & 780300 & & & & & & $\begin{array}{c}3995 \\
136\end{array}$ & 47941632 \\
\hline
\end{tabular}

Elaboración propia

En cuanto a la demanda proyectada (ver la tabla 4.19) se considera un crecimiento acorde al PBI, siendo un indicador que afecta a la economía. Si éste aumenta, todos los NSE, aumentan. Y nos parece apropiado utilizar este indicador.

Tabla 4.19

Cantidad proyectada de demanda

\begin{tabular}{|c|c|c|c|c|c|}
\hline \multirow[t]{2}{*}{ Crecimiento PBI } & & $3 \%$ & $3.50 \%$ & $4 \%$ & $4.50 \%$ \\
\hline & Año 1 & Año 2 & Año 3 & Año 4 & Año 5 \\
\hline Visitas & 27806147 & 28640331 & 29642743 & 30828452 & 32215733 \\
\hline
\end{tabular}

Elaboración propia

Vamos a considerar tener 40 mesas y en cada mesa 4 sillas, dando un aforo de 160 personas. De acuerdo a lo observado en varias visitas a dos restaurantes se apreció que en un día cualquiera menos sábado o domingo, el promedio de mesas ocupadas y el total de personal según la hora, era el que se aprecia en la Tabla 4.20. 
Tabla 4.20

Promedio de visitas en un día cualquiera, menos sábado y domingo, al restaurante

\begin{tabular}{lcc} 
Atención hora & Mesas Ocupadas & Total personas \\
\hline $11 \mathrm{am}-12 \mathrm{~m}$ & 10 & 40 \\
$12 \mathrm{~m}-1 \mathrm{pm}$ & 30 & 120 \\
$1 \mathrm{pm}-2 \mathrm{pm}$ & 30 & 120 \\
$2 \mathrm{pm}-3 \mathrm{pm}$ & 25 & 100 \\
$3 \mathrm{pm}-4 \mathrm{pm}$ & 25 & 100 \\
$4 \mathrm{pm}-5 \mathrm{pm}$ & 20 & 80 \\
$5 \mathrm{pm}-6 \mathrm{pm}$ & 10 & 40 \\
$6 \mathrm{pm}-7 \mathrm{pm}$ & 10 & 40 \\
$7 \mathrm{pm}-8 \mathrm{pm}$ & 10 & 40 \\
\hline
\end{tabular}

Elaboración propia

Fue entonces que, dado el aumento de comensales que se observaba en los fines de semana, que consideramos aumentar el aforo. Notamos que en una semana, las mesas ocupadas eran 873 en las 8 horas de funcionamiento, es decir 3,492 mesas. Al trabajar con la base de una familia, y considerando 4 personas por familia, arribamos a la cifra de 13,970 personas que visitarían el restaurante. (Ver Tablas 4.21 y 4.22).

Tabla 4.21

Mesas ocupadas y personas visitas

\begin{tabular}{lcc} 
& Mesas Ocupadas & Personas /Visitas \\
\hline Día 1 & 170 & 680 \\
Día 2 & 187 & 748 \\
Día 3 & 224 & 898 \\
Día 4 & 292 & 1167 \\
Semanal & 873 & 3492 \\
\hline
\end{tabular}

Elaboración propia 
Tabla 4.22

Cantidad de mesas ocupadas. Mensual y anual

\begin{tabular}{lcc} 
& Mesas & Personas \\
\hline Mes & 3492 & 13970 \\
Año 1 & 41910 & 167639 \\
\hline
\end{tabular}

Elaboración propia

En forma mensual y anual: Nuestras proyecciones nos dan un total de 13,970 personas en el mes y 167,639 personas en el año. Por lo tanto, para la proyección en número de visitas en venta seria: desde el 1er año 167,639 visitas y al 5to año sería de 194,224 visitas (ver tabla 4.24).

Tabla 4.23

Presupuesto de venta por personas

\begin{tabular}{lccccc}
\hline & Año 1 & Año 2 & Año 3 & Año 4 & Año 5 \\
\hline Visitas /venta & 167639 & 172668 & 178712 & 185860 & 194224 \\
$\%$ mercado & $0.60 \%$ & $0.60 \%$ & $0.60 \%$ & $0.60 \%$ & $0.60 \%$ \\
\hline
\end{tabular}

Elaboración propia 


\section{CAPÍTULO V: PLAN DE OPERACIONES}

\subsection{Políticas Operacionales}

\subsubsection{Calidad}

Tendremos las siguientes pautas de calidad:

- Calidad de higiene y control de plagas. Que el personal conozca las plagas más comunes, así como tener conocimiento de cómo evitarlas y cómo erradicarlas. Que el personal sepa distinguir entre limpiar y desinfectar y que tenga conocimiento de la importancia de realizar ambas actividades.

- Calidad de producto. Tener una adecuada higiene para la manipulación de alimentos tanto en su preparación como en su uso y saber la importancia de evitar que los alimentos se contaminen.

- Control de calidad del agua. Importancia del uso del agua, apta para el consumo humano y que no represente un riesgo para la elaboración de alimentos.

- Calidad de la materia prima. Conocer los requisitos mínimos para recibir, almacenar y entregar o retirar productos de acuerdo con el tipo de materia prima, conforme su almacenamiento (María José Oliva, 2011). Elaboración de una guía de buenas prácticas de manufactura para el restaurante.

- La calidad operativa. Es el conjunto de tareas y actividades que organizan y permiten que ocurra la prestación del servicio en la entrega del plato. Se realizan dentro de la organización, en forma diaria, en relación directa o indirecta con el cliente. Por ejemplo: Calidad operativa es una orden bien tomada, un salón de comedor preparado para recibir a los clientes, los cubiertos fajinados, un plato debidamente elaborado, un baño limpio y en perfecto estado de funcionamiento, una heladera organizada en el interior de acuerdo con el tipo y estado de la mercadería, etc.

- Calidad de servicio. Atención al cliente. La atención al cliente es la habilidad que tenemos o desarrollamos para entender y ejecutar aquello que los clientes 
pueden necesitar o desear. Esta habilidad tiene que estar acompañada por factores claves para el servicio.

Factores claves del servicio:

- Conocimiento de técnicas de servicio.

- $\quad$ Actitud de servicio.

- Cuidado por los detalles de imagen personal.

- Criterios de supervisión

- Interés por mejorar (Miguel Libonat, 2006). Procedimientos para la gestión de la calidad, seguridad e higiene de alimentos: supervisor / Miguel Libonati; María Julia Bacigalupo; Mariela Wagner - 1a ed. - Buenos Aires: Federación Empresaria Hotelera Gastronómica de la República Argentina, Consejo Federal de Inversiones, 2006.

Y tendremos en consideración la metodología de calidad:

HACCP. Es un sistema de gestión que brinda un enfoque sistemático para identificar peligros y estimar los riesgos que pueden afectar la inocuidad de un alimento, a fin de establecer las medidas para controlarlos. El sistema hace hincapié en la prevención de los riesgos para la salud de las personas.

ISO 9001:2000. Es una norma internacional que ordena las actividades de las organizaciones, a partir de la instrumentación de un sistema de gestión de la calidad. Esto significa contar con un método de trabajo que facilite a la organización la mejora continua.

\subsubsection{Procesos.}

Se realizaron los siguientes procesos:

- Proceso de compra y almacén. Ver figura 5.1

En el siguiente proceso se realiza la gestión del proveedor, por cada producto o insumo que necesita el restaurant, considerando los puntos de control de acuerdo al HACC de cada producto e insumo y su correcto almacenamiento y utilización. 
Figura 5.1

Procesos de compra y almacén
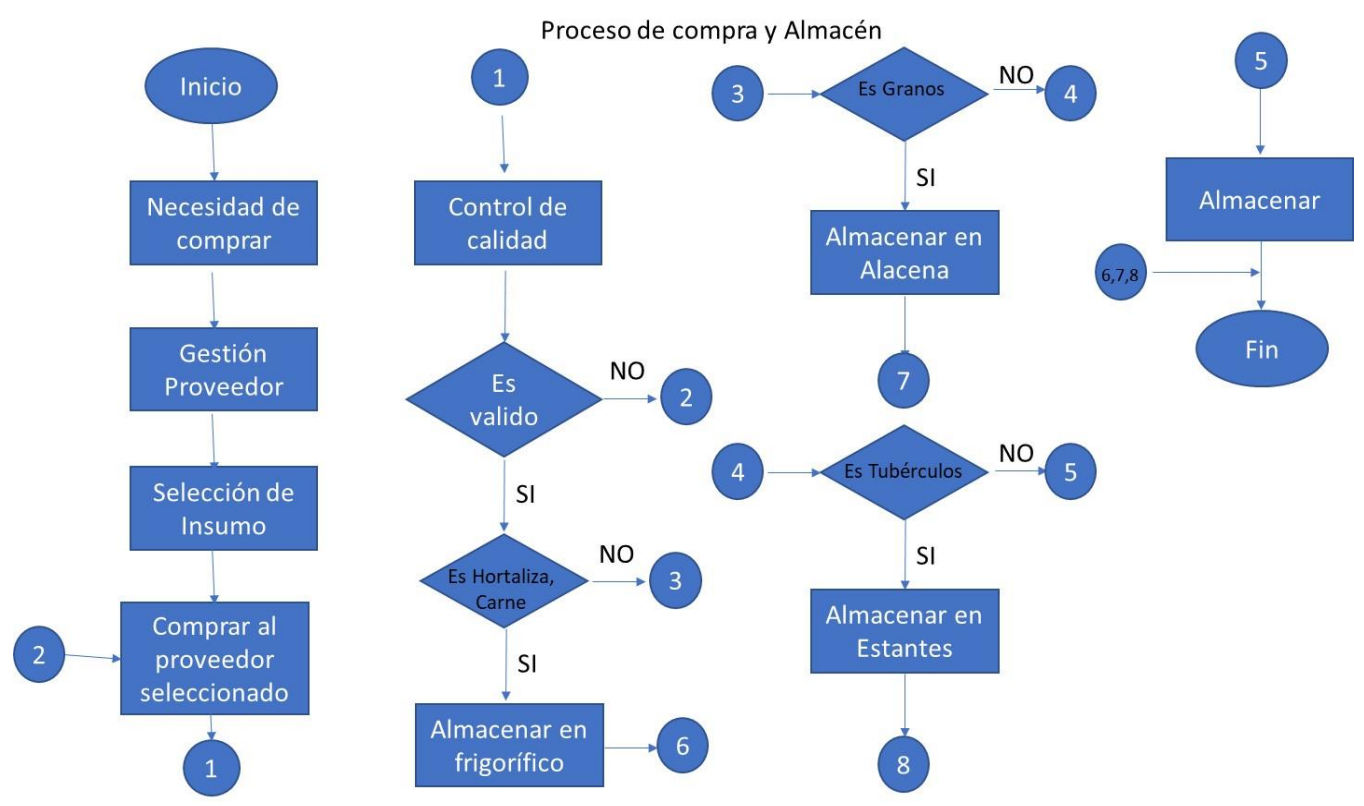

Elaboración propia 
- Proceso de elaboración de Recetas. Ver figura 5.2

En este proceso de recetas se va a estandarizar las recetas, para llevar un control de cada plato y que estos no cambien, así se tenga un nuevo chef o ayudante de cocina. En ella cada procedimiento y medida se llevará a un sistema de información.

Figura 5.2

Proceso de elaboración de recetas

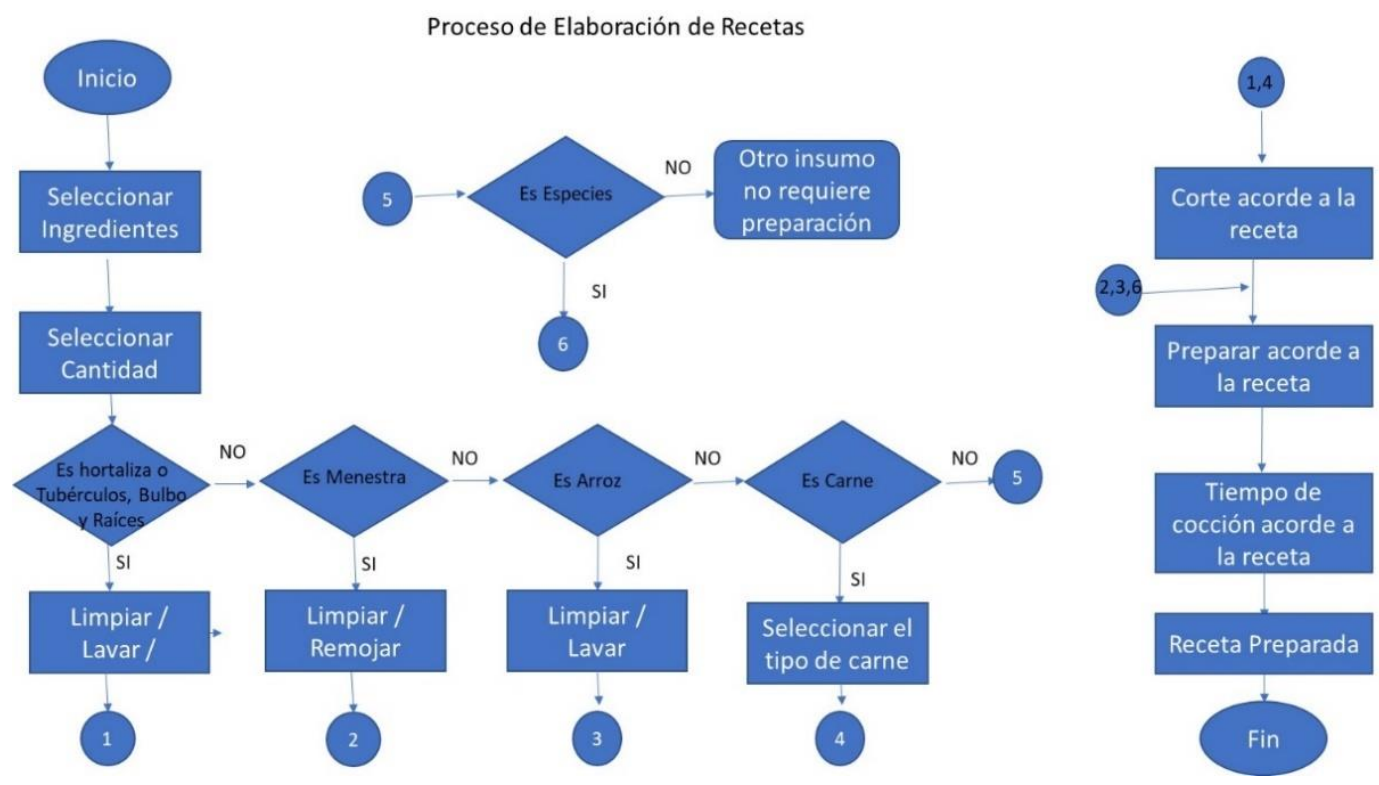

Elaboración propia

- Proceso de atención. Ver Figura 5.3

En este proceso de atención al cliente, partimos desde la bienvenida del comensal al restaurant, para que este realice una atención adecuada desde el ingreso y salida del comensal. 
Figura 5.3

Proceso de atención.

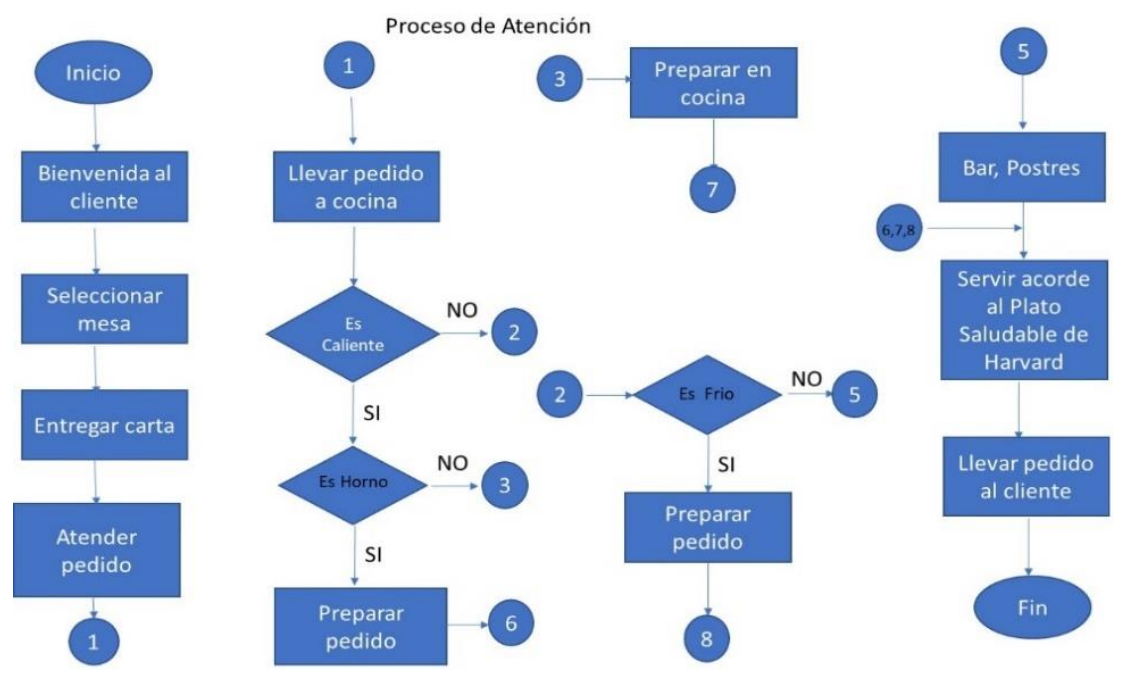

Elaboración propia

- Proceso de atención por delivery.

En dicho proceso se tiene en cuenta la atención (telefónica o a través de un app) del pedido del cliente, teniendo un protocolo de atención, para que el pedido del cliente sea llevado de forma correcta y en un tiempo de 30 minutos como mínimo. Los pedidos se atienden conformen ingresan, es decir los primeros en pedir son los primeros que salen a excepción de platos que tienen un tiempo mayor en su preparación.

Figura 5.4

Proceso de atención por delivery.

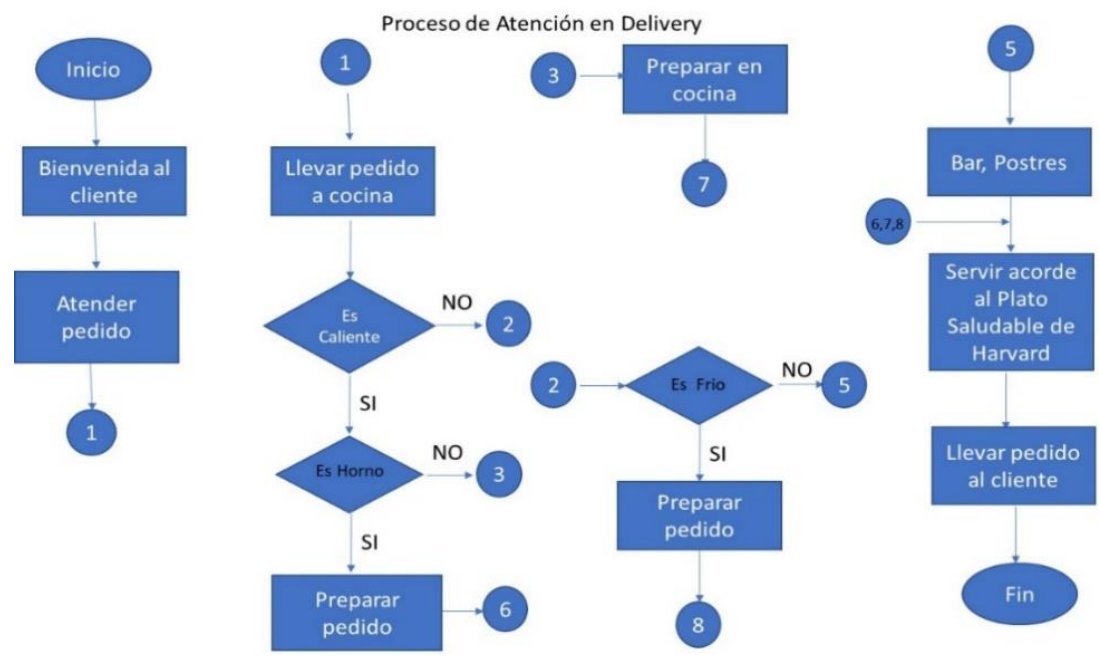

Elaboración propia 
- Proceso de pago a proveedores. Ver Figura 5.5

Este proceso es para pagar a nuestros proveedores. Tratándose de productos perecibles estos se pagarán al día. Para los otros productos se puede negociar con los proveedores partiendo de 7, 15, 30 y 45 días de crédito. Los proveedores dejan su factura en administración y dependiendo de su línea de crédito, se le paga al proveedor.

\section{Figura 5.5}

Proceso de pago a proveedores

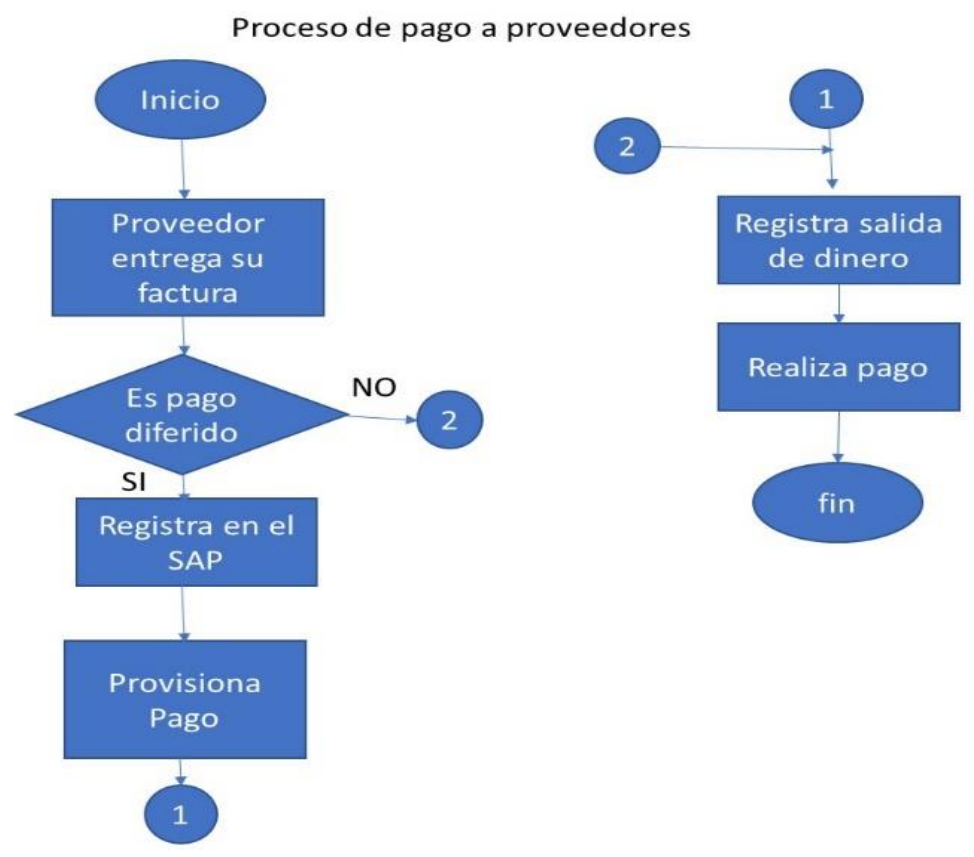

Elaboración propia

- Procesos de selección y reclutamiento de recursos humanos. Ver figura 5.6

Este proceso es para tener el mejor personal más competente e idóneo en cada puesto de trabajo del restaurante o se la parte administrativa del mismo. Se implementarán todos los controles y exámenes necesarios para su selección y contrato, incluyendo su carnet de sanidad, y sus antecedentes policiales. 
Figura 5.6

Procesos de selección y reclutamiento de recursos humanos

Proceso de selección y reclutamiento de Recursos Humanos
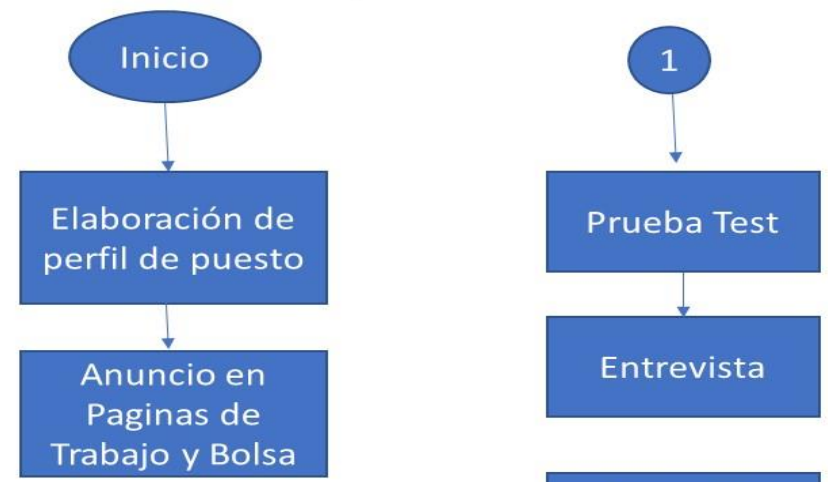

Selección de

candidatos

acorde a perfil

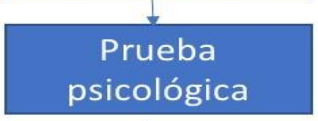

fin

\section{Firma de}

contrato

1

Elaboración propia

\subsubsection{Planificación}

La planificación estará dada en concordancia con las ventas y con el control de la reposición de los insumos, teniendo en consideración la fecha de vigencia de cada insumo y la calidad del mismo para no afectar la salud.

También se realizará la planificación de las tareas a realizar para disfrutar de un restaurante limpio, ordenado, higiénico y con áreas en perfectas condiciones de conservación para la visita de los clientes, quienes tendrán la oportunidad de presenciar todo el proceso relacionado al cultivo de los vegetales orgánicos y no orgánicos en la estación de la agricultura de ambiente controlado (vertical farming) que podrá ser vista a través de vidrios transparentes.

\subsubsection{Inventarios}

Se va a organizar para las materias primas en almacenamiento el sistema de rotación de inventarios aplicando la regla del PEPS (primero en entrar, primero en salir), por eso es 
necesario rotular cada insumo y clasificarlo de acuerdo a los 3 almacenes que se detallaron en la figura 5.1.

Inicialmente se tendrán insumos para un mes, excepto las hortalizas y carnes, los que podrán comprarse a diario tomando en cuenta la frescura de los mismos. Los tubérculos, bulbos o raíces, pueden comprarse cada semana e igualmente se controlarán las mermas de cada insumo.

El proceso se da según va saliendo (venta) cada receta. Para atender un pedido u orden, se descuenta en el almacén respectivo.

Al proveedor se le pagará, según sea el caso, en un plazo no menor a 15 días o el mismo día. Con los terceros, como para el caso de los cultivos orgánicos y no orgánicos que se cultiven fuera del restaurante, el pago se hará a los 30 días, considerando que tendrán un centro de demostración y de visita.

\subsection{Equipos, Actividades y Procesos}

\subsubsection{Diseño y capacidad de instalaciones.}

Se tendrá una cocina adecuada para la preparación, conservación y producción de alimentos, la que se denomina planta de producción.

En la figura 5.7. Se muestran las instalaciones con capacidad, en el salón principal, para un aforo de 80 personas. 
Figura 5.7

Diseño y capacidad de instalación

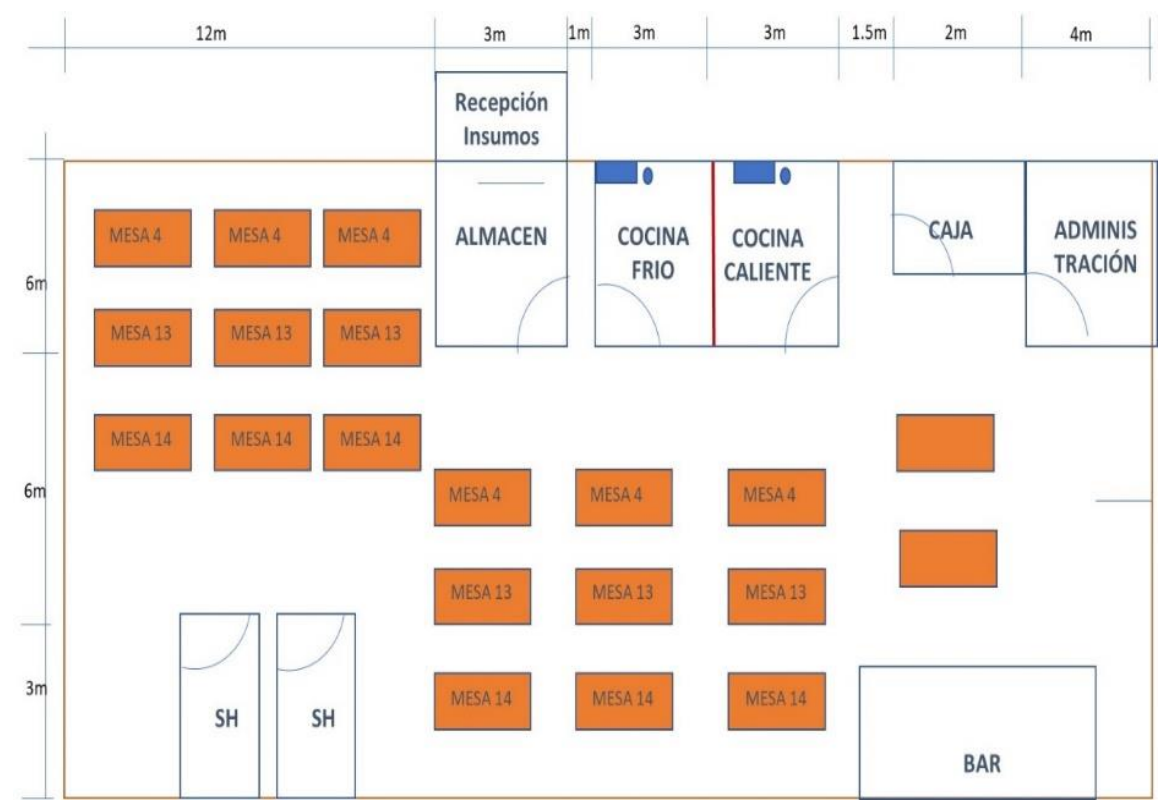

Elaboración propia

Los dos primeros bloques que se muestra en la gráfica 5.6 sin nombre son las cabinas de cultivo orgánico, de donde nos proveeremos de los vegetales.

No existe límite de producción. Se considera una producción por receta preparada al instante, con un promedio de tiempo de espera de 20 minutos. Sólo estará supeditado al aforo del restaurante, en concordancia con la carta de platos, postres, ensaladas y bebidas.

También se cuenta con un área de buffet, el cual funcionará de 12am a 3pm. Los mismos platos o ingredientes se podrán servir a gusto del comensal, considerando el aprendizaje del plato saludable según la Escuela de Salud Pública de la Universidad de Harvard.

Adicionalmente se prepararán las loncheras para que sean enviadas por delivery a los diferentes distritos de Lima Metropolitana.

\subsubsection{Equipos de trabajo y apoyo.}

Los equipos de trabajo son para las áreas: 
- Cocina frio: Ayudante de cocina, Chef.

- Cocina Caliente: Ayudante de cocina, Chef.

- Atención a los clientes: Anfitriona, Mozos, Cajeros, Administrador, Capitán o maître de mozos.

- Área de postre: Ayudante

- Área de contabilidad: Asistente contable, Cajera

- Área de Bar: Barman

En la figura 5.8 se presenta el diagrama de flujo del servicio.

Figura 5.8

Diagrama de flujo del servicio.

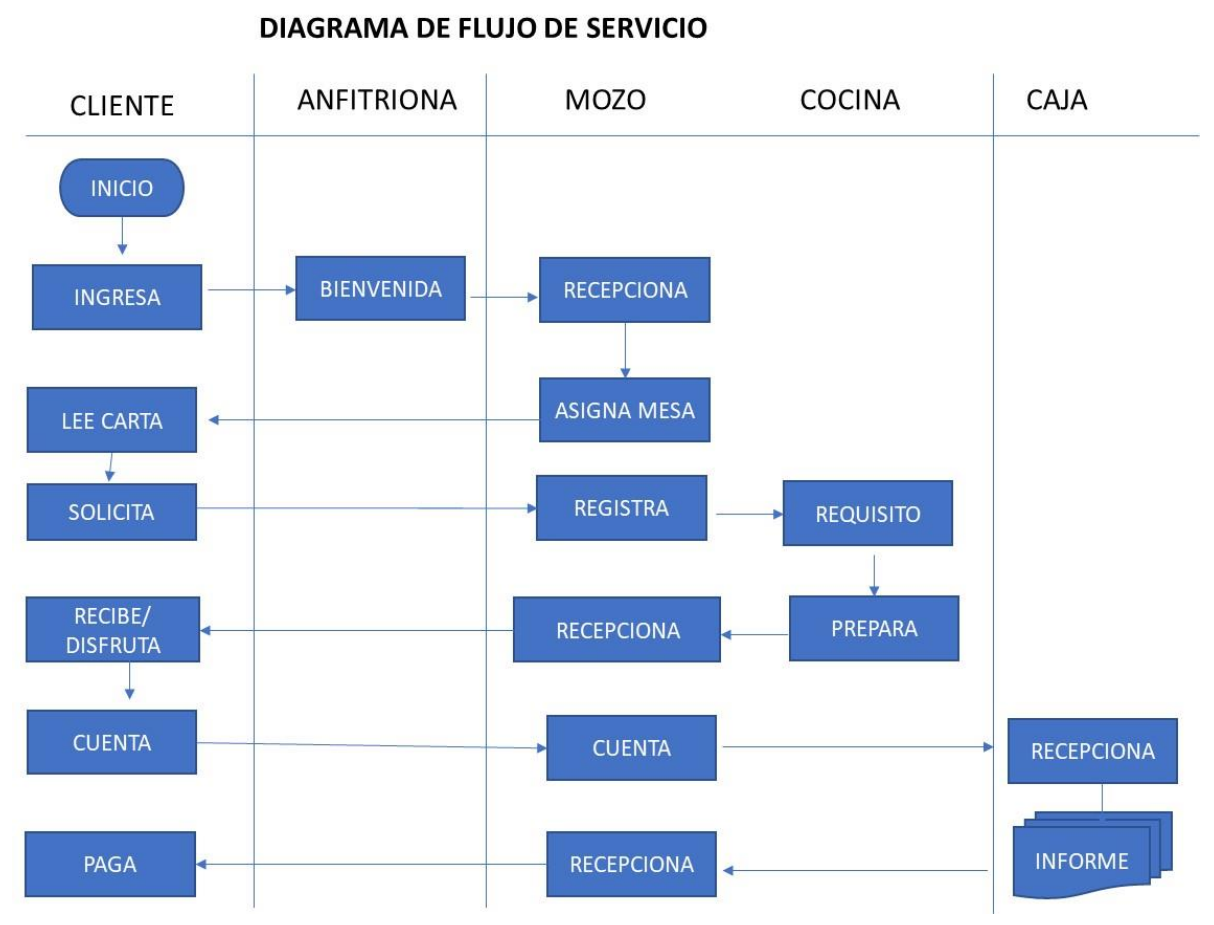

Elaboración propia

Equipos de Apoyo:

- Área de cultivo o entretenimiento: Supervisor de área.

- $\quad$ Área de seguridad: Personal de vigilancia, parking y supervisor de seguridad. 
- Área de mantenimiento: Personal de limpieza, mantenimiento de equipos, enseres y muebles.

- Área de Almacén: Personal Almacenero.

\subsubsection{Gestión de proveedores, compras y stock.}

En esta parte de la tesis, como lo veremos más adelante, el principal gasto para brindar los servicios son los insumos necesarios para cada servicio. Este escenario amerita el tener una gestión de proveedores que se lleve a cabo en forma óptima y oportuna a los mejores precios, sin descuidar la calidad del mismo.

Para ello definir cada una de las actividades descritas en la figura 5.9, es de vital importancia para la gestión diaria del restaurante.

Figura 5.9

Proceso de gestión de proveedores.

PROCESO DE GESTION DE PROVEEDORES

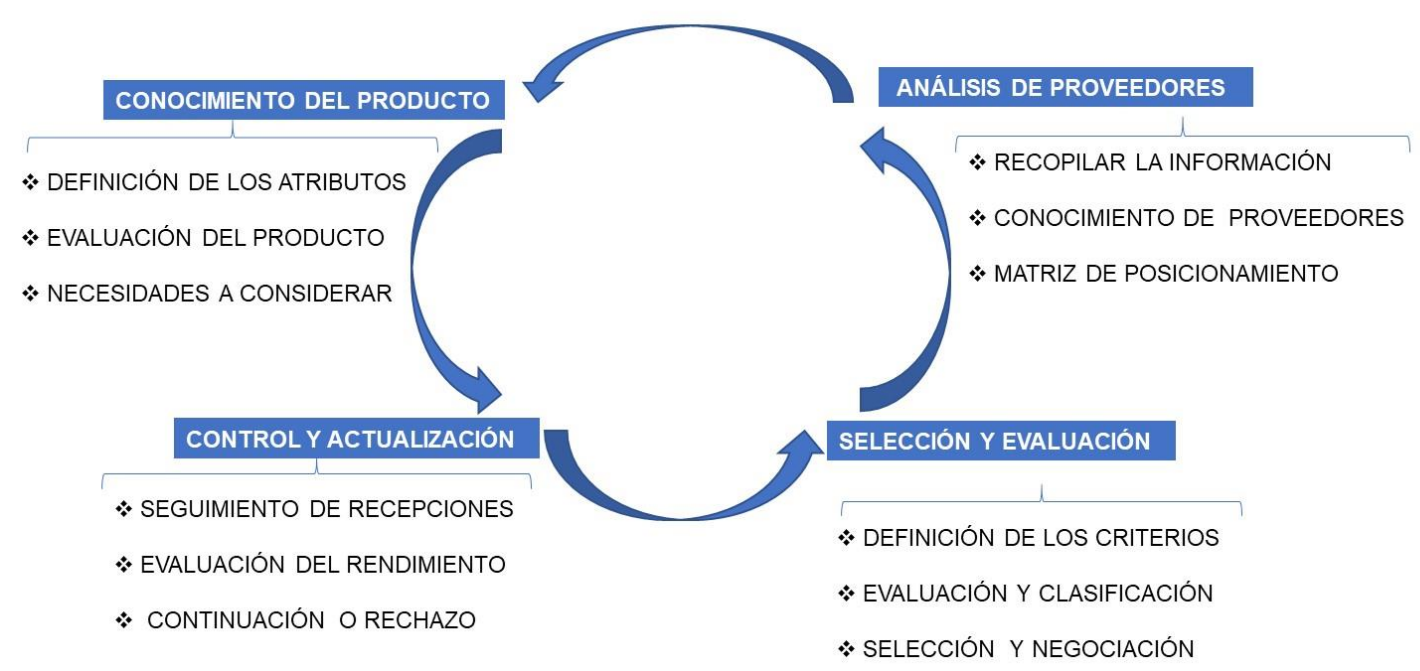

Fuente: Gestión de proveedores: relaciones, proceso, análisis, selección y evaluaciones 4444 (2014) Elaboración propia

Como se vio en la figura 5.1, sobre procesos de compras para el almacenamiento, uso, conservación y preparación de alimentos, se tendrá en cuenta y de manera muy estricta, las condiciones de sanidad e inocuidad de acuerdo con las normas de HACCP, 
así como las políticas de calidad de cada alimento y las normas de Senasa, Digesa y Mincetur.

El stock que se va a considerar, luego del primer año de operación, estará acorde a la rotación de los insumos y a su vigencia de caducidad, entre otros atributos. Con ello, para el primer año, se trabajará con un día de producción para preparar los platos del día que serán máximo para 2 semanas (stock mínimo). Se priorizará el método Just in Time, para todas las compras, asegurando que se trate siempre de un producto fresco.

\subsubsection{Tercerización o integración de procesos.}

La tercerización se realizará para el cultivo orgánico, dando un espacio para un show room en donde se cultiven los vegetales empleando la agricultura en ambiente controlado (vertical farming), de modo que muchos de los principales insumos se produzcan en la misma instalación del restaurante. La contabilidad, los temas y la seguridad igualmente serán tercerizados.

Los servicios de monitorización para dar a conocer el Plato Saludable según la Escuela de Salud Pública de la Universidad de Harvard, así como recomendaciones y sugerencias se realizarán a través de la tercerización con una empresa audiovisual de marketing para que pueda, a través de los monitores pasar una pauta publicitaria de 30 segundos, y así rentabilizar sus operaciones. Las pautas serían sobre los propios insumos que se utilizan en el restaurante, con indicaciones acerca de dónde se les puede comprar o comprar algunos en el propio restaurant.

\subsubsection{Implementación de las actividades por fases. Cadena de valor}

Las fases para implementar el restaurante son:
a) Preparación e instalación de la cocina, equipos.
b) Preparación de las recetas para su estandarización.
c) Preparación de los ambientes del restaurante, ventilación, diseño del interior, seguridad exterior e interior.
d) Acondicionar los espacios de recreación y cultivo orgánico. 
e) Instalar los software y hardware para un sistema de gestión del restaurante.

f) Comprar los insumos para la puesta en marcha.

g) Plan de Recursos Humanos.

h) Plan de marketing.

- Cadena de valor

En la figura 5.10 se muestra la cadena de valor. Se espera que con la cadena de valor la empresa genere márgenes acorde a las expectativas de sus accionistas.

Figura 5.10

Cadena de valor del restaurante

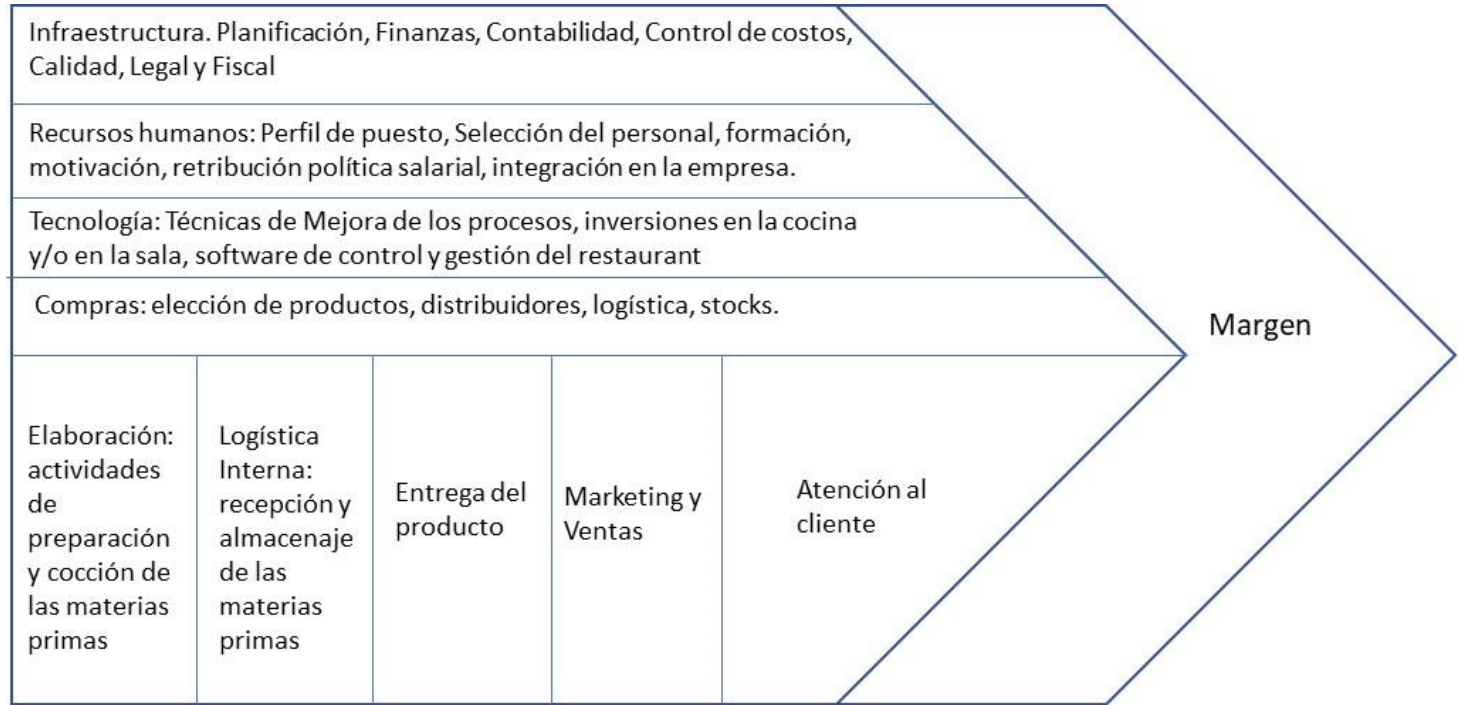

Elaboración propia.

\subsubsection{Proceso de elaboración de bienes y/o prestación de servicio.}

En el diagrama de elaboración de recetas, en la Figura 5.2, se explica cuál es el proceso de elaboración. Se indican las recetas a preparar. Ver tabla 5.1. 


\section{Tabla 5.1}

Recetas y preparación de platos.

\begin{tabular}{|c|c|}
\hline Plato 1 & Pechuga de pollo con crema de verduras y frutos secos. \\
\hline Ingredientes & $\begin{array}{l}\text { Pechuga de pollo } \\
\text { Apio } \\
\text { Zanahoria } \\
\text { Poro } \\
\text { pasas } \\
\text { Pastilla de caldo concentrado de verduras } \\
\text { Aceite virgen extra } \\
\text { Pimientos } \\
\text { Comino }\end{array}$ \\
\hline Preparación & $\begin{array}{l}\text { En una olla con agua y una pastilla de caldo concentrado, cocemos un puñado de } \\
\text { pasas durante un par de minutos, escurrimos y guardamos el caldo. } \\
\text { Lavamos, pelamos y cortamos el poro, el apio, la zanahoria } \\
\text { Lavamos y limpiamos de pieles y de grasa las pechugas de pollo. } \\
\text { En la olla echamos las verduras que hemos troceado, las pechugas de pollo, el } \\
\text { caldo de haber cocido los frutos secos, un vaso de agua y un chorrito de aceite de } \\
\text { oliva y las cocemos durante unos } 10 / 12 \text { minutos. } \\
\text { Sacamos las pechugas en un plato y trituramos las verduras con la batidora. } \\
\text { En una Tabla de cocina cortamos las pechugas a rodajas y colocamos en cada } \\
\text { plato una, le ponemos unas pasas y un poco de pimientos. } \\
\text { En un bol aparte echamos la crema de verduras }\end{array}$ \\
\hline Plato 2 & $\begin{array}{l}\text { Pechugas de pollo a la plancha, ligeramente empanadas con arroz integral o } \\
\text { blanco y ensalada fresca. }\end{array}$ \\
\hline Ingredientes & $\begin{array}{l}\text { Pechuga de pollo } \\
\text { Aceite de oliva } \\
\text { Sal } \\
\text { Pimienta } \\
\text { Pan rallado } \\
\text { Ajo } \\
\text { Perejil } \\
\text { Arroz blanco o integral } \\
\text { Lechuga } \\
\text { Limón }\end{array}$ \\
\hline Preparación & $\begin{array}{l}\text { Sal y pimienta al gusto a las pechugas, pasarlas por pan rallado, sacudir el exceso } \\
\text { Poner en una sartén amplía un poco de aceite de oliva, dejar que se caliente bien, } \\
\text { dorar las pechugas por ambos lados, casi vuelta y vuelta. } \\
\text { Preparar el arroz, lavar, realizar un aderezo de ajos y poner a cocción, con agua } \\
\text { por encima de un } 1 \mathrm{~cm} \text {. de la cantidad de arroz a preparar. } \\
\text { Preparar la lechuga, lavar y cortar en tiras, sazonar con sal y limón. }\end{array}$ \\
\hline Plato 3 & Pechuga de pollo con champiñones y salsa de queso y espinacas \\
\hline Ingredientes & $\begin{array}{l}\text { Tomate } \\
\text { Pechuga de pollo } \\
\text { Espinacas orgánicas frescas } \\
\text { Champiñones enteros } \\
\text { Queso mozzarella } \\
\text { Queso cremoso light } \\
\text { Papa }\end{array}$ \\
\hline
\end{tabular}




\begin{tabular}{|c|c|}
\hline \multirow{15}{*}{ Preparación } & Aceite de oliva extra \\
\hline & Sal \\
\hline & Pimienta \\
\hline & Cortar la pechuga en láminas. \\
\hline & $\begin{array}{l}\text { Corta los champiñones en láminas finas. Lavar con un poco de agua y vinagre el } \\
\text { tomate. }\end{array}$ \\
\hline & En una sartén mediana, se pone a calentar un vaso de agua y agrega los \\
\hline & champiñones. Tapa y cocina hasta que estén blanditas. Una vez listas, sal y \\
\hline & pimienta y reduce el líquido sin la tapa. \\
\hline & En una sartén colocar aceite de oliva y freír los pollos por ambos lados y luego \\
\hline & echar los champiñones. \\
\hline & Lavar las espinacas y cortar en tiras \\
\hline & Lavar las papas, pelar y cocer. \\
\hline & Cortar las papas cocidas en rodajas. \\
\hline & En una sartén derretir los quesos. \\
\hline & $\begin{array}{l}\text { Servir, sobre las papas, pechuga de pollo y champiñones echar el queso derretido, } \\
\text { acompañar con las espinacas en tiras y tomate en rodaja. }\end{array}$ \\
\hline Plato 4 & Pechuga de pollo rellena de espinacas con papas doradas \\
\hline \multirow[t]{10}{*}{ Ingredientes } & Pechugas de Pollo \\
\hline & Espinaca orgánica \\
\hline & Queso Philadelfia light \\
\hline & Sal \\
\hline & Pimienta \\
\hline & Papa \\
\hline & Aceite de oliva \\
\hline & Pan molido \\
\hline & Huevo \\
\hline & Harina preparada \\
\hline \multirow[t]{9}{*}{ Preparación } & Cortar el pollo en fina lamina \\
\hline & Lavar la espinaca y cortar en tiras \\
\hline & Sazonar el pollo con sal y pimienta y rellenar con las espinacas. \\
\hline & Pasar por harina, huevo batido y pan molido \\
\hline & Freír el pollo, para sellarlo. \\
\hline & Colocar el queso en el pollo. \\
\hline & Lavar las papas, pelar y cortar en rodajas \\
\hline & Llevar al horno con el pollo relleno y las papas, con una pizca de aceite a $250^{\circ} \mathrm{c}$. \\
\hline & Retirar a los 20 min. de cocción. \\
\hline Plato 5 & Quinua revuelta de verduras y pollo, con arroz. \\
\hline \multirow[t]{12}{*}{ Ingredientes } & Pechuga de pollo \\
\hline & Brócoli \\
\hline & Apio \\
\hline & Poro \\
\hline & Cebolla \\
\hline & Ajo \\
\hline & Quinua \\
\hline & Sal \\
\hline & Pimienta \\
\hline & Aceite de oliva \\
\hline & Nuez moscada \\
\hline & Arroz \\
\hline \multirow[t]{2}{*}{ Preparación } & Cortar el pollo en trozos \\
\hline & Lavar y cortar en trozo el brócoli, apio, poro \\
\hline
\end{tabular}


Lavar y cortar la cebolla, en estilo juliana.

Pelar y cortar en trozo pequeños los ajos

En una olla, echar un poco de aceite de oliva y hacer un aderezo con el ajo y

cebolla, nuez moscada, sofreír el pollo.

Agregar un vaso de agua y echar la quinua

Una vez cocido la quinua, agregar las verduras

Cocer por unos minutos, para evaporar el agua, por unos minutos.

Servir con arroz.

\begin{tabular}{|c|c|}
\hline Plato 6 & Pollo con verduras al horno y papa \\
\hline \multirow[t]{10}{*}{ Ingredientes } & Pechuga de pollo \\
\hline & Brócoli \\
\hline & Cebolla \\
\hline & Ajo \\
\hline & Pimentón \\
\hline & Sal \\
\hline & Pimienta \\
\hline & Comino \\
\hline & Aceite de oliva \\
\hline & Papa \\
\hline \multirow[t]{9}{*}{ Preparación } & Cortar el pollo en lámina \\
\hline & Lavar y cortar en trozo el brócoli \\
\hline & Lavar y cortar la cebolla, en estilo juliana. \\
\hline & Lavar y cortar el pimentón en trozos cuadrado-regulares \\
\hline & Pelar y cortar en trozo pequeños los ajos \\
\hline & Lavar y pelar y cortar la papa en rodaja. \\
\hline & Colocar el pollo sazonado con sal, pimienta y comino en una fuente, agregar las \\
\hline & verduras y papa, con un chorrito de aceite de oliva \\
\hline & Llevar al horno por 20 min. \\
\hline Plato 7 & Pollo enrollado con espárragos y arroz \\
\hline \multirow[t]{13}{*}{ Ingredientes } & Pechuga de pollo \\
\hline & Cebolla \\
\hline & Ajo \\
\hline & Espárrago \\
\hline & Pimento \\
\hline & Sal \\
\hline & Pimienta \\
\hline & Comino \\
\hline & Aceite de oliva \\
\hline & Huevo \\
\hline & Pan molido \\
\hline & Harina preparada \\
\hline & Arroz \\
\hline \multirow[t]{9}{*}{ Preparación } & Cortar el pollo en lámina \\
\hline & Lavar y cortar en trozo el espárrago \\
\hline & Poner a cocción el espárrago y retirar cuando es blando. \\
\hline & Lavar y cortar la cebolla, en estilo cuadraditos \\
\hline & Lavar y cortar el pimentón en trozos cuadrado-regulares \\
\hline & Pelar y cortar en trozo pequeños los ajos \\
\hline & Sazonar el pollo con sal, pimienta y comino, enrollar con espárrago \\
\hline & Empapar con harina, huevo batido y pan molido. En ese orden. \\
\hline & Freír el pollo enrollado. \\
\hline
\end{tabular}




\begin{tabular}{|c|c|}
\hline & $\begin{array}{l}\text { Realizar un aderezo con el esparrago, la cebolla y los ajos. } \\
\text { Servir con arroz. }\end{array}$ \\
\hline Plato 8 & Spaguettis con brócoli y pollo a la plancha con pimienta negra y orégano \\
\hline Ingredientes & $\begin{array}{l}\text { Brócoli } \\
\text { Pechuga de pollo } \\
\text { Spaguettis } \\
\text { Pimienta negra, } \\
\text { Sal } \\
\text { Orégano } \\
\text { Cebolla } \\
\text { Ajo } \\
\text { Aceite de oliva }\end{array}$ \\
\hline Preparación & $\begin{array}{l}\text { Lavar y cortar el brócoli en trozos pequeños. } \\
\text { Se pone a hervir el brócoli y luego añadimos la pasta en el mismo recipiente y } \\
\text { dejamos ambos hirviendo. } \\
\text { Troceamos la pechuga y la hacemos a la plancha con un poco de pimienta negra y } \\
\text { orégano y aceite. } \\
\text { Lavar y cortar en cuadraditos la cebolla y el ajo } \\
\text { Realizar un aderezo en la sartén con la cebolla y el ajo, sal al gusto. } \\
\text { Una vez cocido el spaguetti y el brócoli, se juntan en la sartén donde teníamos el } \\
\text { pollo y el aderezo, revolvemos y dejamos que se hagan un poco más juntos, por } \\
\text { unos minutos y servir. }\end{array}$ \\
\hline Plato 9 & Pollo revuelto con pimento verde y champiñón \\
\hline Ingredientes & $\begin{array}{l}\text { Pechuga de pollo } \\
\text { Pimentón verde } \\
\text { champiñón } \\
\text { Sal } \\
\text { Pimienta } \\
\text { Comino } \\
\text { Cebolla } \\
\text { Ajo } \\
\text { Aceite de oliva }\end{array}$ \\
\hline Preparación & $\begin{array}{l}\text { Lavar y cortar el pimentón en trozos pequeños. } \\
\text { Se pone a hervir el champiñón y el pimentón, cortado en trozos } \\
\text { Troceamos la pechuga y lo sazonamos con sal, pimienta y comino } \\
\text { En una sartén sofreír el pollo } \\
\text { Lavar y cortar en cuadraditos la cebolla y el ajo } \\
\text { Realizar un aderezo en la sartén con la cebolla y el ajo, sal al gusto. } \\
\text { Una vez cocido el champiñón y pimentón se juntan en la sartén donde teníamos el } \\
\text { pollo y el aderezo y revolvemos, dejamos que se hagan un poco más juntos, por } \\
\text { unos minutos y servir }\end{array}$ \\
\hline Plato 10 & Albóndigas de pollo en salsa de espinacas con arroz \\
\hline Ingredientes & $\begin{array}{l}\text { Cebolla } \\
\text { Pechuga de pollo picado } \\
\text { Huevo } \\
\text { Cebolla en polvo } \\
\text { Ajo en polvo } \\
\text { Sal } \\
\text { Harina de avena } \\
\text { Comino } \\
\text { Pimienta }\end{array}$ \\
\hline
\end{tabular}




\begin{tabular}{|c|c|}
\hline & Espinacas \\
\hline & Vinagre \\
\hline & Vaso de agua \\
\hline & Pastilla de caldo de gallina \\
\hline & Azúcar rubia \\
\hline & Queso \\
\hline & Arroz \\
\hline \multirow[t]{10}{*}{ Preparación } & Limpiar y retirar las hojas de espinaca \\
\hline & $\begin{array}{l}\text { Mezclar en un bol la carne, las especias, el huevo, espinacas, la avena, sal y hacer } \\
\text { bolitas }\end{array}$ \\
\hline & Meter al horno $180^{\circ} 25 / 30$ minutos \\
\hline & Salsa \\
\hline & $\begin{array}{l}\text { En una sartén poner un poco de aceite de oliva, espinacas y cebollas picadas a } \\
\text { fuego lento }\end{array}$ \\
\hline & Cuando empiece a dorarse, añadir agua, vinagre y azúcar rubia \\
\hline & Triturar todo lo anterior junto con la leche, el quesito, el caldo y sal \\
\hline & Probar y rectificar si necesita vinagre, sal o edulcorante al gusto. \\
\hline & $\begin{array}{l}\text { Incorporar las albóndigas y dejarlas a fuego lento durante unos } 10 \text { minutos que se } \\
\text { adoren }\end{array}$ \\
\hline & Servir con arroz \\
\hline Plato 11 & Bacalao con verduras al horno con papa \\
\hline \multirow[t]{11}{*}{ Ingredientes } & Bacalao \\
\hline & Pimentón verde \\
\hline & Pimentón rojo \\
\hline & Espárragos \\
\hline & Papa \\
\hline & Cebolla \\
\hline & Sal \\
\hline & Pimienta, \\
\hline & Cerveza \\
\hline & Vino blanco \\
\hline & Arroz \\
\hline \multirow[t]{7}{*}{ Preparación } & Pelar y partir las papas en rodajas, freír y colocar en un recipiente para horno. \\
\hline & Cortar la cebolla y los pimentón verde y rojo en forma de juliana y sofreír en el \\
\hline & aceite de las papas hasta quedar al dente y poner encima de las papas \\
\hline & En la misma sartén sofreír un poco los espárragos y retirar. Por último, poner \\
\hline & pimienta y sellar a fuego fuerte el bacalao empezando por la piel y luego poner \\
\hline & encima de la verdura. \\
\hline & Antes de meter al horno bañar el bacalao y las verduras con cerveza y vino blanco \\
\hline Plato 12 & Ensalada con merluza en trozo para dieta \\
\hline \multirow[t]{8}{*}{ Ingredientes } & Lechuga orgánica \\
\hline & Merluza sin piel \\
\hline & Nueces \\
\hline & Sal \\
\hline & Vinagre de jeréz, \\
\hline & Aceite de oliva virgen extra \\
\hline & Tomate \\
\hline & Pecanas \\
\hline Preparación & Poner en una olla con agua, y cocer la merluza en baño maría \\
\hline
\end{tabular}




\begin{tabular}{|c|c|}
\hline & $\begin{array}{l}\text { Retirar la merluza y colocar en un bol } \\
\text { Trozar la nueces y pecanas } \\
\text { Trozar el tomate en cuadraditos. } \\
\text { Agregar la lechuga, nueces, tomate en el bol con la merluza } \\
\text { Adicionar aceite de oliva y vinagre y sal, al gusto }\end{array}$ \\
\hline Plato 13 & Lenguado con Champiñones \\
\hline Ingredientes & $\begin{array}{l}\text { Lenguado } \\
\text { Tomates } \\
\text { Cebolla } \\
\text { Champiñones } \\
\text { Vino blanco } \\
\text { Sal } \\
\text { Pimienta } \\
\text { Perejil }\end{array}$ \\
\hline Preparación & $\begin{array}{l}\text { Coger el lenguado, limpiar, filetear y colocar en un plato } \\
\text { Condimentar el lenguado con sal y pimienta } \\
\text { Cortar los tomates en cuadraditos. } \\
\text { Cortar la cebolla estilo juliana } \\
\text { Colocar en un recipiente para hornear las cebollas, tomate, perejil y champiñones. } \\
\text { Agregar el vino blanco. } \\
\text { Encima de todas las verduras añadir el pescado y lo meteremos al horno } 130^{\circ} \mathrm{c} \\
\text { durante } 30 \text { minutos. }\end{array}$ \\
\hline Plato 14 & Lomo de res en salsa de champiñones con puré de papa \\
\hline Ingredientes & $\begin{array}{l}\text { Lomo fino } \\
\text { Champiñones } \\
\text { Pimienta } \\
\text { Sal } \\
\text { Comino } \\
\text { Aceite de oliva } \\
\text { Papa amarilla } \\
\text { Queso Parmesano } \\
\text { Cebolla } \\
\text { Ajos } \\
\text { Leche deslactosada } \\
\text { Caldo de carne concentrado. } \\
\text { Mantequilla }\end{array}$ \\
\hline Preparación & $\begin{array}{l}\text { Cortar el lomo en medallones. } \\
\text { Condimentar con sal, pimienta y comino. } \\
\text { En una sartén con un poco de aceite de oliva, sellar el lomo para dejarlo en } \\
\text { término medio. } \\
\text { Lavar, pelar y cortar en cuadraditos la cebolla y ajos pelar y moler. } \\
\text { En otro sartén salteamos los champiñones con cebolla y ajos y un poco de aceite } \\
\text { de oliva, agregamos la pimienta y sal al gusto. } \\
\text { Dejamos a fuego bajo durante } 3 \text { minutos, luego agregamos un poco de queso } \\
\text { parmesano y una cucharada de azúcar rubia. } \\
\text { Para el puré cocinamos la papa amarilla. Aplastamos con un cubierto hasta dejarla } \\
\text { sin grumo. Agregamos un poco de leche, mantequilla y un poco de parmesano y } \\
\text { sal. }\end{array}$ \\
\hline Plato 15 & Lomo de saltado con arroz y papa horneada \\
\hline Ingredientes & $\begin{array}{l}\text { Lomo de res } \\
\text { Sal } \\
\text { Pimienta }\end{array}$ \\
\hline
\end{tabular}




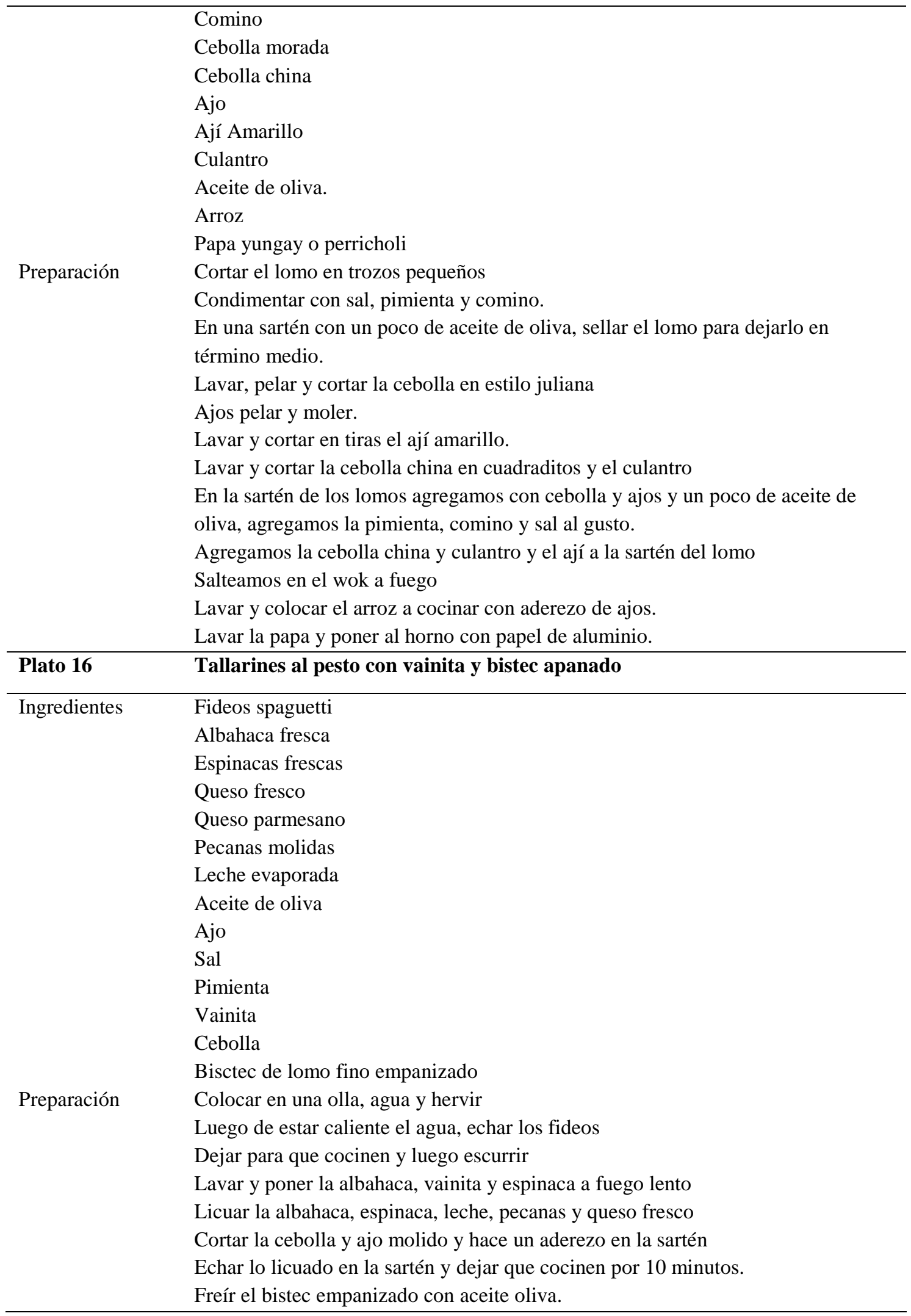

Fuente: Comidas peruanas (2017)

Elaboración propia 


\subsubsection{Políticas de transformación de la actividad.}

En la figura 5.3, vista anteriormente, pudimos apreciar el proceso de transformación del servicio desde el ingreso del cliente que es recibido por la anfitriona y luego atendido por el mozo, que es quien le alcanzará la carta. Posteriormente el mozo tomará el pedido, de acuerdo con la figura 5.1. Una vez preparado el plato, éste será entregado al mozo para que sea llevado al cliente. Posteriormente, el cliente pedirá la cuenta al mozo y éste le entregará la pre cuenta para su chequeo. Si todo está conforme con la pre cuenta, el cliente, procederá al pago de la cuenta.

En la figura 5.10 se resume el proceso del servicio acorde a las buenas prácticas.

Tabla 5.2

Política de transformación de actividad

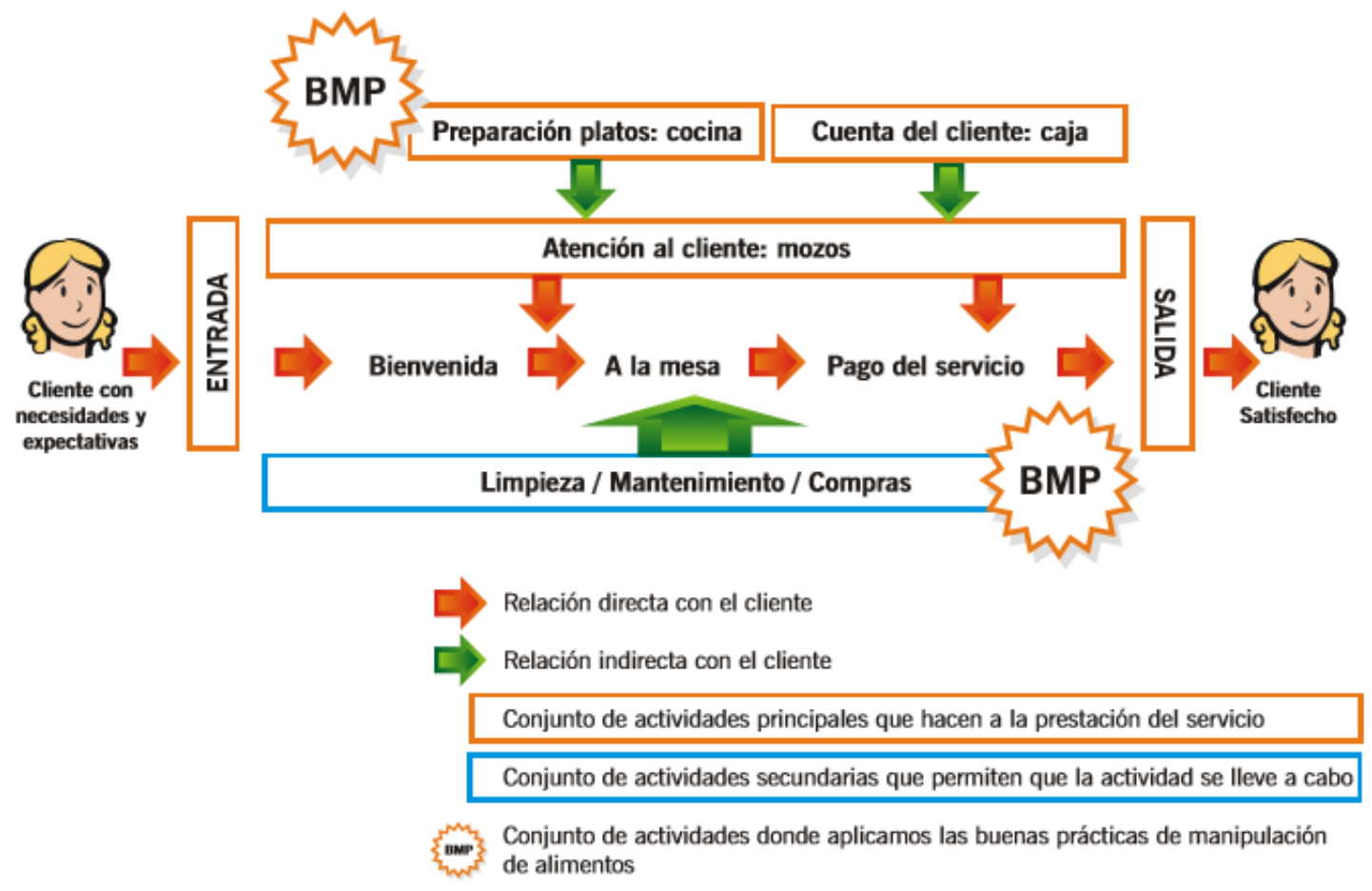

Fuente: Libonati, M.; Bacigalupo, M. J. y Wagner, M. (2006)

En el caso del delivery, el pago se realiza contra entrega del pedido en casa o oficina del cliente. Para ello, a través del sistema de restaurantes previamente descrito se indica la forma de pago, con dinero o con tarjeta, para que según sea el caso se lleve lo 
necesario para dar el vuelto o el POS inalámbrico de VISA, para efectuar el pago con tarjeta.

\subsubsection{Flujograma de la actividad y diagrama de decisiones PERT.}

En el Tabla 5.3 se presentan todas las actividades, con las fases previamente descritas, para implementar el proyecto, con lo cual se realiza el diagrama de PERT el cual se muestra en la figura 5.11.

\section{Tabla 5.3}

Actividades

\begin{tabular}{clc}
\hline Etiqueta & \multicolumn{1}{c}{ Actividad } & Duración \\
\hline 1 & Preparación e instalación de la cocina, equipos & 7 \\
2 & $\begin{array}{l}\text { Coordinar con los proveedores de cocina, acorde a las medidas del área de frio y } \\
\text { caliente }\end{array}$ & 1 \\
3 & Seleccionar y Comprar los equipos y cocina & 3 \\
4 & Instalar los equipos y cocina en el área de cocina & 3 \\
5 & Preparación y elaboración de las recetas, para su estandarización & 10 \\
6 & Elaborar las recetas maestras de cada plato & 8 \\
7 & Elaborar las recetas intermedias & 2 \\
8 & Preparación de los ambientes del restaurant, ventilación, diseño de interior, & 20 \\
9 & seguridad exterior e interior. & \\
10 & Preparar ambiente del restaurant - salón y bufet & 4 \\
11 & Diseño de interior, modelar el áreas & 3 \\
12 & Colocar las redes de seguridad, comunicación y eléctrica & 2 \\
13 & Colocar losetas o mayólicas en el área de cocina & 2 \\
14 & Baños, acondicionar & 3 \\
15 & Colocar la red de monitores - tercerizado & 3 \\
16 & Acondicionar los espacios de recreación y cultivo orgánico. \\
17 & Preparar los espacios para colocar los cultivos orgánicos & 3 \\
18 & Implementarlos con el servicio tercerizado, para el show room & 2 \\
20 & Colocar sillas, alrededor del área de recreación & 15 \\
\hline
\end{tabular}




\begin{tabular}{llc}
\hline 21 & Instalar los juegos de recreación & 3 \\
22 & Instalar los software y hardware, para un sistema de gestión de restaurant & 10 \\
23 & Evaluar los sistemas de gestión de restaurant - proveedor & 3 \\
24 & Comprar el software y hardware & 2 \\
25 & Implementar el software & 5 \\
26 & Comprar los insumos para la puesta en marcha & 7 \\
27 & Selección de proveedores de insumos & 1 \\
28 & Compra de insumos & 6 \\
29 & Recursos Humanos & 30 \\
30 & Contratar a los equipos de trabajo y apoyo & 20 \\
31 & Capacitación & 10 \\
32 & Marketing & 15 \\
33 & Elaborar el plan de marketing & 10 \\
34 & Promoción y publicidad, en medios & 5 \\
35 & Puesta en marcha & \\
\hline
\end{tabular}

Elaboración propia

Figura 5.11

Diagrama PERT - De las actividades de implementación

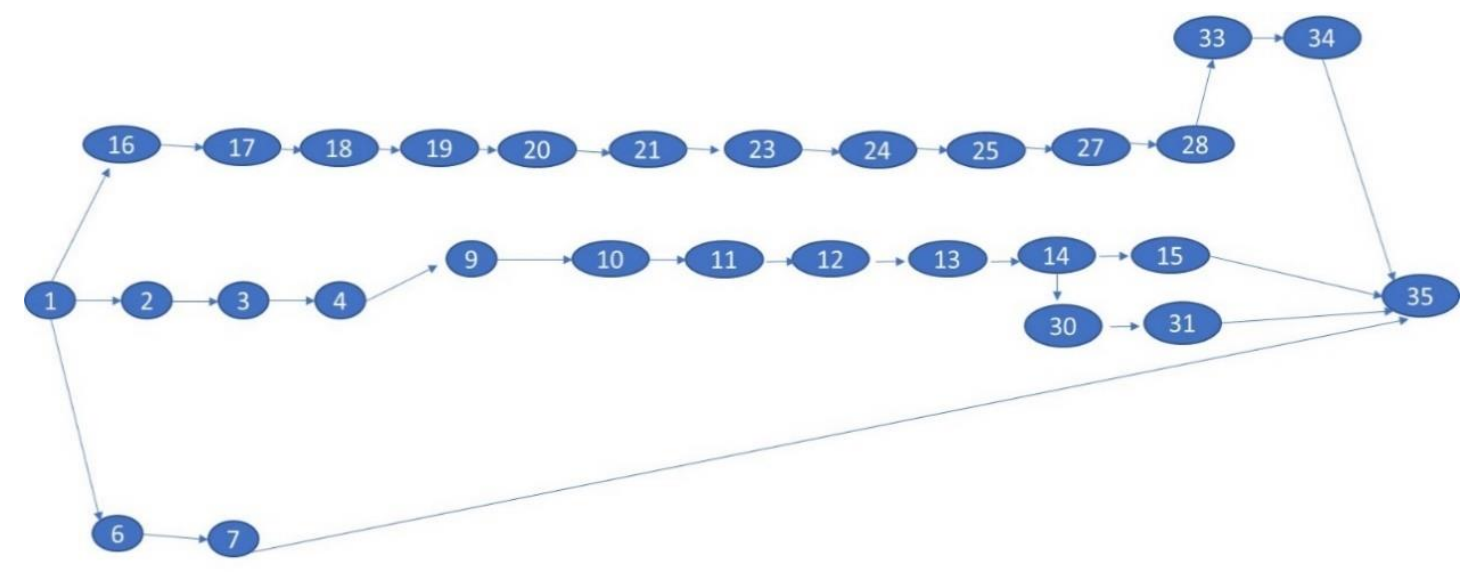

Elaboración propia

El tiempo total de implementación en días es de: 54 días (aprox. 2 meses). Este tiempo de implementación se da debido a que hay actividades en paralelo y que no dependen de otra actividad, reduciéndose el tiempo de implementación (Ver Figura 5.11). 


\subsubsection{Balance scorecard: control de gestión por indicadores}

En la figura 5.12, se presenta el diagrama del Balance Scorecard desde las 4 perspectivas, en las cuales tenemos varios indicadores por cada una de ellas, teniendo como objetivo estratégico ser creativos e innovadores y el ofrecer una experiencia única del cliente.

Figura 5.12

Balance scorecard

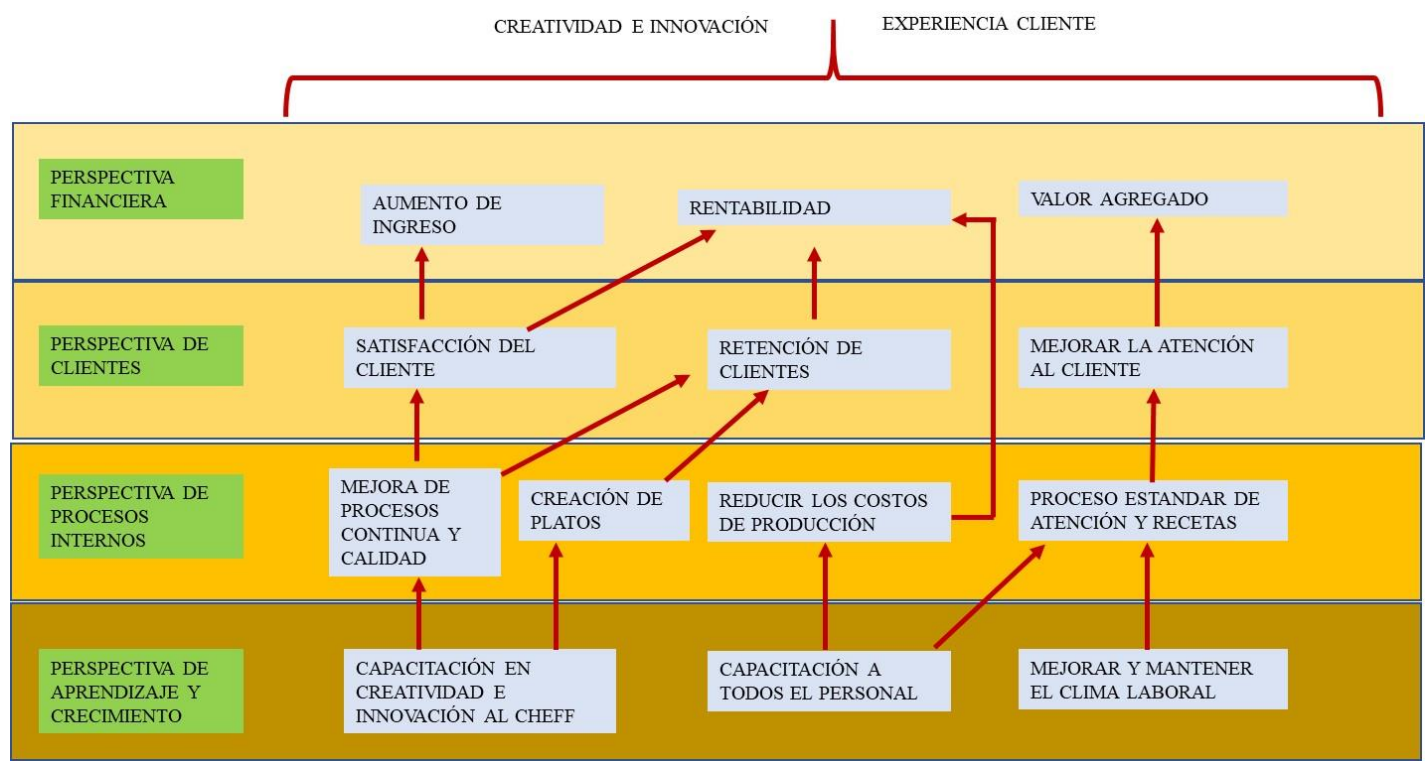

Elaboración propia

En el tabla 5.4, se muestran los indicadores de cada actividad a desarrollar, según las perspectivas financiera, de los clientes, de los procesos internos, así como la de aprendizaje y crecimiento en la gestión del restaurante. 
Tabla 5.4

Indicadores del balance scorecard, para seguimiento

\begin{tabular}{|c|c|c|c|c|c|c|}
\hline & & Rela & ación & & & \\
\hline Perspectiva & Objetivos & Efecto & Causa & Indicador & Periodicidad & Unidad de medida \\
\hline \multirow{3}{*}{ Financiera } & Valor agregado & $\mathrm{x}$ & & EVA & anual & porcentual \\
\hline & Aumento de ingresos & $\mathrm{x}$ & & $\begin{array}{l}\text { Ratio de venta mes Actual / Ventas mes } \\
\text { anterior }\end{array}$ & mensual & porcentual \\
\hline & Rentabilidad & $\mathrm{x}$ & & ROE & anual & porcentual \\
\hline \multirow{3}{*}{ Del Cliente } & Satisfacción del cliente & $\mathrm{x}$ & & $\begin{array}{l}\text { Encuesta de satisfación de cliente. ISC }>=8 \text {, } \\
\text { escala de } 1 \text { a } 10\end{array}$ & trimestral & porcentual \\
\hline & Retención de cliente & $x$ & & $\begin{array}{l}\text { Cantidad de cliente recurrente / cantidad de } \\
\text { cliente total }\end{array}$ & mensual & porcentual \\
\hline & Mejorar la atención al cliente & $\mathrm{x}$ & & Encuesta 5 preguntas & diario & porcentual \\
\hline \multirow{5}{*}{ Procesos Internos } & \multirow[b]{2}{*}{ Mejora de procesos continuo } & $\mathrm{x}$ & & $\begin{array}{l}\text { Tiempo de espera del plato }<10 \mathrm{~min} .=\# \\
\text { platos en espera } / \text { \#platos total }\end{array}$ & mensual & porcentual \\
\hline & & $\mathrm{x}$ & & $\begin{array}{l}\text { Tiempo de espera de atención en mesa, }<2 \text { min } \\
=\text { \# mesa atendida en espera } / \text { \# mesas total } \\
\text { atendidas }\end{array}$ & mensual & porcentual \\
\hline & Creación de platos & $\mathrm{x}$ & & $\begin{array}{l}\text { Crear platos nuevos o innovar con otros } \\
\text { ingredientes }>=2\end{array}$ & bimensual & cantidad \\
\hline & $\begin{array}{l}\text { Reducir los costos de } \\
\text { producción }\end{array}$ & $\mathrm{x}$ & & Merma de insumo/ total insumo $<20 \%$ & mensual & porcentual \\
\hline & $\begin{array}{l}\text { proceso estandar de atención y } \\
\text { recetas }\end{array}$ & $\mathrm{x}$ & & \# Quejas por cliente $=$ \# Quejas $/$ total cliente & mensual & porcentual \\
\hline \multirow{3}{*}{$\begin{array}{l}\text { Aprendizajey } \\
\text { crecimiento }\end{array}$} & $\begin{array}{l}\text { capacitacion en creatividad e } \\
\text { innovación al cheff }\end{array}$ & & $\mathrm{x}$ & Hora de capacitación $>=24$ & trimestral & horas \\
\hline & capacitación a todo el personal & & $\mathrm{x}$ & $\begin{array}{l}\text { Total Aprobado / Total llevado el curso } \\
>=90 \%\end{array}$ & trimestral & porcentual \\
\hline & $\begin{array}{l}\text { Mejorar y mantener el clima } \\
\text { laboral }\end{array}$ & & $\mathrm{x}$ & \# actividades de integración $>=1$ & cuatrimestral & cantidad \\
\hline
\end{tabular}

Elaboración propia 


\section{CAPÍTULO VI: ESTRUCTURA ORGANIZACIONAL Y RECURSOS HUMANOS}

\subsection{Objetivos Organizacionales}

- Mantener un adecuado clima laboral.

- Fomentar y facilitar la comunicación e interacción entre los colaboradores de la empresa.

- Desarrollo personal y profesional.

\subsubsection{Naturaleza de la organización.}

Nuestra organización, forma parte del sector básico secundario de los alimentos y que por su tamaño, número de empleados, patrimonio y activos se considera una PYME.

La empresa tiene como propósito servir a sus clientes con fines de lucro. Según el producto que comercializa es considerado como un servicio; por su alcance territorial es local; por el origen de su capital es privado, y se conforma como una sociedad jurídica del tipo SAC (Sociedad Anónima Cerrada), con personería jurídica para la empresa a crear.

\subsubsection{Organigrama}

En la figura 6.1 se tiene el organigrama de la empresa, siendo una estructura funcional, en donde cada uno se especializa en la actividad que realiza. Para atender tanto en el salón del restaurant como por delivery y gestionar todos los puntos de contacto con el cliente. 
Figura 6.1

Organigrama

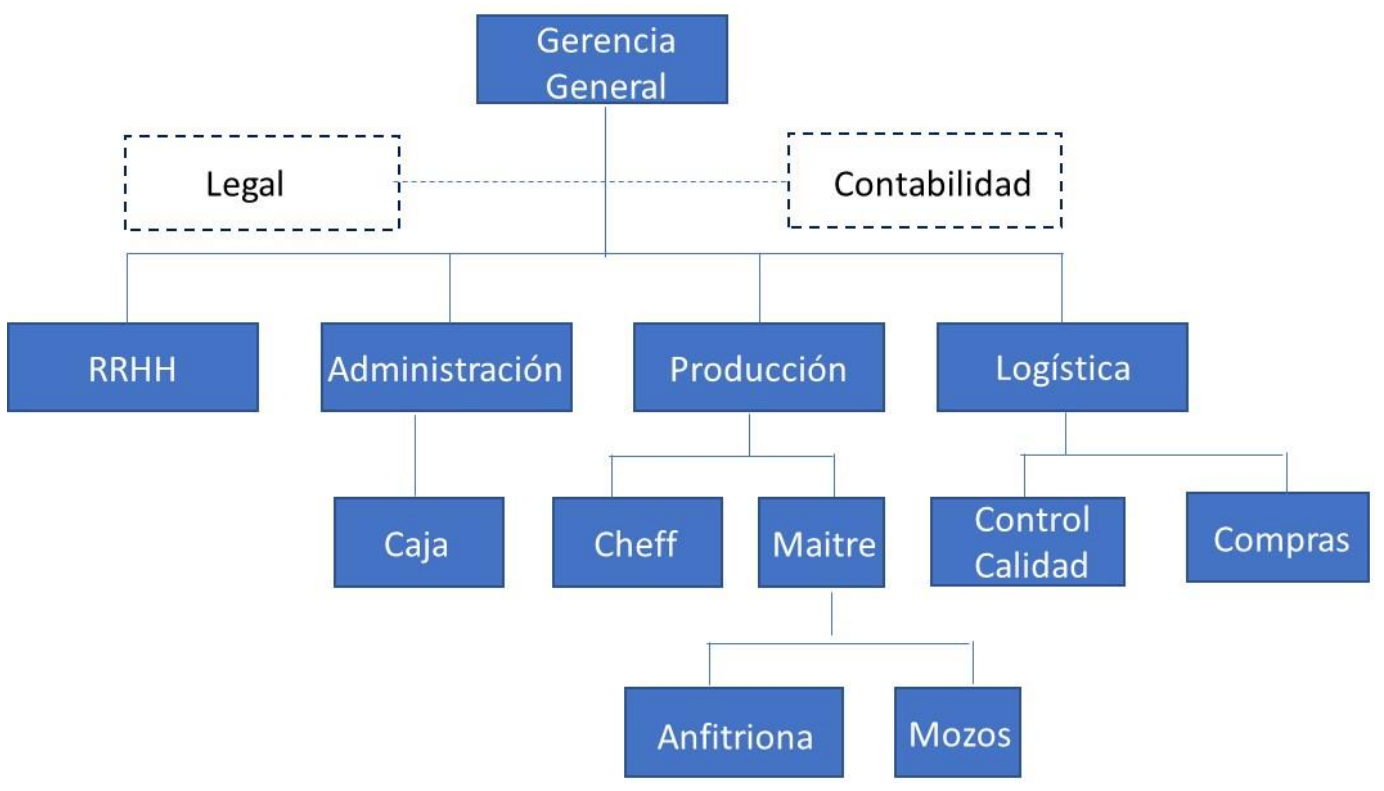

Elaboración propia

\subsubsection{Diseño estructural por proyectos.}

En la Figura 6.1 se tiene el diseño de una estructura matricial equilibrada, la cual, de entre todos los gerentes, se escoge al director del proyecto.

De acuerdo con las líneas punteadas de la gráfica 6.1 se asigna a un personal de cada área para formar el equipo de proyectos liderado por el director de proyecto.

\subsection{Diseño de Puestos y Responsabilidades.}

Gerente General

- Ejecutivo de mayor rango en la empresa.

- Responsable de alcanzar objetivos y supervisar a sus subalternos.

- $\quad$ Su gestión se mide por resultados.

Gerencia de Producción

- Responsable de alcanzar objetivos de producción.

- Responsable de estandarizar todos los procesos. 


\section{Chef}

- Responsable de actividades productivas, incluyendo la provisión de abastecimiento y la elaboración de las recetas.

- $\quad$ RRHH

- Responsable de la contratación del personal.

- Responsable de llevar la planilla.

- Responsable de la capacitación del personal.

Jefe de Logística

- Responsable de las compras y del control de calidad.

Ayudante de Producción (ayudante de cocina)

- Responsable de ayudar al cheff en la elaboración de las recetas.

Anfitriona.

- Responsable de la recepción y bienvenida a los clientes.

Administración

- Responsable de la administración del restaurante.

Maitré

- Responsable del salón y de la atención a los comensales.

Mozos

- Responsables de la atención al cliente.

Motociclista de delivery

- Responsables de la entrega de los pedidos a domicilio u oficina de los clientes.

Ver en Anexo las competencias y los perfiles de cada puesto. 


\subsection{Políticas Organizacionales}

Proveedores: Buscamos y analizamos proveedores que cumplan con los estándares de calidad; para nosotros, es de suma importancia la relación cliente - proveedor ya que sin ellos no podríamos satisfacer a nuestros clientes.

Precio: los precios son establecidos mediante un análisis de mercado, para ser competitivos dentro del mismo, ya que nuestros precios varían de acuerdo con el plato saludable a brindar, para lo cual tenemos una carta variada desde ensaladas hasta platos de fondo.

Política de ventas: Satisfacer las necesidades de nuestros clientes, con precio, calidad y servicio.

Política de servicio: Alcanzar un servicio rápido y eficiente, siempre cuidando los procesos. Ofrecer una carta variada en opciones.

Política de calidad: Control de calidad de los alimentos, manipulación de los mismos. Higiene y limpieza en todas las áreas, equipos y alimentos.

\subsection{Gestión del Talento}

\subsubsection{Selección y contratación.}

El éxito de la estrategia del plan de negocios está garantizada, en gran parte, por una correcta selección del personal. Los socios, en un inicio, se encargarán de seleccionar al personal de los puestos claves; luego, a medida que se genere rotación de personal, la responsabilidad recaerá en el área de recursos humanos. Y en sus jefes directos.

Las fases de la selección son las siguientes:

- Requerimiento de personal.

- Revisión de documentos solicitados.

- Pruebas psicométricas y psicológicas.

- Entrevista personal.

- Entrevista final.

- De pasar todas las fases, se seleccionará al mejor. 


\subsubsection{Remuneración y desempeño.}

La política de compensación está directamente vinculada con el tipo de trabajo que realiza el colaborador, tratándose en todos los casos de una remuneración fija. La empresa, a lo largo de los 5 años previstos, por su facturación y número de trabajadores, estará adscrita al régimen general.

Dentro del régimen general, los trabajadores gozarán de 1 día de descanso semanal, 30 días de vacaciones remuneradas, acceso a la seguridad social y pensionario.

Tomando como base la oferta laboral expuesta en la página web de trabajo www.bumeran.pe al 20.10.17 (Ver tabla 6.1) que coincide con los perfiles y competencias de los puestos, se han previsto, para todos los casos, sueldos promedio de mercado. A partir del año 3, de acuerdo con el desempeño, se plantean incrementos salariales para todos los puestos.

Tabla 6.1

Comparación de sueldo en Bumerán el 20/10/2017

\begin{tabular}{cccc}
\hline Puestos & Mínimo & Máximo & Sueldo Propuesto \\
Gerencia General & 4500 & 7000 & S/ 6,000 \\
Jefe RRHH & 2500 & 3500 & S/ 3,000 \\
Jefe Administrativo & 2500 & 3500 & S/ 3,000 \\
Jefe Producción & 2500 & 3500 & S/ 3,000 \\
Jefe Logística & 2500 & 3500 & S/ 3,000 \\
Chef(a) & 1500 & 3000 & S/ 2,200 \\
Ayudante de cocina & 850 & 850 & S/ 850 \\
Anfitriona & 850 & 850 & S/ 850 \\
Cajera & 850 & 850 & S/ 850 \\
Maitre & 850 & 1500 & S/ 1,200 \\
Mozos & 850 & 1000 & S/ 850 \\
Motociclista para delivery & 1000 & 1200 & S/ 1200 \\
Analista Control calidad & 850 & 1200 & S/ 1,000 \\
Analista de compras & 850 & 1200 & S/ 1,000 \\
Mantenimiento - Limpieza & 850 & 850 & S/ 850 \\
\hline
\end{tabular}

Fuente: Bumerán (2017)

Elaboración propia 


\subsubsection{Empowerment y reconocimiento.}

Reconocer al empleado del mes por su servicio, carisma, colaboración y compromiso.

Delegar las funciones haciendo que todos sean multifuncionales, es decir que se puedan desenvolver en cualquier puesto y que lo hagan bien. Lo anterior es importante en caso alguien falte o pida permiso para ausentarse.

\subsubsection{Capacitación, motivación y desarrollo}

El proceso de capacitación del potencial humano busca que el personal de la empresa desarrolle sus competencias profesionales en el corto y mediano plazo, propiciando que el personal de mayor jerarquía y experiencia laboral induzca y guie al personal a su cargo, con el fin de mejorar constantemente las labores y procesos del negocio.

- Diagnóstico de necesidades. Se analizan los puestos. Se procede a la revisión de las especificaciones de los perfiles y competencias. Se compara lo esperado con lo realizado. Gracias a ello, se establece que puesto cuenta con necesidades de capacitación para su correcto desenvolvimiento y según los recursos disponibles, se establece el orden y prioridades para la capacitación.

- Se capacitará atendiendo considerando la vida laboral de los empleados con mayor incidencia al inicio de la relación laboral, mediante inducciones. En cuanto a herramientas para identificar información sobre necesidades de capacitación, se recurre a la observación y entrevistas personales.

- Diseño de la capacitación. El diseño de la capacitación se centra en la identificación de necesidades del puesto y en los objetivos perseguidos.

- Implementación de la capacitación. Los capacitadores son internos o externos a los que se les asigna tal tarea de acuerdo con sus conocimientos y experiencia dada la ventaja al conocer la idiosincrasia de la empresa y las propias necesidades, generándose un compromiso entre los capacitadores y los capacitados.

- La capacitación se produce en el mismo centro de trabajo siendo participativa, práctica y específica. Como método de capacitación, dada la interacción directa entre el capacitador y capacitado, mayoritariamente se opta por ser práctica y con 
ejemplos, acorde al puesto. Las capacitaciones se hacen dentro del horario de trabajo.

- Evaluación de la capacitación. La evaluación es necesaria en cuanto nos permite tener un indicador de referencia y saber cuáles son los puntos de mejora, para el refuerzo.

\subsection{Estructura de Gastos de RRHH.}

La estructura de gastos de RRHH es como sigue: (ver tabla 6.2).

Tabla 6.2

Estructura del pago de planilla

Mes con Gratificación

Sueldo Básico

1 Gerente General

8,000

2 Jefe de Administración

4,500

3 Jefe de RRHH

4,000

4 Jefe de Producción Ing Alimentario

4,500

5 Jefe de Logística

4,500

6 Analista de RRHH

2,500

7 Analista de Caja

2,000

8 Cheff

4,000

9 Maitre

2,500

10 Analista de control de calidad

2,500

11 Analista de compras

2,500

12 Anfitrionas

1,500

13 Mozos

1,500

14 Motociclista

1200

15 Ayudante de cocina

1,500

16 Barman

1,500

Elaboración propia 
Se tiene todo el personal directo bajo el régimen general, con un costo laboral de aproximadamente un $56 \%$.

Se contempla realizar un aumento del sueldo del 3\% a partir del tercer año, tal como se aprecia en la tabla 6.3, en razón a la tasa de inflación dada por el BCR.

Tabla 6.3

Presupuesto de pago de planilla

\begin{tabular}{|c|c|c|c|c|c|}
\hline Personal Propio & Año 1 & Año 2 & Año 3 & Año 4 & Año 5 \\
\hline Costo de ventas & 932,542 & 960,518 & 989,334 & $1,019,014$ & $1,049,584$ \\
\hline Sueldos & 681,240 & 701,677 & 722,728 & 744,409 & 766,742 \\
\hline Gratificaciones & 113,540 & 116,946 & 120,455 & 124,068 & 127,790 \\
\hline ESSALUD & 71,530 & 73,676 & 75,886 & 78,163 & 80,508 \\
\hline CTS & 66,232 & 68,219 & 70,265 & 72,373 & 74,544 \\
\hline Gasto Administrativos & 252,149 & 259,714 & 267,505 & 275,530 & 283,796 \\
\hline Sueldos & 184,200 & 189,726 & 195,418 & 201,280 & 207,319 \\
\hline Gratificaciones & 30,700 & 31,621 & 32,570 & 33,547 & 34,553 \\
\hline ESSALUD & 19,341 & 19,921 & 20,519 & 21,134 & 21,768 \\
\hline CTS & 17,908 & 18,446 & 18,999 & 19,569 & 20,156 \\
\hline Gasto de Ventas & 119,586 & 123,174 & 126,869 & 130,675 & 134,595 \\
\hline Sueldos & 87,360 & 89,981 & 92,680 & 95,461 & 98,324 \\
\hline Gratificaciones & 14,560 & 14,997 & 15,447 & 15,910 & 16,387 \\
\hline ESSALUD & 9,173 & 9,448 & 9,731 & 10,023 & 10,324 \\
\hline CTS & 8,493 & 8,748 & 9,011 & 9,281 & 9,559 \\
\hline Total gasto de personal & $1,304,277$ & $1,343,406$ & $1,383,708$ & $1,425,219$ & $1,467,976$ \\
\hline
\end{tabular}




\section{CAPÍTULO VII: PLAN ECONÓMICO - FINANCIERO}

\subsection{Supuestos}

- Incrementos de los costos de insumos acorde a la inflación anualizada. 3\% anual al cierre del 2018.

- Incremento de los sueldos considerando la inflación anualizada, en un 3\%.

- $\quad$ Tipo de cambio en 3.30 soles por dólar estadounidense.

- Incremento de los ingresos acorde al PBI esperado, empezando en 3\% al 2 do. año y llegando al 4.5\%, según el BCR, al 4to. año en donde se estabiliza.

- Se considera 5 años de vida útil para los activos fijos y el cálculo de la depreciación.

- Se considera 5 años de evaluación financiera por la renovación de los activos fijos al 5to año en un restaurant.

- Se considera un $0.04 \%$ para el Sampling (comida de muestra y degustación) de los platos.

- Se considera una merma de $10 \%$ de los platos.

- Se consideran 4 platos principales, para calcular el costo promedio ponderado por elaboración de platos más los insumos por bebidas.

- $\quad$ Los costos de marketing, se consideran a valor de mercado.

- Los gastos operativos, se consideran a valor de mercado.

- $\quad$ Los gastos diversos, se consideran a valor de mercado.

- Al ser un restaurante se considera un Just in Time para la mayoría de los productos frescos y 15 días para los productos no perecibles en el día. Esto se considera en el capital de trabajo. Es decir, todos los pagos se realizan dentro del mismo mes de operación.

- Se consideran a los gastos e ingresos sin IGV.

- El alquiler del local comercial es de acuerdo al valor de mercado. 
- Se considera que el ticket promedio de pago por persona es S/. 40.5 con IGV (que es el promedio de pago según la encuesta de la pregunta 4.10 que establece un rango que están más dispuestos a pagar el cliente.)

- Considerando 4 platos con diferentes tipos de carne, sea establecido un costo promedio ponderado por plato de S/.21.5 con IGV de acuerdo con nuestro esperado y preferencias del cliente según la encuesta pregunta 4.8).

- Para el presente análisis financiero el IGV se toma aparte, ingresando a los estados financieros solo la partes sin IGV. Mostrando en otro ítem el escudo fiscal de haber por la compra y venta de productos y servicios.

\subsection{Plan de Inversiones.}

Se tiene el siguiente plan de inversiones en:

- $\quad$ Intangibles. Ver tabla 7.1 
Tabla 7.1

Inversión en intangibles

$\begin{array}{llll}\text { Intangibles } & \text { Valor de venta } & \text { IGV } & \text { Precio de venta }\end{array}$

Software operativo

9,788

1,762

11,550

Desarrollo plataforma web

1,271

229

1,500

Constitución de la empresa:

Notaría y registros públicos

1,846

332

2,178

Gastos Municipales e Digesa

1,741

313

2,054

Registrales y placas

847

153

1,000

Gastos pre-operativos

Total

15,494

0

18,283

Elaboración propia

- $\quad$ Maquinaria y equipos. Ver tabla 7.2 
Tabla 7.2

Inversión en máquinas y equipos

\begin{tabular}{|c|c|c|c|}
\hline Maquinas y Equipos & Valor de venta & IGV & Precio de venta \\
\hline Licuadora & 1,186 & 214 & 1,400 \\
\hline Refrigeradora & 15,254 & 2,746 & 18,000 \\
\hline Microondas & 1,356 & 244 & 1,600 \\
\hline Caldera $2000 \mathrm{lt}$ & 13,983 & 2,517 & 16,500 \\
\hline Cocina industrial completa & 16,949 & 3,051 & 20,000 \\
\hline Exprimidor mecánico & 21 & 4 & 25 \\
\hline Set de ollas & 4,068 & 732 & 4,800 \\
\hline Juego de fuentes de vidrio & 839 & 151 & 990 \\
\hline Sala Bar & 16,949 & 3,051 & 20,000 \\
\hline $\begin{array}{l}\text { Juego de cucharas y } \\
\text { tenedores }\end{array}$ & 4,576 & 824 & 5,400 \\
\hline Tabla de picar & 85 & 15 & 100 \\
\hline Set de cuchillos & 1,271 & 229 & 1,500 \\
\hline Bowls & 847 & 153 & 1,000 \\
\hline $\begin{array}{l}\text { Set porta cubiertos y } \\
\text { escurridor }\end{array}$ & 508 & 92 & 600 \\
\hline Set de secadores & 169 & 31 & 200 \\
\hline Jarras & 5,085 & 915 & 6,000 \\
\hline Juego de Colador & 85 & 15 & 100 \\
\hline Monitores con RAP pedestal & 21,186 & 3,814 & 25,000 \\
\hline Laptops & 6,356 & 1,144 & 7,500 \\
\hline Tablets & 3,719 & 670 & 4,389 \\
\hline Celulares & 169 & 31 & 200 \\
\hline Impresora & 254 & 46 & 300 \\
\hline Cámara de video seguridad & 1,695 & 305 & 2,000 \\
\hline $\begin{array}{l}\text { Detector de humo } \\
\text { inalámbrico }\end{array}$ & 51 & 9 & 60 \\
\hline Extintor PQS $6 \mathrm{~kg}$ & 297 & 53 & 350 \\
\hline Total & 116,961 & 21,053 & 138,014 \\
\hline
\end{tabular}

Elaboración propia. 
- $\quad$ Muebles y enseres. Ver tabla 7.3

Tabla 7.3

Muebles y enseres

\begin{tabular}{lccc} 
Muebles y enseres & Valor de venta & IGV & Precio de venta \\
\hline Escritorio & 763 & 137 & 900 \\
Silla Giratoria & 381 & 69 & 450 \\
sillas de visita & 407 & 73 & 480 \\
Mesas de salón & 3,390 & 610 & 4,000 \\
Mesa de Buffet & 2,712 & 488 & 3,200 \\
Sillas de salón & 5,424 & 976 & 6,400 \\
Sillas de Buffet & 4,339 & 781 & 5,120 \\
Banca Madera y base acero & 1,017 & 183 & 1,200 \\
Archivador & 169 & 31 & 200 \\
Estantes & 1,695 & 305 & 2,000 \\
Canastillas para tubérculos & 2,542 & 458 & 3,000 \\
Sillas de plástico & 102 & 18 & 120 \\
Mesa de cocina & 76 & 14 & 90 \\
Total & 23,017 & 4,143 & 27,160 \\
\hline
\end{tabular}

Elaboración propia

Tabla 7.4

Inversión en vehículos

\begin{tabular}{lrrr} 
Vehículos & Valor de venta & \multicolumn{1}{c}{ IGV } & Precio de venta \\
Motocicletas & 8,475 & 1,525 & 10,000 \\
Accesorios de seguridad & 2034 & 366 & 2,400 \\
Instalación GPS & 1035 & 186 & 1,221 \\
Total & 11543 & 2078 & 13,621 \\
\hline
\end{tabular}

Elaboración propia 
- $\quad$ Resumen. Ver tabla 7.5

Tabla 7.5

Resumen de inversiones

\begin{tabular}{lrrr} 
Inversiones & Valor de venta & \multicolumn{1}{c}{ IGV } & Precio de venta \\
Muebles y accesorios & 23,017 & 4,143 & 27,160 \\
Maquinas y Equipos & 116,961 & 21,053 & 138,014 \\
Vehículos & 11,543 & 2,078 & 13,621 \\
Acondicionamiento de & & & \\
local & 84,746 & $15,254.2$ & 100,000 \\
Alquiler $1 * 1$ & 62,304 & 0 & 62,304 \\
Intangibles & 15,494 & 2,789 & 18,283 \\
Capital de Trabajo & 0 & 0 & 150,948 \\
Total Inversiones & 314,065 & 45,317 & 510,330 \\
\hline
\end{tabular}

Elaboración propia

\subsection{Activos y Depreciación}

Se tienen las siguientes tablas:

- Los activos por depreciar. Ver tabla 7.6

Tabla 7.6

Activos fijos a depreciar

\begin{tabular}{lrrrrrr} 
& Total & Total & & & & \\
Activo fijo bruto & Año 0 & \multicolumn{1}{c}{ Año 1 } & Año 2 & \multicolumn{1}{c}{ Año 3 } & Año 4 & Año 5 \\
Muebles & 23,017 & 23,017 & 23,017 & 23,017 & 23,017 & 23,017 \\
Maquinaria y equipo & 116,961 & 116,961 & 116,961 & 116,961 & 116,961 & 116,961 \\
Vehículos & 11,543 & 11,543 & 11,543 & 11,543 & 11,543 & 11,543 \\
Intangibles & 100,240 & 100,240 & 100,240 & 100,240 & 100,240 & 100,240 \\
Total & 251,761 & 251,761 & 251,761 & 251,761 & 251,761 & 251,761 \\
\hline
\end{tabular}

Elaboración propia 
- $\quad$ La depreciación de los activos se muestra en la Tabla 7.7

Tabla 7.7

Depreciación de los activos fijos

\begin{tabular}{l|rrrrrr|}
\hline & Total & Total & & & & \\
Depreciación & Año 0 & Año 1 & Año 2 & Año 3 & Año 4 & Año 5 \\
Muebles & 0 & 4,603 & 4,603 & 4,603 & 4,603 & 4,603 \\
Maquinaria y equipo & 0 & 23,392 & 23,392 & 23,392 & 23,392 & 23,392 \\
Vehículos & 0 & 2,309 & 2,309 & 2,309 & 2,309 & 2,309 \\
Intangibles & 0 & 20,048 & 20,048 & 20,048 & 20,048 & 20,048 \\
Total & 0 & 50,352 & 50,352 & 50,352 & 50,352 & 50,352 \\
\hline
\end{tabular}

Elaboración propia

- Depreciación acumulada. Ver tabla 7.8

Tabla 7.8

Depreciación acumulada

\begin{tabular}{lrrrrrr} 
& Total & Total & & & & \\
Depreciación acumulada & Año 0 & Año 1 & Año 2 & Año 3 & Año 4 & \multicolumn{1}{c}{ Año 5 } \\
\hline Muebles & 0 & 4,603 & 9,207 & 13,810 & 18,414 & 23,017 \\
Maquinaria y equipo & 0 & 23,392 & 46,784 & 70,176 & 93,569 & 116,961 \\
Vehículos & 0 & 2,309 & 4,617 & 6,926 & 9,235 & 11,543 \\
Intangibles & 0 & 20,048 & 40,096 & 60,144 & 80,192 & 100,240 \\
Total & 0 & 50,352 & 100,704 & 151,056 & 201,408 & 251,761
\end{tabular}

Elaboración propia 
- $\quad$ Los activos netos por año. Ver tabla 7.9

Tabla 7.9

Activo fijo neto

\begin{tabular}{lrrrrrr} 
& Total & \multicolumn{1}{c}{ Total } & & & & \\
Activo fijo neto & Año 0 & \multicolumn{1}{c}{ Año 1 } & Año 2 & \multicolumn{1}{c}{ Año 3 } & \multicolumn{1}{c}{ Año 4 } & Año 5 \\
\cline { 3 - 8 } Muebles & 0 & 18,414 & 13,810 & 9,207 & 4,603 & 0 \\
Maquinaria y equipo & 0 & 93,569 & 70,176 & 46,784 & 23,392 & 0 \\
Vehículos & 0 & 9,235 & 6,926 & 4,617 & 2,309 & 0 \\
Intangibles & 0 & 80,192 & 60,144 & 40,096 & 20,048 & 0 \\
Total & 0 & 201,408 & 151,056 & 100,704 & 50,352 & 0 \\
\hline
\end{tabular}

Elaboración propia

\subsection{Capital de Trabajo}

Para el capital de trabajo, se consideró el método del déficit máximo acumulado más la caja mínima para cualquier imprevisto del mes (5000 soles).

Capital de trabajo para 2 semanas de compra $=$ S/. 150,948

\subsection{Fuentes de Financiamiento y Amortización}

La fuente de financiamiento es con recursos propios y con préstamos bancarios, como se muestra en la tabla 7.10

Tabla 7.10

Fuentes de financiamiento

\begin{tabular}{lcc}
\multicolumn{1}{c}{ Fuente } & Monto en soles & $\%$ \\
\hline $\begin{array}{l}\text { Préstamo } \\
\text { Aporte } \\
\text { accionistas }\end{array}$ & 158,584 & $31 \%$ \\
\hline \multicolumn{1}{c}{ Total } & 351,746 & $69 \%$ \\
\hline
\end{tabular}

Elaboración propia 
En la tabla 7.11 se muestran las condiciones del préstamo y en la tabla 7.12, se muestran las amortizaciones y cuotas a pagar. La tasa de interés activa es el promedio esperado para las PYMES según la SBS y que tomamos como referencia.

Tabla 7.11

Condiciones del préstamos bancario

\begin{tabular}{lrc}
\hline Inversion Total & 510,330 & \\
Préstamo \% & $31 \%$ & \\
Préstamo & 158,584 & Soles \\
Costo de la & $20 \%$ & Anual \\
deuda & $1.53 \%$ & Mensual \\
& 5 & Años \\
Periodo & 60 & Meses \\
& 4,059 & \\
Cuota mensual & & \\
\hline
\end{tabular}

Elaboración propia

Tabla 7.12

Amortizaciones e intereses

\begin{tabular}{lrrrrrr}
\multicolumn{1}{c}{ Año } & Año 0 & \multicolumn{1}{c}{ Año 1 } & Año 2 & Año 3 & Año 4 & Año 5 \\
Préstamo & 158,584 & & & & & \\
Saldo & 0 & 137,273 & 111,701 & 81,014 & 44,189 & 0 \\
Amortización & 0 & 21,310 & 25,572 & 30,687 & 36,824 & 44,189 \\
Interés & 0 & 27,399 & 23,137 & 18,022 & 11,885 & 4,520 \\
Cuota & 0 & 48,709 & 48,709 & 48,709 & 48,709 & 48,709 \\
\hline
\end{tabular}

Elaboración propia

\subsection{Balances Previsionales (Balance General)}

En la tabla 7.13 se observa el balance general para los 5 años de vida del proyecto. 
Tabla 7.13

Balance general

\begin{tabular}{lrrrrr} 
& Año 1 & Año 2 & Año 3 & Año 4 & Año 5 \\
\hline Activo & & & & & \\
Caja & 107,578 & 354,656 & 648,891 & $1,043,798$ & $1,735,603$ \\
Cuentas por cobrar & 0 & 0 & 0 & 0 & 0 \\
Inventario & 363,725 & 374,637 & 399,383 & 427,818 & 460,482 \\
Alquiler 1*1 & 62,304 & 62,304 & 62,304 & 62,304 & 62,304 \\
Crédito Fiscal & 0 & - & - & - & - \\
Activo Fijo + Intangible & 251,761 & 251,761 & 251,761 & 251,761 & 251,761 \\
Dep. y Amort. Acum & $-50,352$ & $-100,704$ & $-151,056$ & $-201,408$ & $-251,761$ \\
\hline Total activo & 735,016 & 942,653 & $1,211,282$ & $1,584,272$ & $2,258,390$ \\
\hline Pasivo & & & & & \\
Cuentas por pagar & 201,900 & 207,593 & 219,064 & 232,101 & 246,931 \\
CTS por pagar & 15,439 & 15,902 & 16,379 & 16,870 & 17,377 \\
Gratificaciones por pagar & - & - & - & - & - \\
& & & & & \\
Tributos por pagar & $8,453.99$ & 69,475 & 105,269 & 147,959 & 198,545 \\
Deuda & 137,273 & 111,701 & 81,014 & 44,189 & - \\
\hline Total pasivo & 363,066 & 404,671 & 421,725 & 441,120 & 462,853 \\
\hline Patrimonio neto & & & & & \\
Capital Social & 351,746 & 351,746 & 351,746 & 351,746 & 351,746 \\
Reserva Legal & - & - & - & - & - \\
Utilidades Retenidas & 20,204 & 186,236 & 437,810 & 791,406 & $1,443,790$ \\
\hline Total patrimonio & 371,950 & 537,983 & 789,557 & $1,143,153$ & $1,795,537$ \\
Total pasivo y patrimonio & 735,016 & 942,653 & $1,211,282$ & $1,584,272$ & $2,258,390$ \\
\hline
\end{tabular}

Elaboración propia

\subsection{Cuentas de Explotación Previsionales (GGPP)}

En la tabla 7.14 se observa el estado de resultados de ganancia y pérdidas por los 5 años de vida del proyecto. 
Tabla 7.14

Estado de resultados

\begin{tabular}{|c|c|c|c|c|c|c|}
\hline Estado de resultados & $\begin{array}{c}\text { Año } \\
0\end{array}$ & Año 1 & Año 2 & Año 3 & Año 4 & Año 5 \\
\hline Ingresos netos & 0 & $5,753,711$ & $\begin{array}{r}6,104,106 \\
-\end{array}$ & $6,507,305$ & $6,970,607$ & $7,502,825$ \\
\hline Costo de Ventas & 0 & $-4,845,588$ & $4,982,244$ & $-5,257,535$ & $-5,570,431$ & $5,926,346$ \\
\hline Utilidad Bruta & 0 & 908,123 & $1,121,863$ & $1,249,771$ & $1,400,176$ & $1,576,478$ \\
\hline Gastos administrativos & 0 & $-422,721$ & $-430,285$ & $-438,276$ & $-446,302$ & $-454,568$ \\
\hline Cargas de Personal & 0 & $-252,149$ & $-259,714$ & $-267,505$ & $-275,530$ & $-283,796$ \\
\hline Gastos Operativos & 0 & $-132,801$ & $-132,801$ & $-133,001$ & $-133,001$ & $-133,001$ \\
\hline Gastos Diversos & 0 & $-15,420$ & $-15,420$ & $-15,420$ & $-15,420$ & $-15,420$ \\
\hline Depreciación y & & & & & & \\
\hline Amortización & 0 & $-22,350$ & $-22,350$ & $-22,350$ & $-22,350$ & $-22,350$ \\
\hline Gastos de ventas & 0 & $-429,347$ & $-432,934$ & $-436,629$ & $-440,435$ & $-444,356$ \\
\hline Cargas de Personal & 0 & $-119,586$ & $-123,174$ & $-126,869$ & $-130,675$ & $-134,595$ \\
\hline Gastos Operativos & 0 & $-91,827$ & $-91,827$ & $-91,827$ & $-91,827$ & $-91,827$ \\
\hline Gastos Diversos & 0 & $-214,016$ & $-214,016$ & $-214,016$ & $-214,016$ & $-214,016$ \\
\hline Depreciación y & & & & & & \\
\hline Amortización & 0 & $-3,918$ & $-3,918$ & $-3,918$ & $-3,918$ & $-3,918$ \\
\hline Utilidad operativa & 0 & 56,056 & 258,644 & 374,865 & 513,439 & 677,555 \\
\hline Gastos Financieros & 0 & $-27,399$ & $-23,137$ & $-18,022$ & $-11,885$ & $-4,520$ \\
\hline $\begin{array}{l}\text { Utilidad antes de } \\
\text { impuestos }\end{array}$ & 0 & 28,658 & 235,507 & 356,843 & 501,554 & 673,035 \\
\hline
\end{tabular}

Participación de

$\begin{array}{lrrrrrr}\text { Trabajadores } & 0 & 0 & 0 & 0 & 0 & 0 \\ \text { Impuesto a la renta } & 0 & -8,454 & -69,475 & -105,269 & -147,959 & -198,545\end{array}$

\section{Utilidad neta}

0

$20,204 \quad 166,033$

251,574

\begin{tabular}{l|l}
353,596 & 474,490
\end{tabular}

Elaboración propia 


\subsection{Proyección de Ventas y Flujo de Tesorería (Cash flow)}

En la Tabla 7.15 se observa la proyección de ingresos por las ventas y el flujo de caja económico y financiero.

Tabla 7.15

Flujo de caja

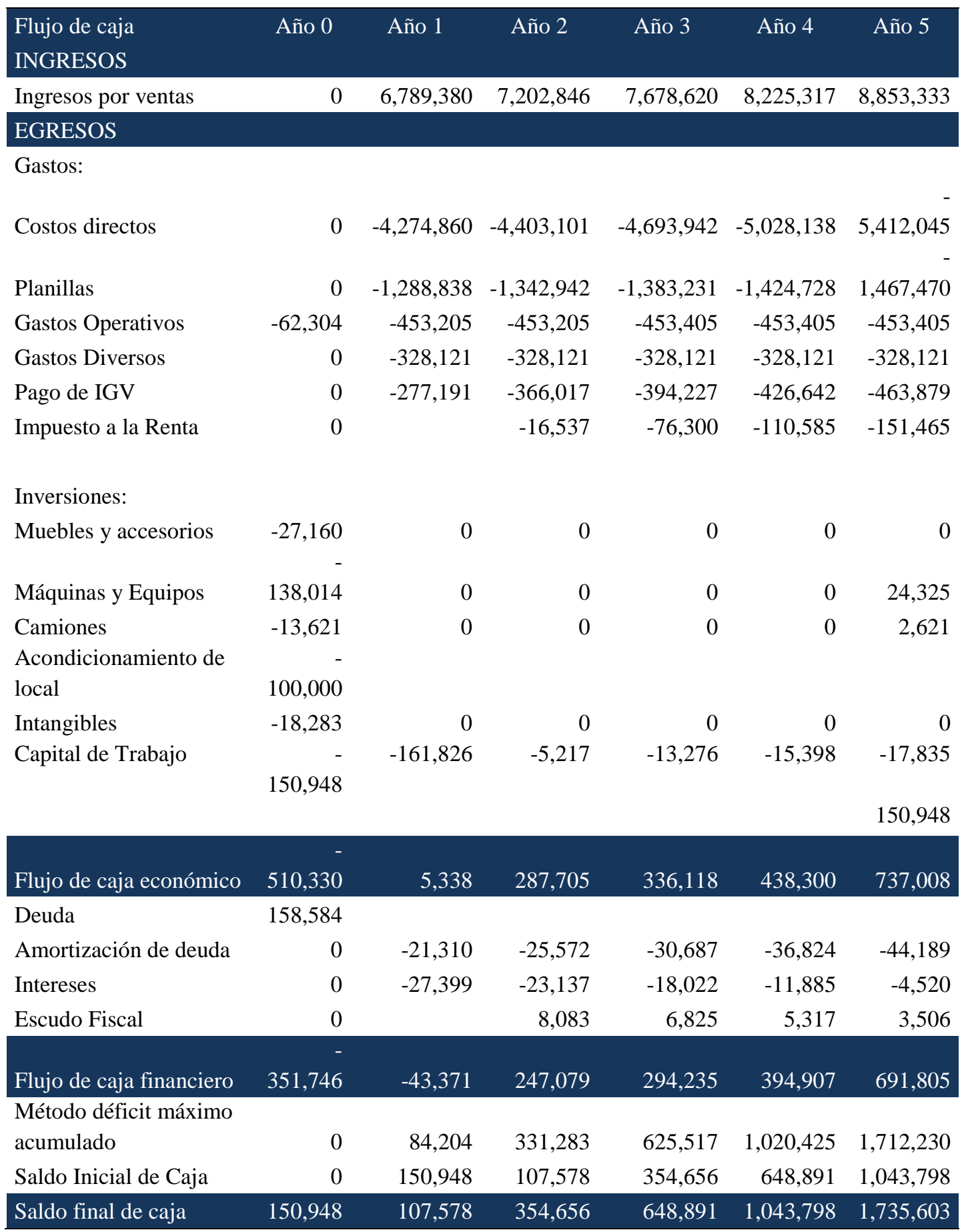




\subsection{Análisis de Viabilidad y Rentabilidad Financiera}

De acuerdo con los ratios de beneficio - costo, el flujo de caja, económico, es de 1.01. Siendo mayor a 1, por lo tanto, el proyecto debe ser llevado a cabo.

Si evaluamos el ratio beneficio - costo, en el flujo de caja económico - financiero, este es de 1.03. Al ser mayor a 1, por lo tanto, el proyecto debe ser llevado a cabo.

Considerando ambos escenarios, el proyecto es viable y se puede llevar a cabo.

\subsection{Políticas de Aplicación de Resultados}

Para la repartición de las utilidades, sólo se considera el reparto de utilidades a los trabajadores. En cuanto a los accionistas, en los 5 años de vida del proyecto, no hay repartición de dividendos, estos serán reinvertidos, para incrementar el patrimonio e invertir en futuros proyectos.

\subsection{Tasa de Descuento del Accionista}

Se considera la tasa de descuento del WACC, con información de fuente de Damodaran, SUNAT, BCR y SBS. Como se aprecia en la tabla 7.16 
Tabla 7.16

Tasa de descuento del accionista (WACC)

\begin{tabular}{|c|c|}
\hline Año & 0 \\
\hline Tasa Impuesto a la renta & $29.5 \%$ \\
\hline Beta Desapalancado & 2.58 \\
\hline \multicolumn{2}{|l|}{ Estructura de capital } \\
\hline Deuda & 158,584 \\
\hline Patrimonio $€ E$ ) & 351746 \\
\hline $\mathrm{D}+\mathrm{E}$ & 510330 \\
\hline $\mathrm{D} / \mathrm{E}$ & 0.45 \\
\hline Beta Apalancado (2) & 3.41 \\
\hline Rf: tasa libre de riesgo (1) & $2.1 \%$ \\
\hline Prima Riesgo de Mercado (Rm - RF) (3) & $6.24 \%$ \\
\hline Riesgo Pais & $1.74 \%$ \\
\hline $\operatorname{Re}(\mathrm{COK}$ - tasa mínima del accionista) & $25.03 \%$ \\
\hline $\mathrm{Rd}$ (costo de la deuda) & $20.00 \%$ \\
\hline $\mathrm{D} /(\mathrm{D}+\mathrm{E})$ & $31.07 \%$ \\
\hline $\mathrm{E} /(\mathrm{D}+\mathrm{E})$ & $68.93 \%$ \\
\hline Tasa Impuesto a a la renta & $29.5 \%$ \\
\hline WACC (tasa mínima para la empresa) & $21.64 \%$ \\
\hline $\operatorname{Re}(\mathrm{COK})$ & $25.03 \%$ \\
\hline
\end{tabular}

Elaboración propia

\subsection{Indicadores de Rentabilidad Representativos}

(WACC, TIR, VAN, ROI, Pay Back, Punto de equilibrio). 
Para el presente proyecto el VAN es de 352,328 y el TIR es de $41.10 \%$, con un WACC (tasa de descuento) de 21.64\%, con un periodo de recuperación (payback) de 3.5 años. Entonces con estos valores concluimos que el proyecto es viable. Para mayor detalle ir a las siguientes Tablas:

- En la tabla 7.17 se muestra los indicadores WACC, TIR, VAN.

Tabla 7.17

Indicadores de rentabilidad representativos

\begin{tabular}{lr} 
VAN Económico & \multicolumn{1}{c}{ Año 0} \\
Flujo de caja Económico & $-510,330$ \\
WACC & $22 \%$ \\
VAN Económico & 352,328 \\
TIRE & $41.10 \%$ \\
Beneficio/ Costo & 1.01 \\
VAN Financiero & Año 0 \\
\hline Flujo de caja Financiero & $-351,746$ \\
RE (COK) & $25 \%$ \\
VAN Financiero & 310,127 \\
TIRF & $48.26 \%$ \\
Beneficio/ Costo & 1.03 \\
\hline
\end{tabular}

Elaboración propia

- En la tabla 7.18 se muestra el payback, es decir el tiempo de retorno del capital.

Tabla 7.18

Payback

\begin{tabular}{|l|l|l|}
\hline Pay back & 1.7 & años \\
\hline
\end{tabular}

- En Tabla 7.19 se muestra el punto de equilibrio. 
Tabla 7.19

Punto de equilibrio

\begin{tabular}{lccccc}
$\begin{array}{l}\text { Punto equilibrio contable por } \\
\text { año }\end{array}$ & Año 1 & Año 2 & Año 3 & Año 4 & Año 5 \\
Precio de venta por persona & 34.32 & 35.35 & 36.41 & 37.50 & 38.63 \\
Unidades de personas & 167,639 & 172,668 & 178,712 & 185,860 & 194,224 \\
Costos Fijos & $2,110,745$ & $2,206,632$ & $2,277,814$ & $2,355,878$ & $2,441,856$ \\
Costo variable unitario & 21.61 & 21.61 & 22.26 & 22.93 & 23.61 \\
Punto de equilibrio en & & & & & \\
Unidades (personas) & 166,050 & 160,585 & 160,937 & 161,605 & 162,624 \\
Ingresos del punto de equilibrio & & & & & \\
(en soles) & $5,699,160$ & $5,676,958$ & $5,860,085$ & $6,060,919$ & $6,282,114$ \\
No de veces (ventas estimada / & & & & & \\
punto equilibrio) & 1.01 & 1.08 & 1.11 & 1.15 & 1.19 \\
Ingresos & $5,753,711$ & $6,104,106$ & $6,507,305$ & $6,970,607$ & $7,502,825$ \\
Costos variables & $3,622,763$ & $3,731,442$ & $3,977,917$ & $4,261,134$ & $4,586,479$ \\
Costos fijos & $2,110,745$ & $2,206,632$ & $2,277,814$ & $2,355,878$ & $2,441,856$ \\
Costo total & $5,733,508$ & $5,938,074$ & $6,255,731$ & $6,617,012$ & $7,028,335$ \\
\hline & & & & & \\
Ganancia o pérdida & 20,204 & 166,033 & 251,574 & 353,596 & 474,490 \\
\hline
\end{tabular}

Elaboración propia

\subsection{Análisis de Riesgo y Costo de Oportunidad}

Para el siguiente punto se analizará el riesgo desde el flujo de caja descontado en la cual se tienen las variaciones, como se aprecia en la Tabla 7.15. Se observa que los flujos de cajas son positivos en todos los años. Pero en el primer año de operación, por el pago de gratificaciones, aumentan los costos, esto hace que el flujo de caja económico sea negativo en julio y en diciembre.

Si consideramos el costo de oportunidad comparándolo con la inversión mediante un depósito a largo plazo en una entidad financiera ( $6 \%$ a $7 \%$ ), vemos que el proyecto arroja más del $40 \%$ como tasa interna de retorno, siendo mayor en más de 33puntos porcentuales concluyendo que es completamente rentable realizar el proyecto de inversión e implementar el restaurant. 


\subsection{Análisis por Escenarios y Figuras}

En la tabla 7.19, se tienen los 3 escenarios de evaluación, considerando un escenario pesimista, normal y optimista, con una variación en un 5\% respecto al volumen de ventas en platos.

Según el análisis de sensibilidad, el número de servicios (venta en platos) es una variable sensible porque en el escenario pesimista ante una disminución de esta en $-5 \%$, el VANE disminuye en $-80.37 \%$ y el proyecto sigue generando valor para los accionistas ya que el VANE igual a 69,145 es mayor que cero y la TIRE mayor que el WACC.

En las figuras 7.1 y 7.2, se aprecia un escenario favorable, así bajen las ventas, en un $5 \%$ y si éstas suben también suben los beneficios.

Tabla 7.20

Escenario ante una variación de las ventas

\begin{tabular}{lrrr} 
Escenario & Pesimista & Normal & Optimista \\
$\begin{array}{l}\text { Variable de entrada } \\
\text { Variación \% volumen de ventas en } \\
\text { personas }\end{array}$ & & & \\
Variables de salida & $-5 \%$ & $0 \%$ & $5 \%$ \\
VANE & & & \\
TIRE & 69,145 & 352,328 & 620,278 \\
VANF & $25.51 \%$ & $41.10 \%$ & $55.57 \%$ \\
TIRF & 46,020 & 310,127 & 560,656 \\
Cambio del VANE & $28.57 \%$ & $48.26 \%$ & $66.97 \%$ \\
\hline
\end{tabular}

Elaboración propia

\subsection{Principales Riesgos del Proyecto (cualitativos).}

Se consideran los siguientes riesgos:

- Riesgo individual. Si es el único activo, lo cual es bajo, debido que al ser un restaurante posee una carta amplia de productos y se puede innovar cada cierto tiempo cambiando la carta.

- Riesgo de costo. Por una mala estimación de los costos o por sobrepasar los costos debido a incrementos de los precios de la materia prima o insumos utilizados para elaborar los platos, costos por encima de la tasa de inflación 
esperada. Ejemplo, casos como el limón cuyo precio pasó de 3 soles a 14 soles el kilo.

- Riesgo de calendario. Sobrepasar el tiempo de implementación ocasiona un mayor gasto pre operativo La demora se puede dar en la implementación o la remodelación del local.

- Riesgo tecnológico. Problemas en comprender la nueva tecnología utilizada, o no siendo capacitados para el funcionamiento de esta nueva tecnología en forma debida, o usar equipos con fallas o desperfectos requiriendo de un cambio o renovación del mismo.

- Riesgos operacionales. Falta de liderazgo, comunicación y motivación en la implementación.

- Riesgos externos. Cambio en la parte legal, normas, desastres naturales como inundaciones, terremotos, incendios lo que podría afectar al proyecto.

\subsection{Plan de Contingencia y Disolución}

- Como medida de contingencia ante la disminución del número de visitas en el restaurante, se optaría por diversificar nuestra carta realizando publicidad y promoción para la venta por delivery.

- Realizar acuerdos con empresas para que sus eventos de integración o workshop se realicen dentro de las instalaciones del restaurante.

- Ampliar la zona de influencia colocando sucursales propias, o a través de franquicias, servicio de delivery y expansión a provincias. 


\section{CONCLUSIONES}

- El proyecto de comida saludable, partiendo del principio del Plato Saludable de Harvard, hace referencia a una correcta forma de alimentarse en forma saludable y nutritiva en donde combina los 4 elementos principales para una dieta diaria.

- El usar productos orgánicos en la elaboración de los platos le da un valor adicional a nuestra comida saludable evitando el riesgo por no usar productos contaminados por el tipo de riego, fertilizantes y plaguicidas utilizados en su siembra.

- El tener los monitores que expliquen las condiciones o elaboración de los platos, le da un instrumento de aprendizaje y enseñanza en el comer saludable e incluso poder comprar los propios insumos en el local del restaurante.

- Propiciar charlas sobre la nutrición y formas nuevas de cultivo, aumenta la rentabilidad del proyecto, esto en la medida que la tendencia mundial indica que más personas prefieren productos orgánicos en sus platos.

- El tener un espacio de recreación con tecnología multimedia que integre la música y las artes visuales, sin ocupar gran espacio, permite a la familia disfrutar de un espacio seguro para sus hijos, en donde puedan divertirse y aprender sobre la comida saludable.

- El proyecto es altamente viable, siendo el VAN de 352,328 una TIR de $41.10 \%$ que está por encima del WACC que es de $22 \%$.

- Los escenarios pesimista, normal y optimista dan un resultado positivo en todos los indicadores, mostrando que el proyecto es viable. 


\section{RECOMENDACIONES}

- Para poder incrementar sus ingresos a otros mercados, la empresa puede optar por colocar sucursales o franquicias, considerando un manual de franquiciado o de operación estándar para toda la cadena.

- Se recomienda elaborar un proyecto de ley sobre comida saludable partiendo del Plato Saludable según la Escuela de Salud Pública de la Universidad de Harvard o actualizar la ley sobre comida chatarra, reglamentada recientemente en agosto del 2017 por el Congreso de la República del Perú.

- Se recomienda abrir nuevos locales luego del tercer año de operación, viendo que la marca sea posicionado en el mercado.

- Para poder expandirse a otros mercados, se recomienda realizar los platos de acuerdo a los sabores que les agrade a la población de la zona de influencia, pero siempre considerando que el Plato Saludable según la Escuela de Salud Pública de la Universidad de Harvard sea un rasgo distintivo de la marca y sus productos. 


\section{REFERENCIAS}

Banco Central de Reserva del Perú (s.f.). PBI, riesgo país, inflación. Recuperado de www.bcrp.gob.pe

Cosechando Natural del huerto a la sopa (11 de noviembre del 2017). ¿Qué es hidroponía? Recuperado de https://www.cosechandonatural.com.mx/articulosque-es-hidroponia.html

Damodaran. Beta desampalancado, Prima de riesgo. Recuperado de http://www.damodaran.com

Solo $26 \%$ de los limeños considera que su alimentación es saludable. ( 8 de febrero del 2016). Gestión. Recuperado de http://gestion.pe/tendencias/solo-26-limenosconsidera-que-su-alimentacion-saludable-2154181

Chen, L. (2016). La cocina y el jardín, una aproximación del habitar desde lo más cotidiano (Trabajo fin de grado inédito). Universidad de Sevilla, Sevilla

Conceptos de hidroponía. Agricultura técnica avanzada (AADAA). Recuperado de http://aadaa.es/que-es-la-hidroponia-organica/

Conceptos y estudios de clúster por producto. Realizado por la Cámara Nacional de Comercio. Recuperado de https://www.cnc.gob.pe/images/cnc/LAvance 12 13/archivos/Informe-Final-Mapeo-Clúster.pdf

Coquillat, D. (2016). 10 Claves en la industria de los restaurantes para el 2016.

Recuperado de http://www.diegocoquillat.com/10-claves-en-la-industria-de-losrestaurantes-para-el-2016/

El plato para comer saludable. Escuela Pública de Salud de Harvard. Recuperado de https://www.hsph.hawrvard.edu/nutritionsource/healthy-eatingplate/translations/círspanish/

Guimera, A. (2016). El círculo de oro. Comunicar para inspirar. Recuperado de www.marketing-esencial.com/2016/05/12/el-circulo-de-oro.

Instituto Nacional de Estadística e Informática (2013). Encuesta demográfica y de salud familiar 2013. Recuperado de https://www.inei.gob.pe/media/MenuRecursivo/publicaciones_digitales/Est/Lib $\underline{1151 /}$

Instituto Nacional de Estadística e Informática. (20 de junio del 2016). El 35,5\% de la población peruana de 15 y más años de edad padece de sobrepeso. Recuperado de https://www.inei.gob.pe/prensa/noticias/el-355-de-la-poblacion-peruana-de15-y-mas-anos-de-edad-padece-de-sobrepeso-9161/ 
Jiménez Navarro, R. I. (2016). Plan de negocio de empresa de venta de productos nutricionales de origen natural con perspectiva multinacional.

Libonati, M., Bacigalupo, M. J., Wagne, M. (2006). Procedimientos para la gestión de la calidad, seguridad e higiene de alimentos: empleados. Buenos Aires: Federación Empresaria Hotelera Gastronómica de la República Argentina, Consejo Federal de Inversiones. Recuperado de http://www.smandeshoteles.com.ar/contenidos/pdf/mpgce.pdf

Organización Mundial de la Salud (2017). Obesidad y sobrepeso. Recuperado de http://www.who.int/mediacentre/factsheets/fs311/es/

Recetas de comidas peruanas. Recuperado de http://comidasperuanas.net/escabechede-pescado/

Sánchez, P. (2004). Conceptos de hidroponía orgánica y aplicaciones. Recuperado de

http://www.itson.mx/micrositios/nch/Documents/hidroponia_organica.pdf

Sociedad peruana de gastronomía. (Apega, s.f.). Dieta Peruana: Un nuevo enfoque en torno a la alimentación saludable y la seguridad alimentaria. Recuperado de http://www.apega.pe/noticias/prensa-y-difusion/dieta-peruana-un-nuevoenfoque-en-torno-a-la-alimentacion-saludable-y-la-seguridad-alimentaria.html

Superintendencia Nacional de Aduanas y de Administración Tributaria. (s.f). Impuestos y tributos a pagar. Recuperado de www.sunat.gob.pe

Superintendencia de Banca y Seguros del Perú. (s.f.). Tasas de créditos. Recuperado de www.sbs.gob.pe 


\section{BIBLIOGRAFÍA}

Sinek, S. (2009). Start with why: How great leaders inspire everyone to take action. New York: Porfolio / Penguin.

Alvites, C. y Prado, J. (2013). Estudio de pre-factibilidad de un restaurant buffet criollo, en la ciudad de Lima (Tesis de pregrado). Pontificia Universidad Católica del Perú. Recuperado de http://tesis.pucp.edu.pe/repositorio/handle/123456789/1682

Veintimilla Cedeño, M., Pazmiño Medina, S., Sánchez Reyes, K. y Mendoza Macias, O. (2016). Proyecto de inversión para la implementación de un restaurant en la ciudad de Guayaquil (Artículo de tesis, Escuela Superior Politécnica del Litoral - Facultad de Economía y Negocios, Ecuador). Recuperado de https://www.dspace.espol.edu.ec/bitstream/123456789/19064/1/PROYECTO\%2 0DE\% 20INVERSI\%C3\%93N\%20PARA\%20LA\%20IMPLEMENTACI\%C3\% 93N\%20DE\%20UN\%20RESTAURANTE\%20EN\%20LA\%20CIUDAD\%20D E\%20GUAYAQUIL.pdf

Von Der Thusen, L. (2016). El juego como medio para la concientización de alumnos de escuelas primarias sobre el excesivo consumo de gaseosas. Concientizar sobre alimentación saludable a través del desarrollo de un dispositivo lúdicoeducativo. 
ANEXOS 


\section{ANEXO 1: Descripción de puestos, competencias y perfil}

\begin{tabular}{|c|c|c|}
\hline Puesto & Perfil & Competencias \\
\hline Gerente General & $\begin{array}{l}\text { *Formación superior con } \\
\text { experiencia en administrar } \\
\text { negocios similares. }\end{array}$ & $\begin{array}{l}\text { *Identificado con el estilo de } \\
\text { vida saludable. }\end{array}$ \\
\hline $\begin{array}{l}\text { Ejecutivo de mayor rango en la } \\
\text { empresa. }\end{array}$ & $\begin{array}{l}\text { *Capaz de planificar, dirigir, } \\
\text { organizar y evaluar el plan de } \\
\text { negocios. }\end{array}$ & *Desarrollo de personas. \\
\hline $\begin{array}{l}\text { Responsable de alcanzar } \\
\text { objetivos y supervisar a sus } \\
\text { subalternos. }\end{array}$ & $\begin{array}{l}\text { * Motivación para la búsqueda y } \\
\text { el logro de metas establecidas. }\end{array}$ & *Planificación y organización. \\
\hline \multirow[t]{4}{*}{$\begin{array}{l}\text { Su gestión se mide por } \\
\text { resultados. }\end{array}$} & $\begin{array}{l}\text { *Coordinar que las áreas de } \\
\text { producción, RRHH, } \\
\text { Administración y Logística, se } \\
\text { encuentren siempre en } \\
\text { comunicación constante. }\end{array}$ & $\begin{array}{l}\text { *Compromiso con los valores } \\
\text { institucionales. }\end{array}$ \\
\hline & $\begin{array}{l}* \text { Ejercer las políticas del } \\
\text { accionariado. }\end{array}$ & *Integración con el entorno. \\
\hline & * Radicar en el lugar de Trabajo. & *Responsabilidad. \\
\hline & $\begin{array}{l}\text { *Sexo y Estado Civil, } \\
\text { indistintos. }\end{array}$ & *Orientación al cliente. \\
\hline Puesto & Perfil & Competencias \\
\hline Gerencia de Producción & *Formación en Alimentos & * Orientado al cliente \\
\hline $\begin{array}{l}\text { Responsable de alcanzar } \\
\text { objetivos de producción. }\end{array}$ & $\begin{array}{l}\text { *Experiencia en producción de } \\
\text { restaurant, cultivos y cadenas de } \\
\text { restaurant. }\end{array}$ & *Planificación y organización \\
\hline $\begin{array}{l}\text { Responsable de estandarizar } \\
\text { todos los procesos }\end{array}$ & $\begin{array}{l}\text { *Coordinar con el Cheff, y la } \\
\text { Gerencia el manejo de la carta. }\end{array}$ & $\begin{array}{l}\text { * Identificado con el estilo de } \\
\text { vida saludable }\end{array}$ \\
\hline Cheff & $\begin{array}{l}\text { *Formación técnica en cocina o } \\
\text { formación de campo como } \\
\text { cocinera. }\end{array}$ & $\begin{array}{l}\text { * Identificado con el estilo de } \\
\text { vida saludable. }\end{array}$ \\
\hline \multirow[t]{4}{*}{$\begin{array}{l}\text { Responsable de actividades } \\
\text { productivas, incluyendo la } \\
\text { provisión del abastecimiento y } \\
\text { la elaboración de las recetas. }\end{array}$} & $\begin{array}{l}\text { *Experiencia en elaborar e } \\
\text { implementar el plan de compras } \\
\text { de abastecimiento (hacer y } \\
\text { seguir lista de compras). }\end{array}$ & *Mantener estándares sanitarios. \\
\hline & $\begin{array}{l}\text { *Experiencia en la elaboración y } \\
\text { manipulación de alimentos. }\end{array}$ & *Planificación y organización. \\
\hline & $\begin{array}{l}\text { *Capacidad para recibir } \\
\text { directrices y poder delegar y } \\
\text { dirigir trabajo de subalternos. }\end{array}$ & * Responsabilidad. \\
\hline & * Radicar en el lugar de Trabajo. & *Orientación al cliente. \\
\hline
\end{tabular}


*Sexo y Estado Civil, indistintos.

\begin{tabular}{|c|c|c|}
\hline Puesto & Perfil & Competencias \\
\hline RRHH & $\begin{array}{l}\text { *Experiencia en selección de } \\
\text { personal }\end{array}$ & $\begin{array}{l}\text { * Mantener al personal motivado } \\
\text { y capacitado }\end{array}$ \\
\hline $\begin{array}{l}\text { Responsable de la contratación } \\
\text { del personal. }\end{array}$ & $\begin{array}{l}\text { *Formación en sicología y } \\
\text { especialización en recursos } \\
\text { humanos }\end{array}$ & \\
\hline Llevar la planilla, & $\begin{array}{l}\text { *Con capacidad para dar } \\
\text { directrices y delegar. }\end{array}$ & \\
\hline \multicolumn{3}{|l|}{ Capacitación al personal } \\
\hline Jefe de Logística & $\begin{array}{l}\text { *Formación de ingeniería } \\
\text { industrial y con especialización } \\
\text { en supply chain management. }\end{array}$ & $\begin{array}{l}\text { *Identificado con el estilo de } \\
\text { vida saludable. }\end{array}$ \\
\hline \multirow[t]{3}{*}{$\begin{array}{l}\text { Responsable de la compras y } \\
\text { control de calidad }\end{array}$} & $\begin{array}{l}\text { *Experiencia en conocimiento } \\
\text { de alimentos. }\end{array}$ & *Mantener estándares sanitarios. \\
\hline & $\begin{array}{l}\text { *Capacidad para seguir } \\
\text { directrices y elaborar } \\
\text { presupuestos. }\end{array}$ & * Planificación y organización. \\
\hline & $\begin{array}{l}\text { *Sexo y Estado Civil, } \\
\text { indistintos. }\end{array}$ & $\begin{array}{l}\text { *Responsable } \\
\text { *Orientado al cliente. }\end{array}$ \\
\hline
\end{tabular}

\begin{tabular}{lll}
\hline Puesto & Perfil & Competencias \\
\hline $\begin{array}{l}\text { Ayudante de producción } \\
\text { (ayudante de cocina) }\end{array}$ & *Experiencia en elaboración y & *Identificado con el estilo de vida \\
saludable.
\end{tabular}

Responsable de ayudar al cheff en *Capacidad para seguir $\quad *$ Mantener estándares sanitarios. la elaboración de las recetas directrices.

*Carnet de sanidad *Sentido de orden y limpieza.

*Sexo y Estado Civil, indistintos.

*Formación en gastronomía

\begin{tabular}{|c|c|c|}
\hline Anfitriona. & $\begin{array}{l}\text { *Experiencia como anfitriona por } \\
\text { más } 6 \text { meses. }\end{array}$ & $\begin{array}{l}\text { *Identificado con el estilo de vida } \\
\text { saludable. }\end{array}$ \\
\hline \multirow[t]{4}{*}{$\begin{array}{l}\text { Responsable de la recepción y } \\
\text { bienvenida a los clientes }\end{array}$} & * Carnet de sanidad & $\begin{array}{l}\text { *Atender llamadas, reservar } \\
\text { mesas y resolver consultas en } \\
\text { general. }\end{array}$ \\
\hline & *Formación en carrera técnica & $\begin{array}{l}\text { * Recibir a los clientes y ubicarlos } \\
\text { en las mesas. }\end{array}$ \\
\hline & *Con cursos de atención al cliente & $\begin{array}{l}\text { *Mantener contacto directo con } \\
\text { los mozos para la rápida atención } \\
\text { del cliente. }\end{array}$ \\
\hline & & $\begin{array}{l}\text { *Comunicar al Chef la llegada de } \\
\text { proveedores }\end{array}$ \\
\hline
\end{tabular}




\begin{tabular}{ll}
\hline Administración & $\begin{array}{l}\text { *Formación en Administración de *Dirigir el personal de todo el } \\
\text { empresas o ingeniería industrial } \\
\text { restaurant. }\end{array}$ \\
personal & Entrevistar a nuevo
\end{tabular}

Responsable de la administración *Experiencia en administración de*Controlar de horarios. del restaurante restaurant mínimo un año.

*Carnet de sanidad

*Controlar de horas extra.

*Conocimiento de alimentos y

*Controlar de existencias manejo del mismo.

*Mantener activa comunicación

* Manejar las relaciones públicas con los clientes.

* Supervisar la atención al cliente

\begin{tabular}{|c|c|c|}
\hline Puesto & Perfil & Competencias \\
\hline Maitré & $\begin{array}{l}\text { *Experiencia en atención a } \\
\text { comensales }\end{array}$ & $\begin{array}{l}\text { *Manejar la planilla de horarios } \\
\text { de personal del comedor. }\end{array}$ \\
\hline \multirow[t]{6}{*}{$\begin{array}{l}\text { Responsable del salón y de } \\
\text { atender a los comensales }\end{array}$} & $\begin{array}{l}\text { *Saber dirigir y ordenar los } \\
\text { pedidos }\end{array}$ & $\begin{array}{l}\text { *Supervisar y coordinar el } \\
\text { personal. }\end{array}$ \\
\hline & $\begin{array}{l}\text { *Conocimientos en atención de } \\
\text { clientes }\end{array}$ & $\begin{array}{l}\text { * Dictar pautas para los } \\
\text { inventarios. }\end{array}$ \\
\hline & *Conocimientos en liderazgo & $\begin{array}{l}\text { *Resolver situaciones de } \\
\text { emergencias o cambios de último } \\
\text { momento. }\end{array}$ \\
\hline & * Carnet de sanidad & $\begin{array}{l}\text { *Controlar de uniformes y } \\
\text { presentación del personal de } \\
\text { salón. }\end{array}$ \\
\hline & & $\begin{array}{l}\text { * Manejar información de faltas de } \\
\text { stock y sus causas. }\end{array}$ \\
\hline & & $\begin{array}{l}\text { *Controlar de estilo de trabajo y } \\
\text { de las reglas }\end{array}$ \\
\hline Mozos & $\begin{array}{l}\text { *Experiencia de atención al } \\
\text { cliente. }\end{array}$ & *Llevar el pedido \\
\hline \multirow[t]{3}{*}{$\begin{array}{l}\text { Responsable de la atención al } \\
\text { cliente }\end{array}$} & \multicolumn{2}{|c|}{$\begin{array}{l}\text { * Formación de técnica o superior *Tomar el pedido } \\
\text { indistinta }\end{array}$} \\
\hline & *Carnet de sanidad & * Llevar la cuenta \\
\hline & & *Atender a los comensales \\
\hline
\end{tabular}

Elaboración propia 